\title{
NUCLEAR DIVISION
}

Report No. RN-TM-0570

HIGH-TEMPERATURE WATER PENETRATION, PRETEST PREDICTION

September 1968

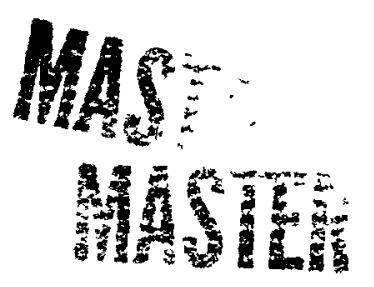

\section{(1)}




\section{DISCLAIMER}

This report was prepared as an account of work sponsored by an agency of the United States Government. Neither the United States Government nor any agency Thereof, nor any of their employees, makes any warranty, express or implied, or assumes any legal liability or responsibility for the accuracy, completeness, or usefulness of any information, apparatus, product, or process disclosed, or represents that its use would not infringe privately owned rights. Reference herein to any specific commercial product, process, or service by trade name, trademark, manufacturer, or otherwise does not necessarily constitute or imply its endorsement, recommendation, or favoring by the United States Government or any agency thereof. The views and opinions of authors expressed herein do not necessarily state or reflect those of the United States Government or any agency thereof. 


\section{DISCLAIMER}

Portions of this document may be illegible in electronic image products. Images are produced from the best available original document. 
Report No。 RN-TM-0570

HIGH-TEMPERATURE WATER PENETRATION, PRETEST PREDICTION

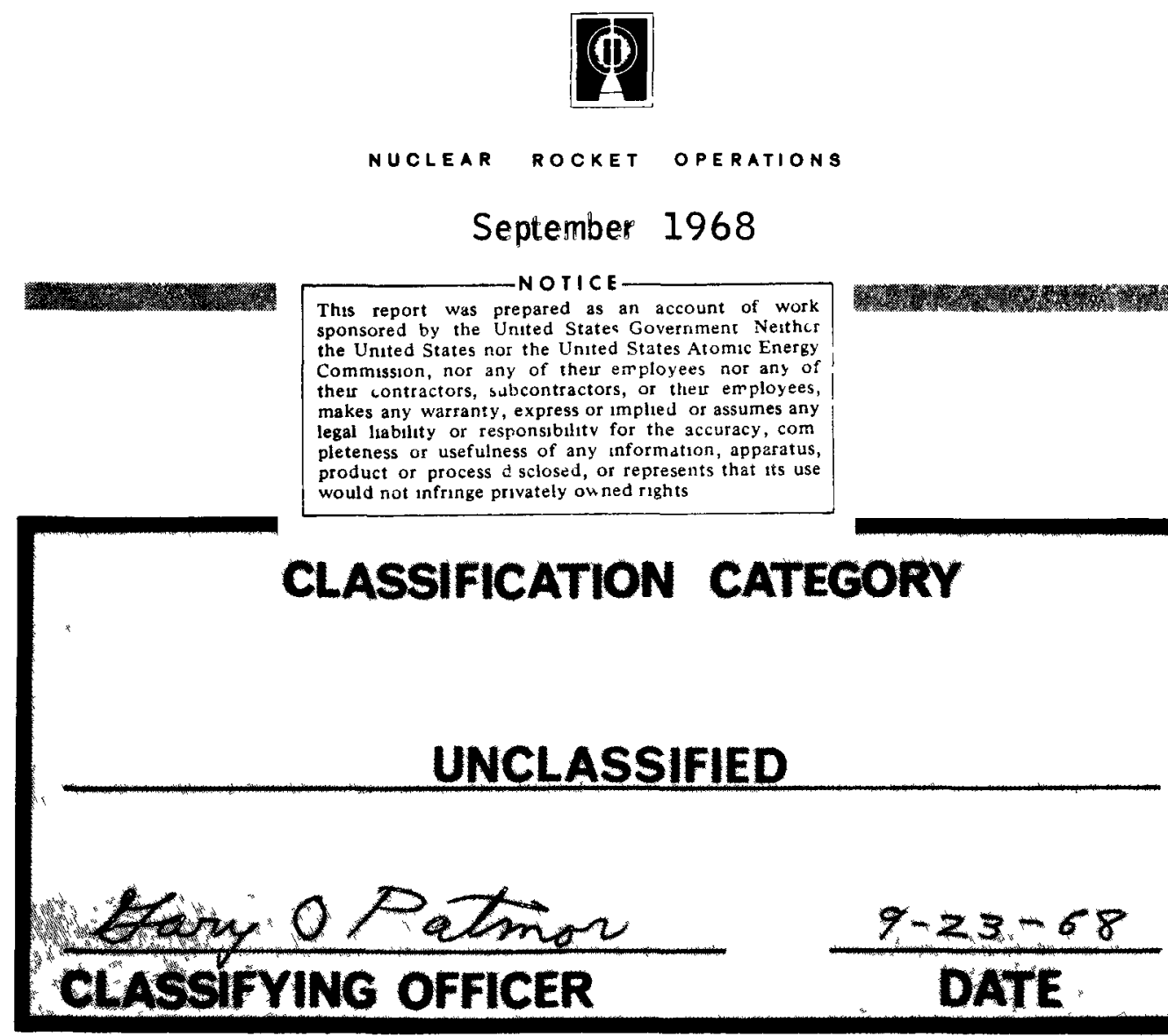

\section{AEROJET - GE NERAL C ORPORATION \\ A SUBSIDIARY OF THE GENERAL TIRE \& RUBBER COMPANY}


PAGE BLANK

ii 
Report No. RN-TM-0570

\section{HIGH-TEMPERATURE WATER PENETRATION, PRETEST PREDICTION}
M. J. Margetts
E. L. Geery

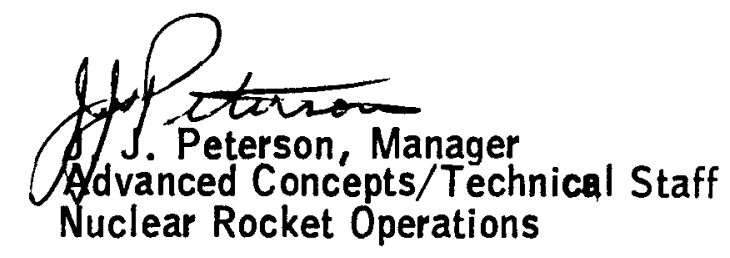


PAGE BLANK 


\section{CONTENTS}

I. Introduction

II. Summary

III. Discussion of Model Studies

A. Scale-Model Studies

1. Water Penetration

a. Previous Studies

b. Aerojet-General Investigations 5

c. Water-Penetration Correlation 6

d. Deflector Studies 8

2. Water Mixing and Evaporation 24

a. Previous Investigations 24

b. Aerojet-General Studies 25

c. Westinghouse Studies 35

B. Analytical Studies 38

1. Water-Mixing Models 38

a. Greyrad Mode1 38

b. Westinghouse Model 39

2. Aerojet-Genera1 Water-Evaporation Mode1 43

IV. Prediction of Test Results for High-Temperature Tests 57

at Sacramento Facility

A. Gas Flow Field 57

B. Water Spray System 61

1. Instrumentation 62

2. Gas-Stream Temperatures and Pressures 65

a. Mixing Model 65

b. Evaporation Mode1 76

C. Pretest Predictions 84

List of Symbols $\quad 93$

References

APPENDIX

Test P1an, High-Temperature Water Penetration Test 


\section{TABLES}

No.

$\underline{\text { Page }}$

1 Summary of Test Conditions

7

2 Static and Total Pressures; Exhaust-Gas Cooling

73

Mixing Program

3 Nozzle Array for Case IV

84

4 Temperatures and Pressures at Various Distances 


\section{FIGURES}

No.

$\underline{\text { Page }}$

1 Scale-Model Diffuser - Wet E1bow Assembly

2 Diffuser Exit Pressure Profile

3 Water Penetration into Hydrogen Gas Flow for DifferentDiameter Nozzles

4 Predicted Water-Injection Pattern 12

5 Deflectors - Wet Elbow Study 14

6 Water-Injector Design 16

7 Water-Injector Manifold $\quad 17$

8 Water-Injector Nozzles $\quad 18$

9 Curved-Deflector-Plate Temperatures with Water Injection 19

10 Deflector-Plate Temperatures with Water Injected into Hydrogen Gas, Test 337

11 Deflector-Plate Temperatures with Water Injection into Hydrogen Gas, Test 339

12 Temperature on Outside of Plenum with Water Injection into Hydrogen Gas, Tests 337 and 339

13 Mixing and Evaporation Evaluation Duct Assembly

Total-Pressure and Total-Effective-Temperature Rakes

16 Velocity Flow Field in Evaluation Duct

17 Total Effective Temperature, $1000^{\circ} \mathrm{R}$ Gaseous Nitrogen with

18 Total Effective Center-Line Temperature $1500^{\circ} \mathrm{R}$ Hydrogen Gas with Water Injection

19 Moisture-Probe Measurements, Water Injection from Spray A

20 Comparison of Analytical and Experimental EvaluationDuct-Temperatures; Water-to-Gas Mass Ratio $\approx 2.0$

21 Comparison of Analytical and Experimental EvaluationDuct Temperatures; Water-to-Gas Mass Ratio $\approx 2.8$ 


\section{FIGURES (cont.)}

No.

Page

23 Calculated Trajectory of Droplets and Water Distribution for

Scale-Model Tests; Three 1/8-in.-dia Nozzles (Spray A)

24 Calculated Trajectory of Droplets and Water Distribution for

Scale-Mode1 Tests; Three 1/20-in.-dia Nozzles (Spray B)

25 Calculated Trajectory of Droplets and Water Distribution for Scale-Model Tests; 96 1/32-in.-dia Nozzles (Spray C)

26 Calculated Water Distribution in Scale-Mode1 Evaporation Studies; Flow from all Nozzles $1.4 \mathrm{lb} / \mathrm{sec}$ Hydrogen Gas Initially at $1450^{\circ} \mathrm{R}$

27 J-4 Test No. 1186-X01-DJ-002, Mach Number Profiles

60

28 Water-Spray Pattern in Duct, Case II 63

29 Water-Spray Pattern in Duct, Case III 64

30 High-Temperature Water-Penetration Tests, Instrumentation Rake 66

31 Exhaust-Gas Cooling, Case II; Azimuth $0^{\circ}, \mathrm{C}_{\mathrm{m}}=0.0375 \quad 68$

32 Exhaust-Gas Cooling, Case II; Azimuth $0^{\circ}, \mathrm{C}_{\mathrm{m}}=0.075 \quad 69$

33 Exhaust-Gas Cooling, Case II; Azimuth $0^{\circ}, \mathrm{C}_{\mathrm{m}}=0.10 \quad 70$

34 Exhaust-Gas Cooling, Case II; Azimuth $0^{\circ}, \mathrm{C}_{\mathrm{m}}=0.15 \quad 71$

35 Exhaust-Gas Cooling, Case II and Case III; Azimuth $0^{\circ}, \quad 72$

$\mathrm{C}_{\mathrm{m}}=0.075$

36 J-4 Test Stand; Stream Tube Profile $\quad 77$

37 Trajectory of Droplets and Water Distribution, J-4 Nozzle A 78

38 Trajectory of Droplets and Water Distribution, J-4 Nozzle B 79

39 Trajectory of Droplets and Water Distribution, J-4 Nozzle C 80

40 Trajectory of Droplets and Water Distribution, J-4 Nozzle D 81

41 J-4 Water Nozzles, Case II 82

42 Water-Spray Pattern in Duct, Case IV; Static Pressure 83

6.5 psia, Average Mach No. 0.62

$43 \mathrm{~J}-4$ Trajectory of Droplets and Water Distribution in an 85 Expanding Flow Field, Nozzle W-2

$44 \mathrm{~J}-4$ Trajectory of Droplets and Water Distribution in an Expanding Flow Field, Nozzle X 


\section{FIGURES (cont.)}

No. $\quad \underline{\text { Page }}$

$45 \mathrm{~J}-4$ Trajectory of Droplets and Water Distribution in an 87 Expanding Flow Field, Nozzle Y

46 J-4 Trajectory of Droplets and Water Distribution in an 88 Expanding Flow Field, Nozzle Z

47 Calculated Water Distribution for J-4 Test Using Spray 89 Nozzles $\mathrm{W}-2, \mathrm{X}, \mathrm{Y}$ and $\mathrm{Z}$, Case IV 


\section{INTRODUCTION}

The E/STS 2-3 efforts conducted during development of ETS-1 were examined and evaluated to determine the relative advantages of wet and dry duct-elbow configurations.* One of these elbow configurations, along with a new duct will be used to test E-2 and subsequent NERVA engines in the existing ETS-1 facility. This evaluation, which was based on the significant parameters of cost, schedule, reliability, and safety, and which recognized the specific development problems for each system, resulted in the recommendation that the wet-elbow configuration be investigated further.

This recommendation was made with full recognition of the potential problems associated with water injection and mixing, particularly in extrapolating subscale design data to full scale. After demonstrating a knowledge of these problems by way of a full-scale design, a series of largescale, high-temperature tests was planned. This report outlines the analytical approaches used and gives the pretest predictions for this test program.

A rather extensive series of tests has been conducted previously by using scale-model hardware operating at scaled flow rates but at lower-thanactual temperatures. The results were compared with those for various analytical models. These analytical models would be used to demonstrate performance of the full-scale duct.

These scale model tests have been of two types: aerodynamic tests and mixing and evaporation tests. The purpose of these tests was to permit an evaluation of the correlation techniques that predict the hydrogen, steam and water mixture temperature and composition downstream of the point of

\footnotetext{
*Wet - water injected internally to cool the $90^{\circ}$-turn elbow; Dry - convectively cooled (externally) by means of coolant tubes.
} 
injection, given as input, and the gas and water inlet conditions. After satisfactory correlation of the scale-model tests, the analytical technique should then be applicable to any gas stream-water interaction problem, and in particular, to the wet elbow. However, since only limited functional testing can be performed on the ful1-scale duct, confidence in the design can only be demonstrated using properly designed scale-model tests and an adequate mathematical model. The difficulty in achieving a direct simulation of operating conditions in a high-enthalpy hydrogen stream creates the need for some high-temperature subscale tests to further evaluate and verify the adequacy of these correlation techniques.

Recognizing the problems of simulation, a series of high-temperature tests have been devised that will be a direct test of the analytical models, but not necessarily a simulation of a NERVA duct. The high-temperature-gas source for these tests is provided by combustion of liquid-fluorine and mixed-hydrazine fuel in a rocket engine. The combustion temperature is about $7000^{\circ} \mathrm{R}$ and the propellant flow rate as high as $20 \mathrm{lb} / \mathrm{sec}$. The engine tests will be conducted at the Propulsion Division's high-altitude test facility (Test Cell J-4) in Sacramento. At this facility the engine exhausts into a 30-in.-diameter cylindrical diffuser, then into a 6-ft-diameter duct, and finally into a 12-ft-diameter duct. Cooling water is injected at the 30 in. - $6 \mathrm{ft}$ duct interface. The entire system is pumped by a series of steam injectors. The fluorine engine operates at a chamber pressure of 100 psia and the exhaust duct must be evacuated by the steam ejectors. This system is similar to a nuclear exhaust duct; however, it does not simulate an elbow or turn as is the case in the NERVA duct.

The tests to be conducted using this facility will enable a direct comparison of analytical capability developed on systems with relatively low temperatures and in ducts $18 \mathrm{in.}$ in diameter with tests of a gas at a temperature of $7000^{\circ} \mathrm{R}$ and a duct 72 in. in diameter. 
It is necessary to predict temperatures when using the NES wet-elbow because the temperature of any object exposed to the gas flow downstream of the diffuser should not exceed $1000^{\circ} \mathrm{R}$. If the gas-water interaction time is of sufficient duration, the problem is simplified by the use of sprays along the wall; however, turning the gases within three diameters downstream from the diffuser exit requires the rapid mixing of the water and gas within this distance.

\section{SUMMARY}

A test program has been prepared to evaluate analytical procedures for predicting test conditions resulting from the injection of water into a high-temperature gas stream. Two analytical methods have been developed to perform these calculations; one by Greyrad Corporation, based on a mixing model and the other by Aerojet, based on an evaporation model. Each program was evaluated by comparing predictions for some scale-model tests with test data. No clear superiority for either program was evident on the basis of this comparison. The fundamental drawbacks of the Greyrad model are: (1) it relies strongly on experimental mixing coefficients, which have not yet been determined, and (2) it assumes a point-source water injection so that water is distributed throughout the stream by mixing alone, without including the effect of water droplets being shredded in large quantities from the jet stream as it traverses toward the center of the duct. The major drawback of the Aerojet model is its inability to account for any mixing and relies totally on penetration and shredding to distribute the injected water.

The Aerojet model, however, at its present state of development, calculates an initial distribution of water in the stream in a manner that is insensitive to any empirical mixing coefficient. Since there is particular interest in the region within three duct diameters, the Aerojet program should be especially applicable for predicting the performance of the spray system in the proposed program. Therefore, the spray system has been designed based on calculations made using the Aerojet model. 
The high-temperature tests are to consist of spraying water from a series of nozzles into a subsonic flow of high-temperature gas to cool the gases. The high-temperature gases are the combustion products of a liquid fluorine, mixed-fuel system of hydrazine and MMH. The predictions show that approximately $50 \%$ of the water is evaporated 30 in. from the point of injection and an average gas temperature of $1600^{\circ} \mathrm{R}$. The quantity of water evaporated and the resultant gas temperature at $90 \mathrm{in.}$, respectively, are $75 \%$ and $750^{\circ}$.

Throughout the analytical portion of this study there is a problem of establishing a droplet size or range of sizes. The analytical tools that have been employed are satisfactory but need further substantiation for this particular application. In the Aerojet analysis every effort has been made to avoid inferring a droplet size for the subscale-model tests, since the scaling parameters are unknown. The consequence of this constraint is a possible over or under estimation of evaporation rates for the tests.

\section{DISCUSSION OF MODEL STUDIES}

\section{A. SCALE-MODEL STUDIES}

A series of tests was conducted to determine the penetrability of high-velocity gas streams with water jets. This series was followed by tests with scale-model hardware to demonstrate the ability of water jets to penetrate and effectively cool a sealed duct system consisting of a deflector plate and plenum downstream of a supersonic diffuser. Subsequent tests permitted a quantitative measure of the rate of mixing and evaporation of water in an elevated-temperature gas stream. 


\section{Water Penetration}

\section{a. Previous Studies}

Several studies have been made of the problem of injecting water into high-velocity gas streams. Chelko (Reference 1), an early investigator, studied the penetration characteristics of water discharged from nozzles 0.0135 to 0.0625 in. in diameter directed perpendicular to a $742 \mathrm{ft} / \mathrm{sec}$ air stream. The result of his analysis was an empirical expression relating penetration to the velocity and density ratios of the two streams. Fenn (Reference 2) investigated the penetration of a liquid ammonia jet into an air stream and correlated his test data in a manner similar to Chelko. More recently Forde, Moldes, and Szpiro (Reference 3) developed an analytical expression for the penetration of a liquid jet into a supersonic stream and compared it with data for penetration of water jets into a Mach 4 high-temperature air stream. Here too only small orifices were investigated that were restricted in range.

Ingebo (Reference 4) in a recently completed study has correlated drop-penetration data in terms of a Reynolds and Weber number relationship. The correlations resulting from this and the previous investigations are all basically empirical and are valid only for the particular range of test conditions evaluated.

\section{b. Aerojet-General Investigations}

Differences in the various aforementioned empirical equations and the lack of data for large nozzles led to a test program designed to extend the range of test data to include large-diameter nozzles and to arrive at specific empirical relationships. These relationships could be used to size an arrangement of injection nozzles to cool the hot gases and thereby protect an otherwise uncooled exhaust duct. The range of test 
variables is shown in Table I. The result of this program, reported in Reference 5, is an empirical correlation that enables the prediction of jet penetration for nozzles ranging from 0.0625 through $1.5 \mathrm{in}$. over a range of gas and water velocities as a function of mixing length. In addition, a correlation for predicting jet spread was also generated.

\section{c. Water-Penetration Correlation}

The penetration of water jets from nozzles ranging in size from 0.0625 to $1.5 \mathrm{in}$. has been correlated by the empirical equation:

$$
\frac{z}{\mathrm{~d}}=2.0 \quad\left(\mathrm{q}_{\mathrm{w}} / \mathrm{q}_{\mathrm{a}}\right)^{0.5}\left(\frac{\mathrm{x}}{\mathrm{d}}\right)^{0.7}
$$

for $x \leq z$

Two types of nozzles were tested: the penetration of one nozzle, a maximum penetration nozzle as discussed in Reference (6), compared favorably with that of a standard fire-fighting nozzle, although there were significant differences in design.

The width of the jet (for purposes of predicting regions of interaction between two adjacent jets or volume occupied by the water spray as a function of axial distance) can be estimated from the equation representing jet spread:

$$
Y / d=2.6(x / d)^{0.3}
$$

for $7<X<22$ 
TABLE 1

SUMMARY OF TEST CONDITIONS

Phase I Tests

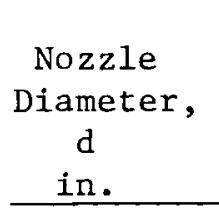

$0.02625-0.5$

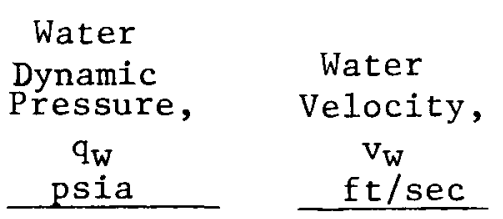

$31.5-172.5$

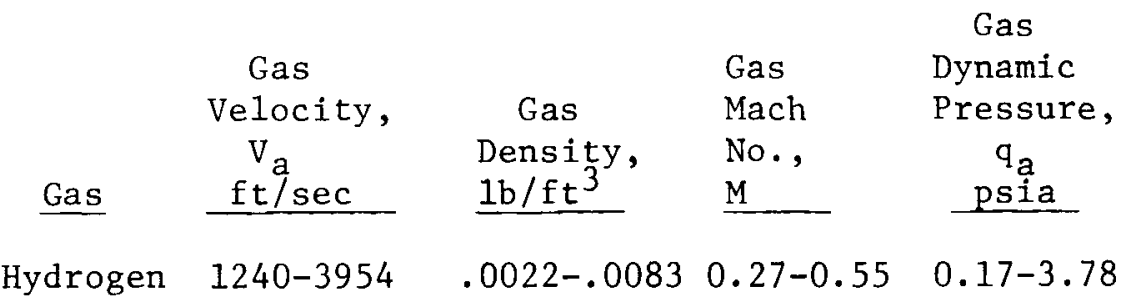

Nitrogen

$388-1342$

$.031-.119$

$0.38-0.72 \quad 1.62-5.40$

Phase II Tests

\begin{tabular}{|c|c|c|c|c|c|}
\hline Nozzle & $\begin{array}{c}\text { Water } \\
\text { Dynamic }\end{array}$ & Water & & & $\begin{array}{c}\text { Gas } \\
\text { Dynamic }\end{array}$ \\
\hline $\begin{array}{c}\text { Diameter } \\
\mathrm{d}, \\
\text { in. } \\
\end{array}$ & $\begin{array}{c}\text { Pressure, } \\
\mathrm{q}_{\mathrm{w}} \\
\text { psia }\end{array}$ & $\begin{array}{c}\text { Velocity, } \\
v_{\mathrm{H}} \\
\mathrm{ft} / \mathrm{sec}\end{array}$ & Gas & $\begin{array}{c}\text { Gas } \\
\text { Mach No., } \\
\text { M } \\
\end{array}$ & $\begin{array}{c}\text { Pressure, } \\
\mathrm{q}_{a} \\
\mathrm{ps} 1 \mathrm{a} \\
\end{array}$ \\
\hline $0.25-1.5$ & $29-142$ & $62-139$ & Air & $0.22-0.43$ & $0.46-1.65$ \\
\hline
\end{tabular}

NERVA (E-2)

\begin{tabular}{|c|c|c|}
\hline \multirow{3}{*}{$\begin{array}{l}\text { Nozzle } \\
\text { Diameter } \\
\text { d, } \\
\text { in. }\end{array}$} & \multicolumn{2}{|l|}{ Water } \\
\hline & Dynamic & Water \\
\hline & $\begin{array}{c}\text { Pressure, } \\
q_{\mathrm{w}} \\
\text { psia }\end{array}$ & $\begin{array}{l}\text { Velocity, } \\
v_{\mathrm{y}} \\
\mathrm{ft} / \mathrm{sec}\end{array}$ \\
\hline $.1-2.00$ & 125 & 136 \\
\hline
\end{tabular}

\begin{tabular}{|c|c|c|}
\hline Gas & $\begin{array}{l}\text { Average } \\
\text { Gas } \\
\text { Mach No., } \\
\text { M } \\
\end{array}$ & $\begin{array}{c}\text { Average } \\
\text { Gas } \\
\text { Dynamic } \\
\text { Pressure, } \mathrm{q}_{\mathrm{a}} \text {, } \\
\text { psia } \\
\end{array}$ \\
\hline Hydrogen & 0.42 & 1.87 \\
\hline
\end{tabular}




\section{d. Deflector Cooling Studies}

A series of tests was conducted with scale-model hardware to demonstrate the ability of water jets to penetrate and effectively cool a duct system consisting of a deflector plate and plenum located downstream of a supersonic diffuser. The tests were of a scale model wet-elbow system as shown in Figure 1. The test equipment consisted of a contoured nozzle with a 40:1 expansion ratio in an air-tight enclosure, a second throat diffuser with a 4:1 length-to-diameter throat section, a water injection system at the exit of the diffuser designed to inject sufficient water to cool the stream to the saturation temperature, plus a plenum that included a deflector plate to aid in turning the exhaust gases.

\section{(1) Water Injection System}

A water-injection system was designed in accordance with the correlation in Reference 5 to penetrate the gas stream leaving the diffuser and to produce a uniform distribution of water in the gas stream. The gas-flow field at the exit of the diffuser was calculated using the test data shown in Figure 2. At the time this program was conducted, the penetration was calculated in a step wise manner as though the gas was flowing at a constant velocity in each of three concentric stream tubes. The penetration profile for each diameter nozzle was determined and the slopes were matched at the steps in the flow field. The calculated penetration profiles are shown in Figure 3. Knowing the penetration distance at different mixing lengths it was possible to estimate the jet spread for each nozzle. Knowing the penetration and spread of the jets it was possible to geometrically arrange the nozzles so that the water spray would fill the duct. Although several arrangements will fill the duct with a water spray, one other restraint is the water distribution. For this series of tests the mass addition was designed to be essentially uniform or tailored for a uniform gas flow field. The nozzle-injection patterns predicted for the nozzles are shown in Figure 4. 


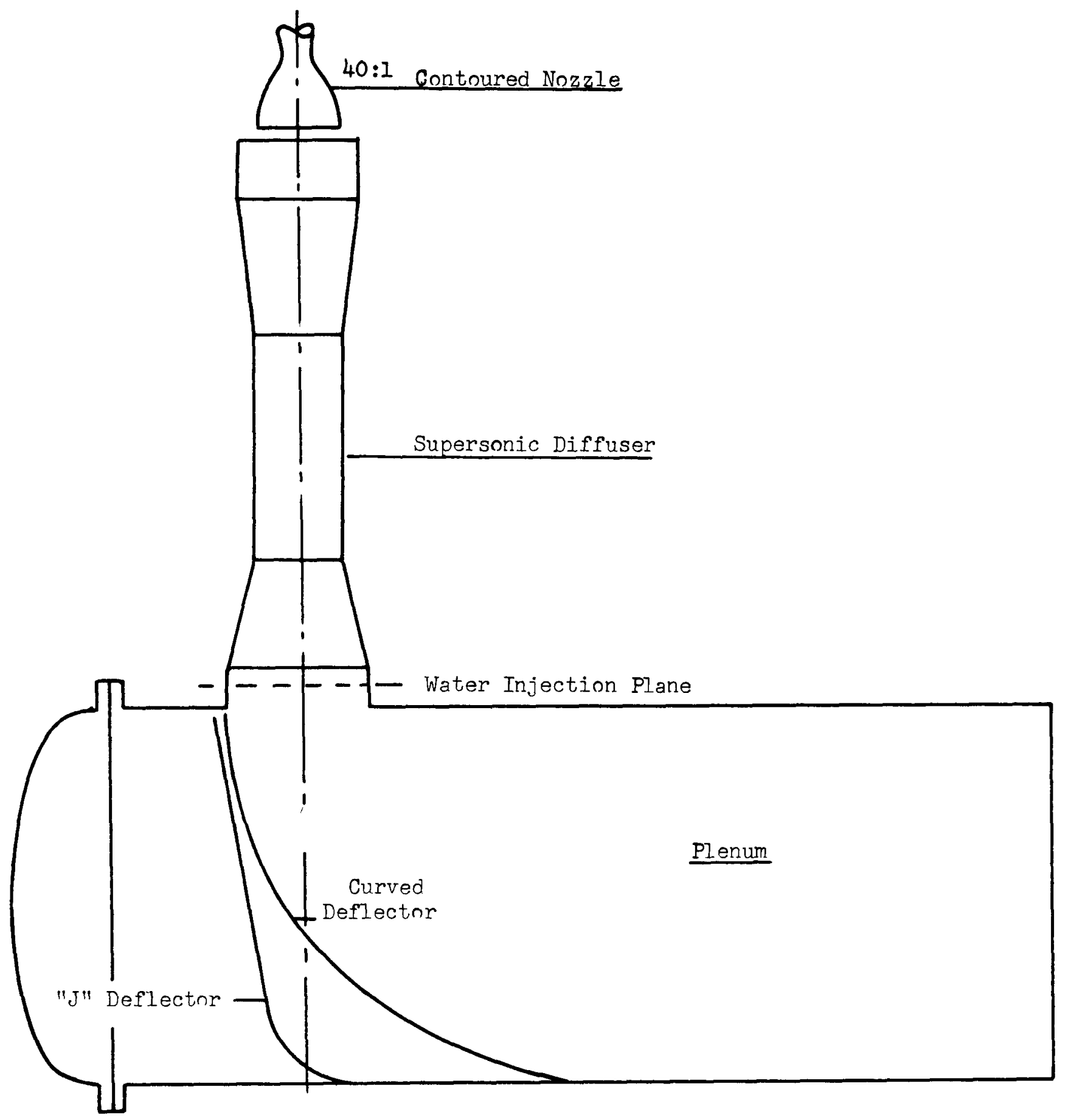

Figure 1 - Scale-Mode1 Diffuser - Wet Elbow Assemb1y 


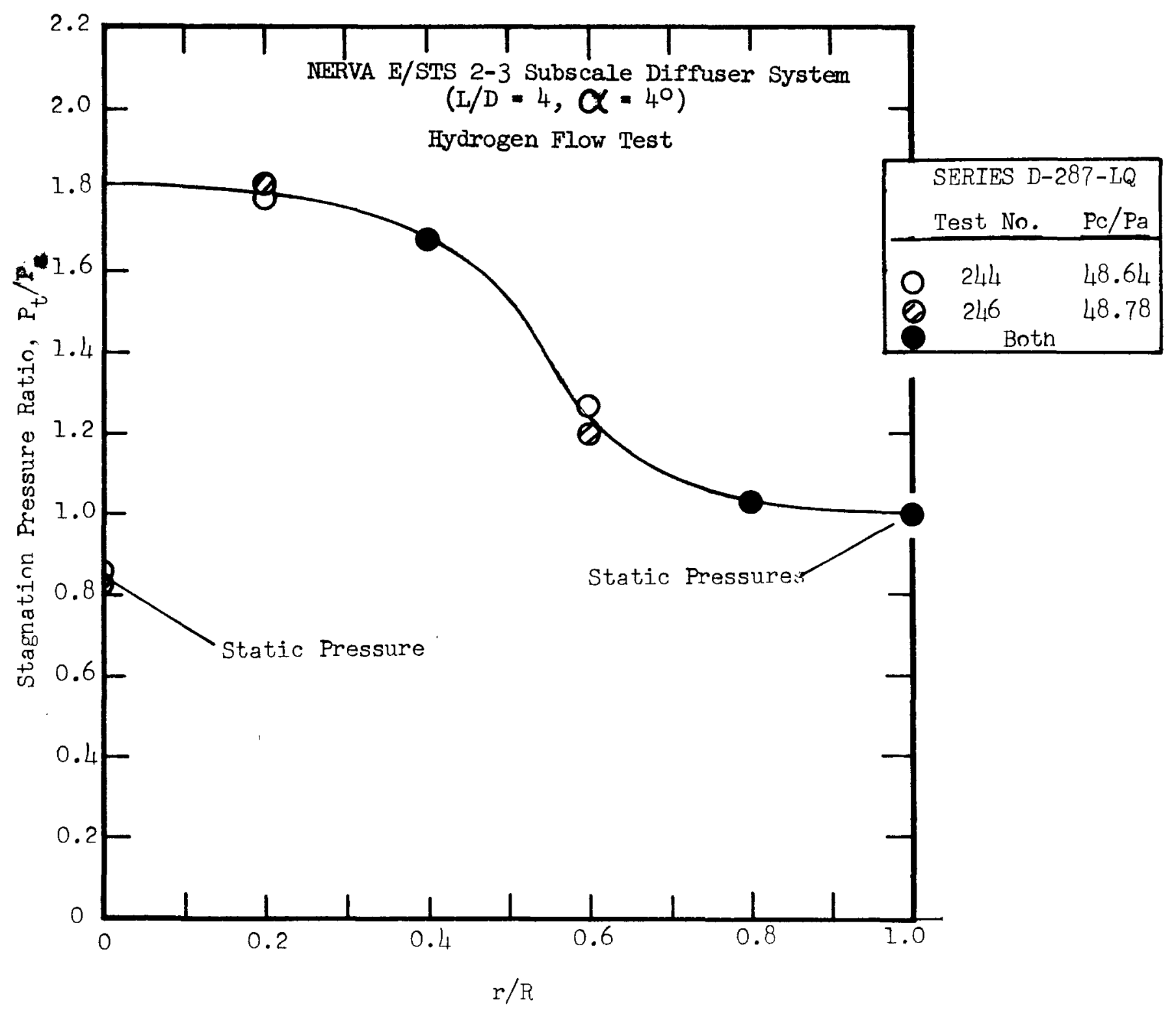

Figure 2 - Diffuser Exit Pressure Profile 


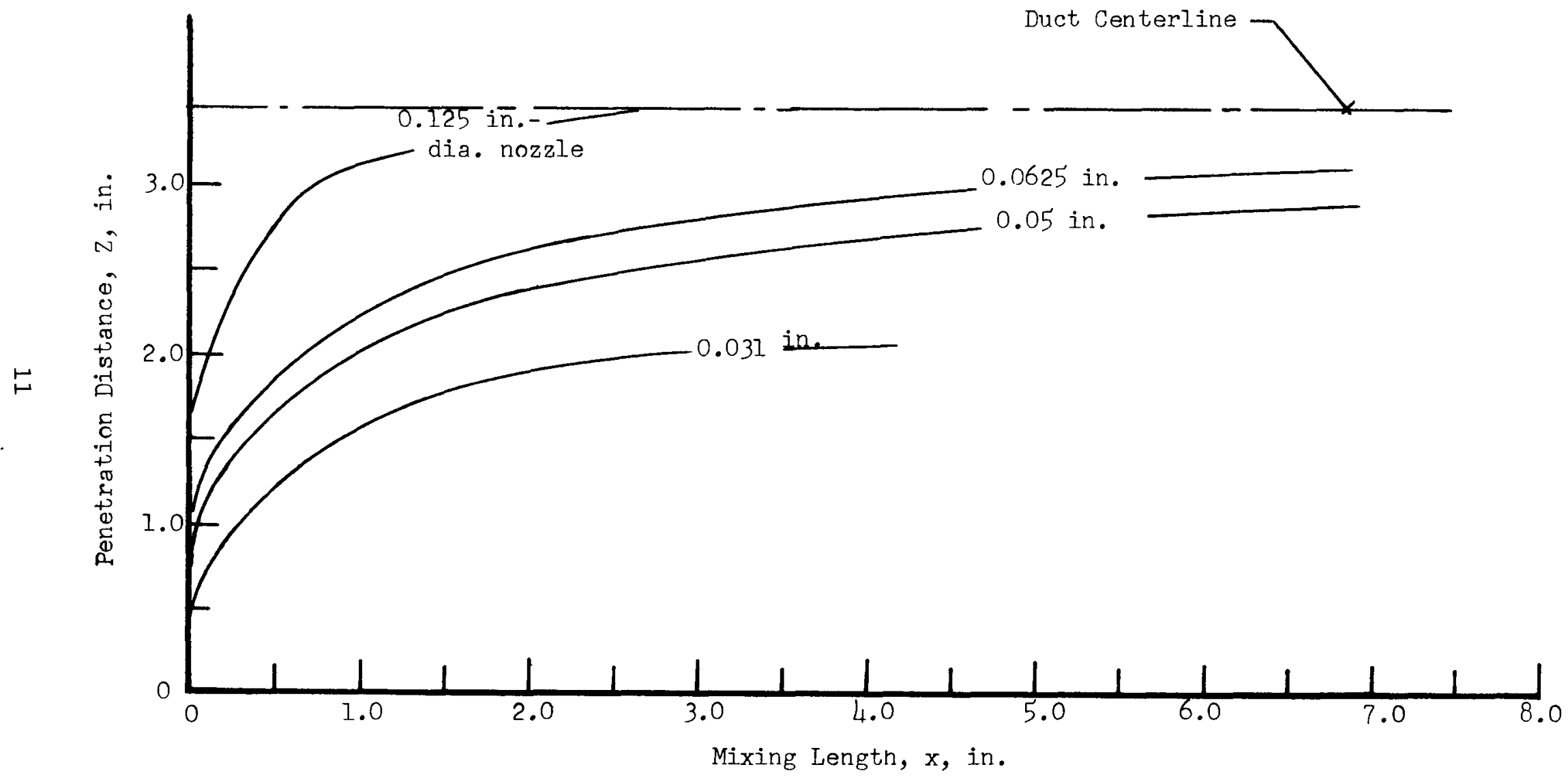

Figure 3 - Water Penetration into Hydrogen Gas Flow for DifferentDiameter Nozzles 


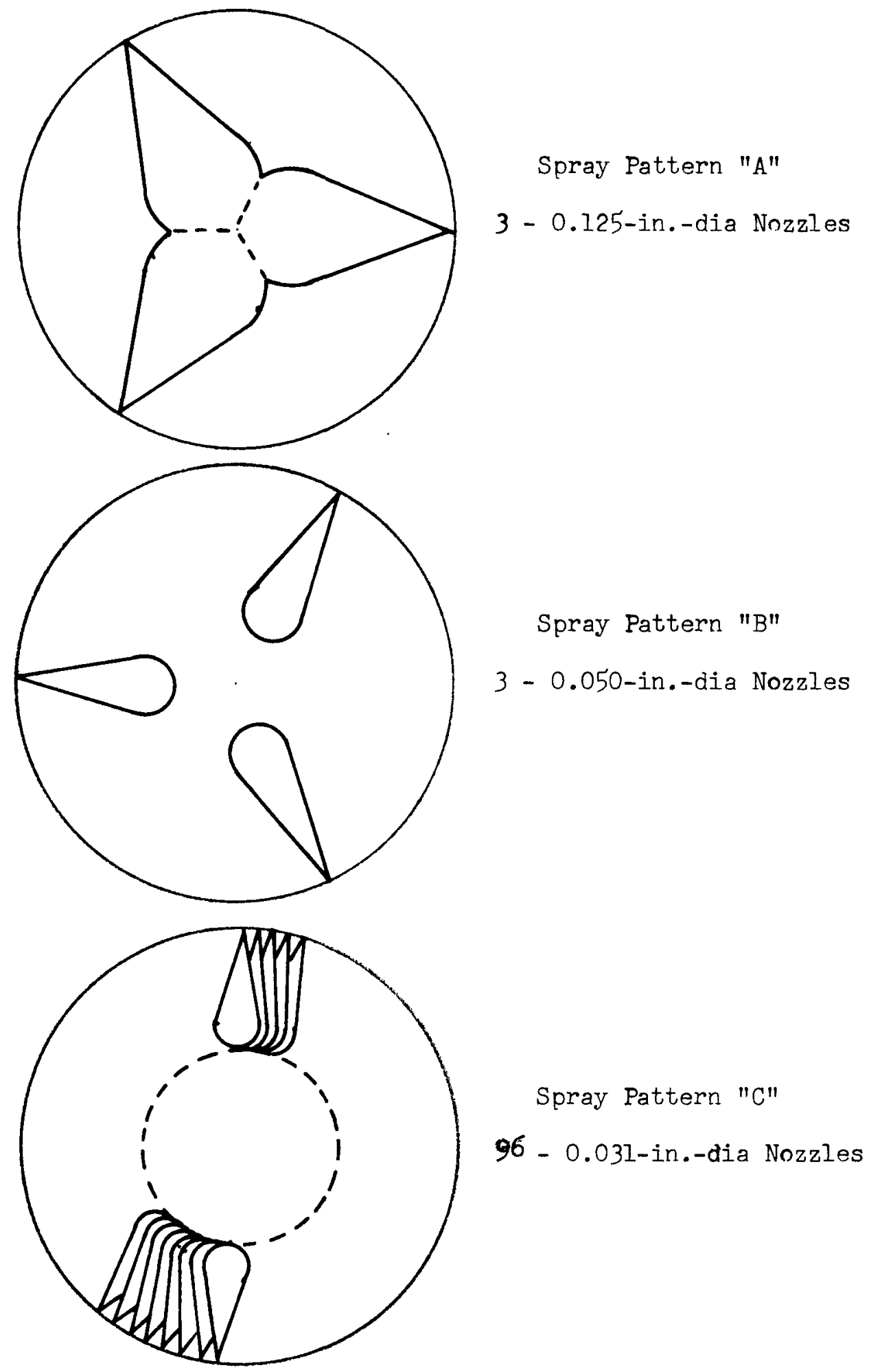

Figure 4 - Predicted Water-Injection Pattern 


\section{(2) Deflector Plate}

One of the advantages of a wet elbow compared with a dry elbow is the reduced overall duct height made possible by a wet elbow. With either system, a $90^{\circ}$ turn of the gas flow is necessary, and it is desirable to achieve this turn with the minimum possible loss in total pressure. The efficiency of a $90^{\circ}$-turn increases with an increase in bend radius; therefore, the minimum turn radius would have the highest pressure drop and correspondingly based on the results of Reference 7, would have the highest heat-transfer coefficient. For a given stand height and engine size the optimum design will be a compromise between the aerodynamic and heat-transfer factors. Figure 5 shows two deflector plate designs tested in this study. The curved plate deflector is the maximum-turn-radius plate that can be accommodated in the available space. It appeared that this would be the most efficient deflector design. Since contact between the core of the hot-gas stream and the hot-gas stream and the deflector occurs at a limited distance from the diffuser exit with this deflector, an alternate deflector where this does not occur was also tested. This J deflector represents a configuration that is drastically different from that of the curved plate. The heat transfer to the face should be at a minimum because of the small angle of contact and the point of maximum impingement between the hot core of the gas stream and the deflector occurs at the most distant point consistant with the envelope dimensions.

\section{(3) Experimental Results}

Ten tests were performed; six flowing heated gaseous nitrogen and four flowing heated gaseous hydrogen, to characterize the influence of water injection on diffuser performance and to qualitatively determine the cooling ability of the injected water. 

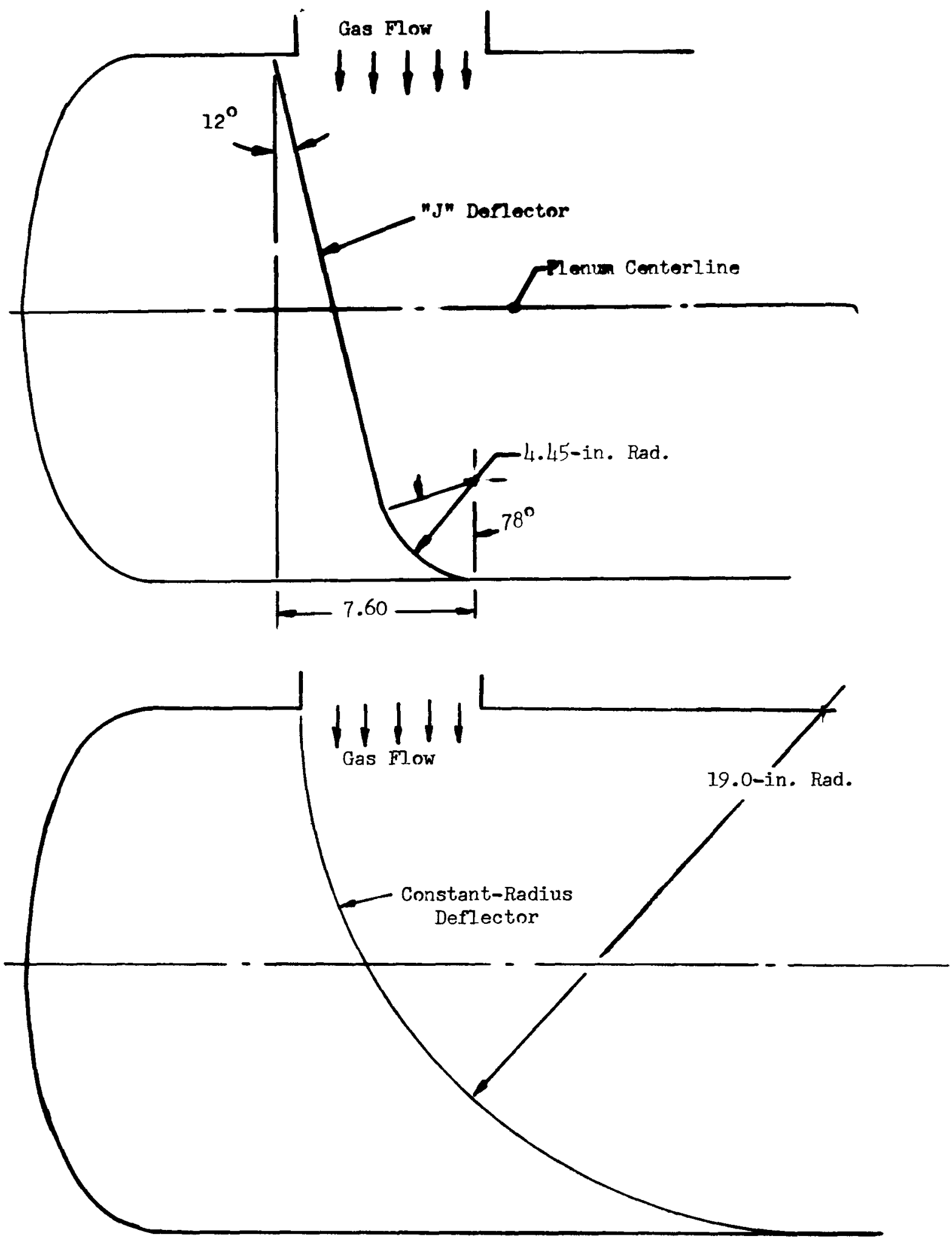

Figure 5 - Deflectors - Wet Elbow Study 
The flow of water necessary to cool and saturate the gaseous nitrogen gas stream was approximately $1.01 \mathrm{~b} / \mathrm{sec}$ compared with approximately $4.5 \mathrm{lb} / \mathrm{sec}$ to $\operatorname{coo} 1$ the hydrogen stream. Only one water injection system was tested. Figure 6 shows the water injection design, and Figures 7 and 8 show the completed water injector.

Since only $1.01 \mathrm{~b} / \mathrm{sec}$ of water was required to cool the nitrogen gas flow, only the 1/8-in.-diameter nozzle flow was necessary to cool the gases. Although this nozzle was designed specifically to penetrate the stream, it effectively cooled the entire curved deflector plate as shown in Figure 9. These data are representative of how the deflector plate was cooled in each test. For the test data plotted in Figure 9, the gas flow was initiated and chamber pressure was brought to 48.5 atmospheres prior to injecting water. Diffuser performance was not adversely affected by the addition of water at flow rates up to $4.51 \mathrm{~b} / \mathrm{sec}$.

Two types of tests were conducted with gaseous hydrogen. System performance evaluation studies with water injection rates ranging from zero to $4.5 \mathrm{lb} / \mathrm{sec}$ were conducted in one series of tests. In a second group diffuser performance was evaluated when the water injection rate exceeded the nominal saturation flow rate of $4.5 \mathrm{lb} / \mathrm{sec}$.

Temperature measurements were obtained for the plenum and the deflector plate. Figures 10, 11, and 12 are plots of the deflector plate temperatures with varying amounts of water injection at different regions of the deflector. The results of the temperature measurements are only qualitative, but show that when water was injected in quantities sufficient to saturate the gas all surfaces contacted by the gas were cooled. As indicated in Figure 10, when water is injected from the three 0.125-in.diameter injectors (Spray A) the center portion of the deflector is cooled $(\mathrm{Tc}-1,-2,-4,-6)$ but the regions away from the center $(\mathrm{Tc}-8,-10)$ are not cooled; conversely, with spray from on1y the 96-0.031-in.-diameter injectors 

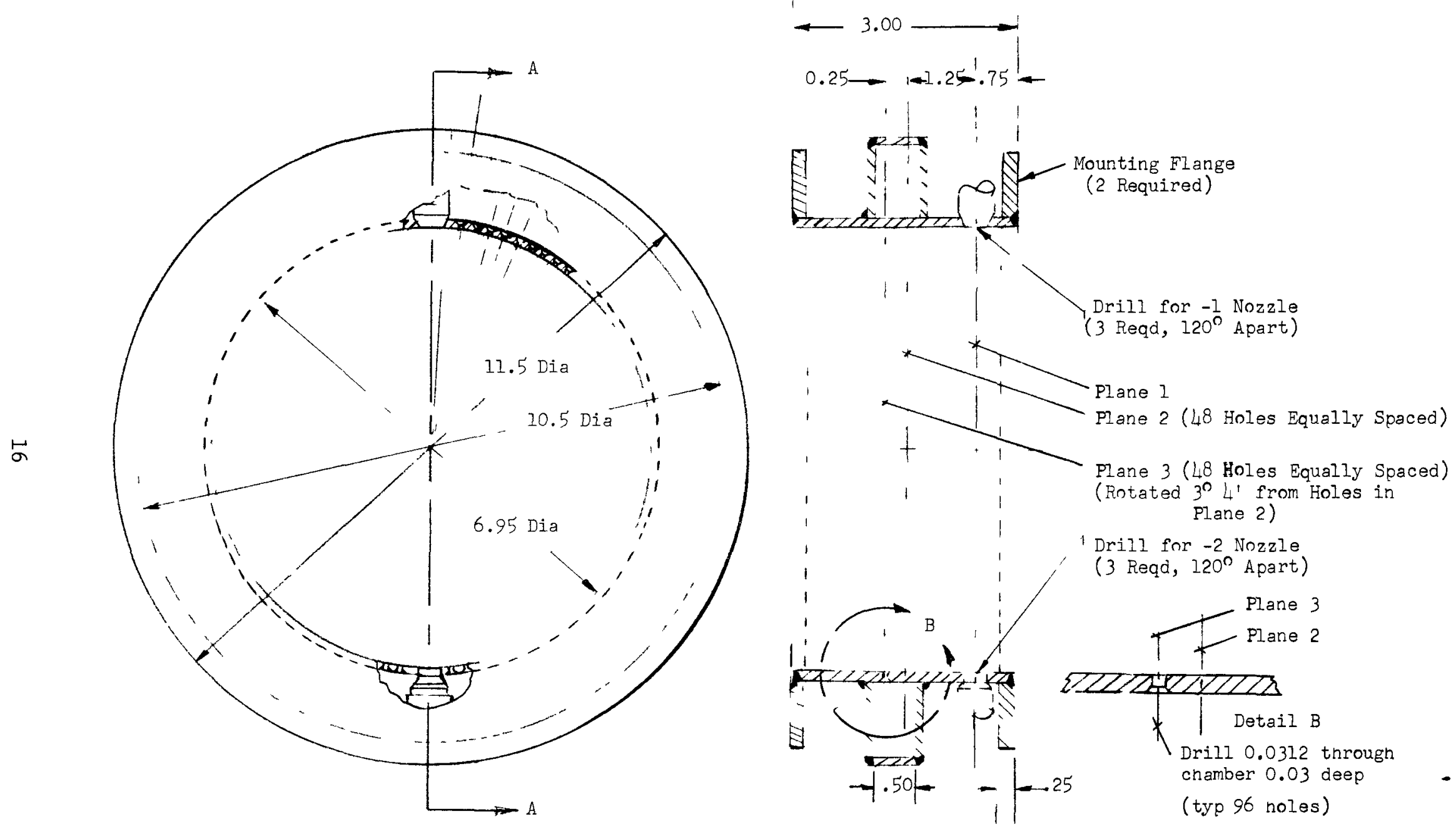

Section A-A

Figure 6 - Water-Injector Design 


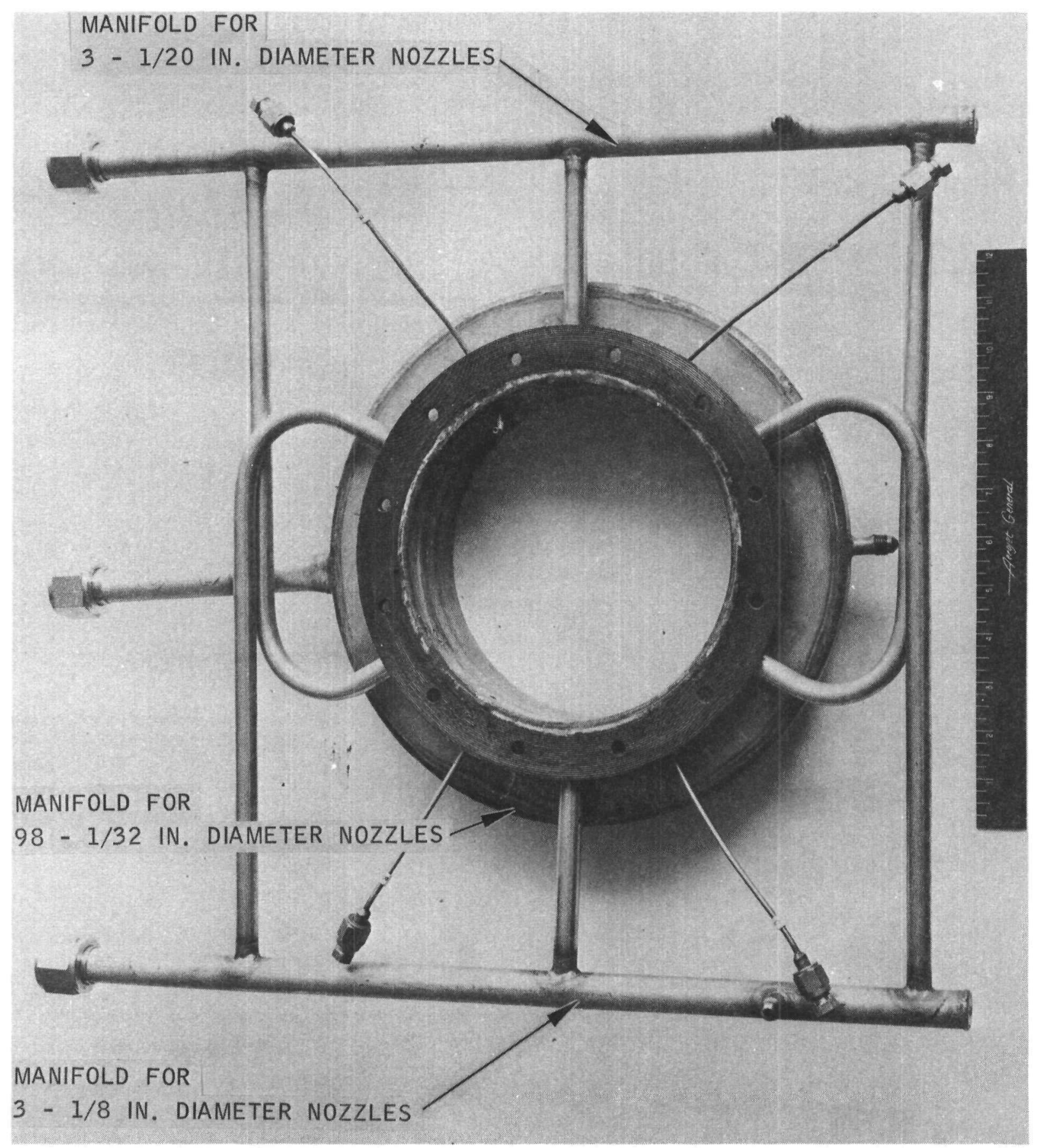

Figure 7 - Water-Injector Manifold 


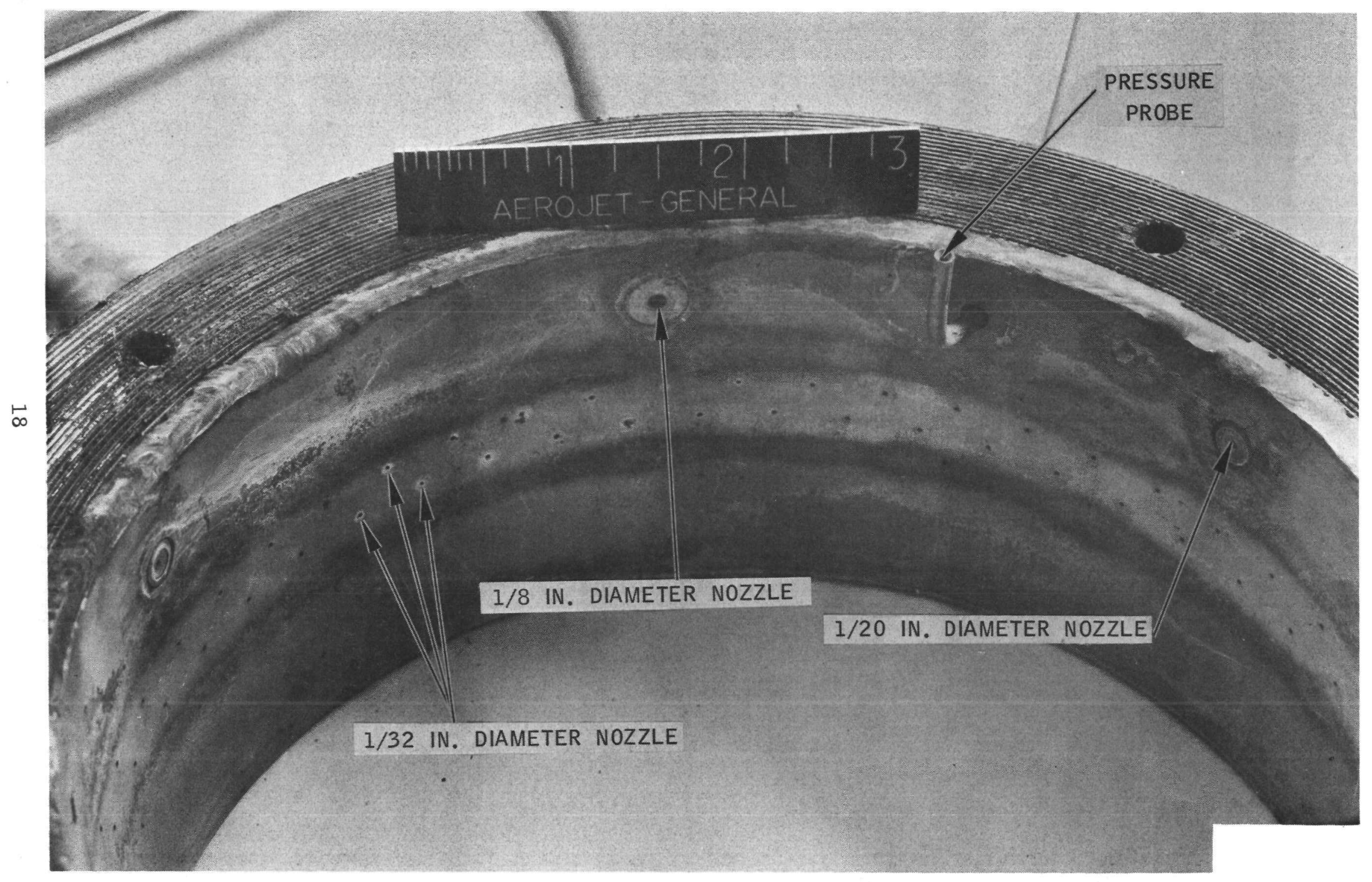

Figure 8 - Water-Injector Nozzles

$\bullet \bullet \bullet \bullet \bullet \bullet \bullet \bullet \bullet \bullet \bullet \bullet \bullet \bullet \bullet \bullet \bullet \bullet \bullet$ 

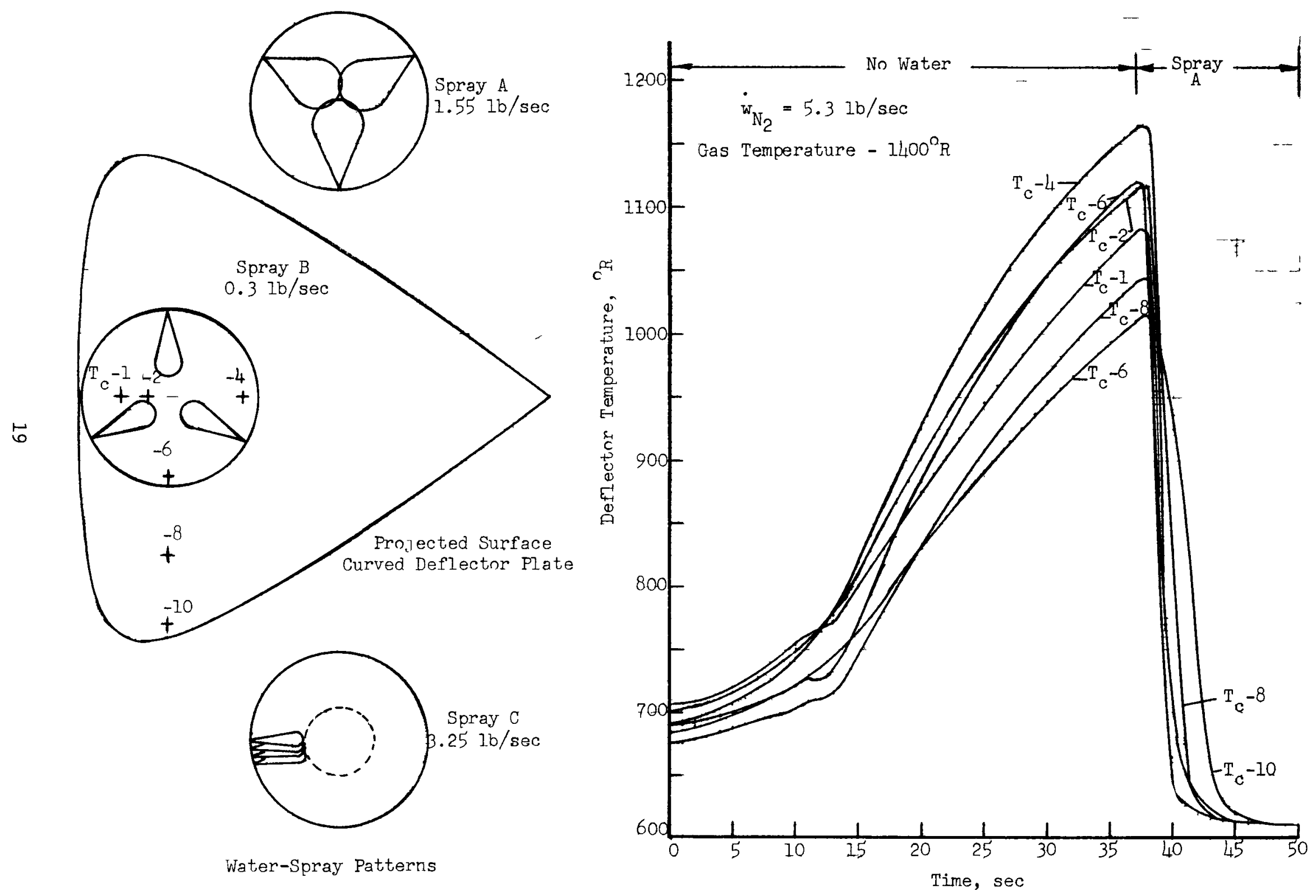

Figure 9 - Curved-Deflector-Plate Temperatures with Water Injection into Nitrogen Gas, Test 334 


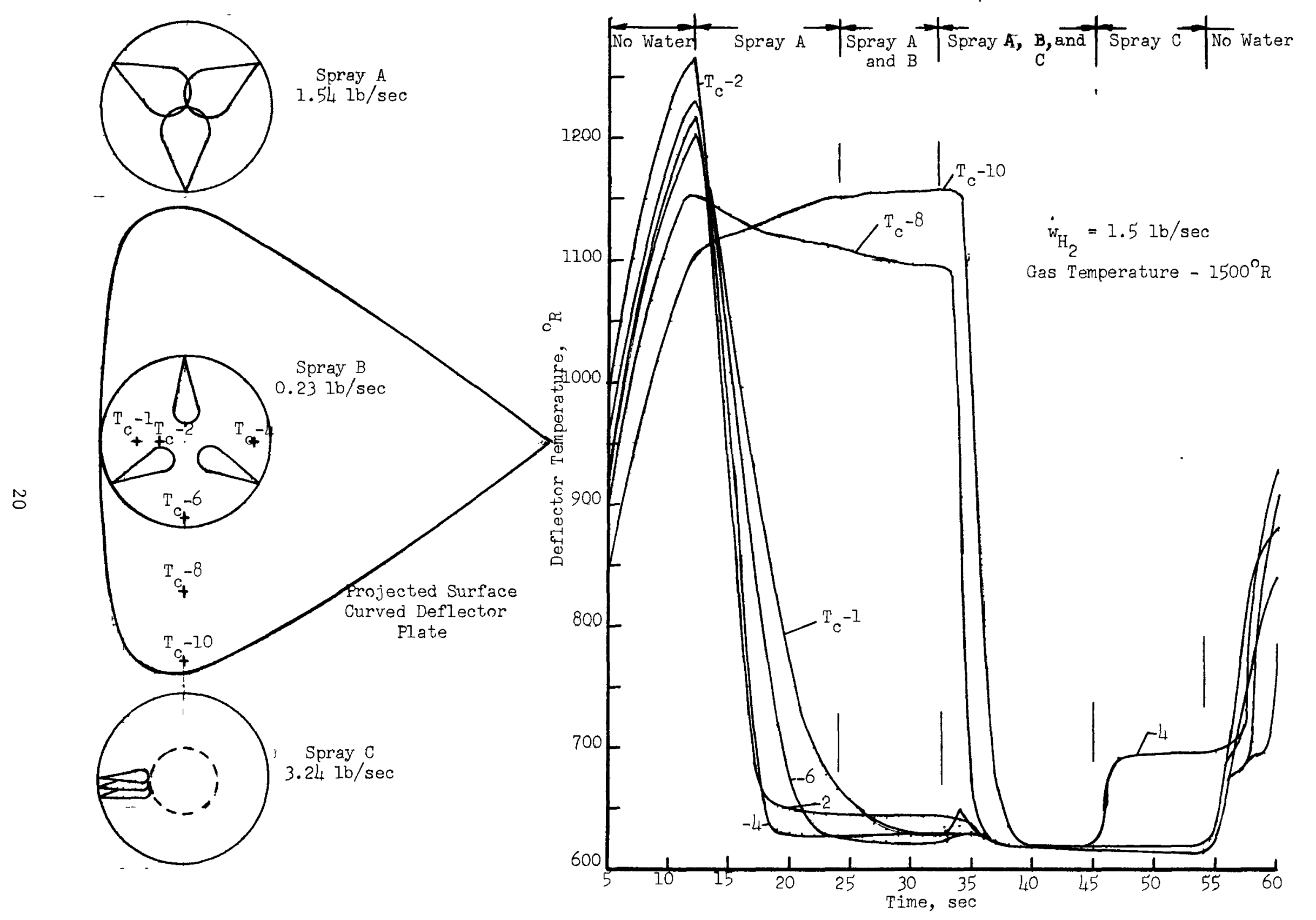

Figure 10 - Deflector-Plate Temperatures with Water Injected into Hydrogen Gas, Test 337 

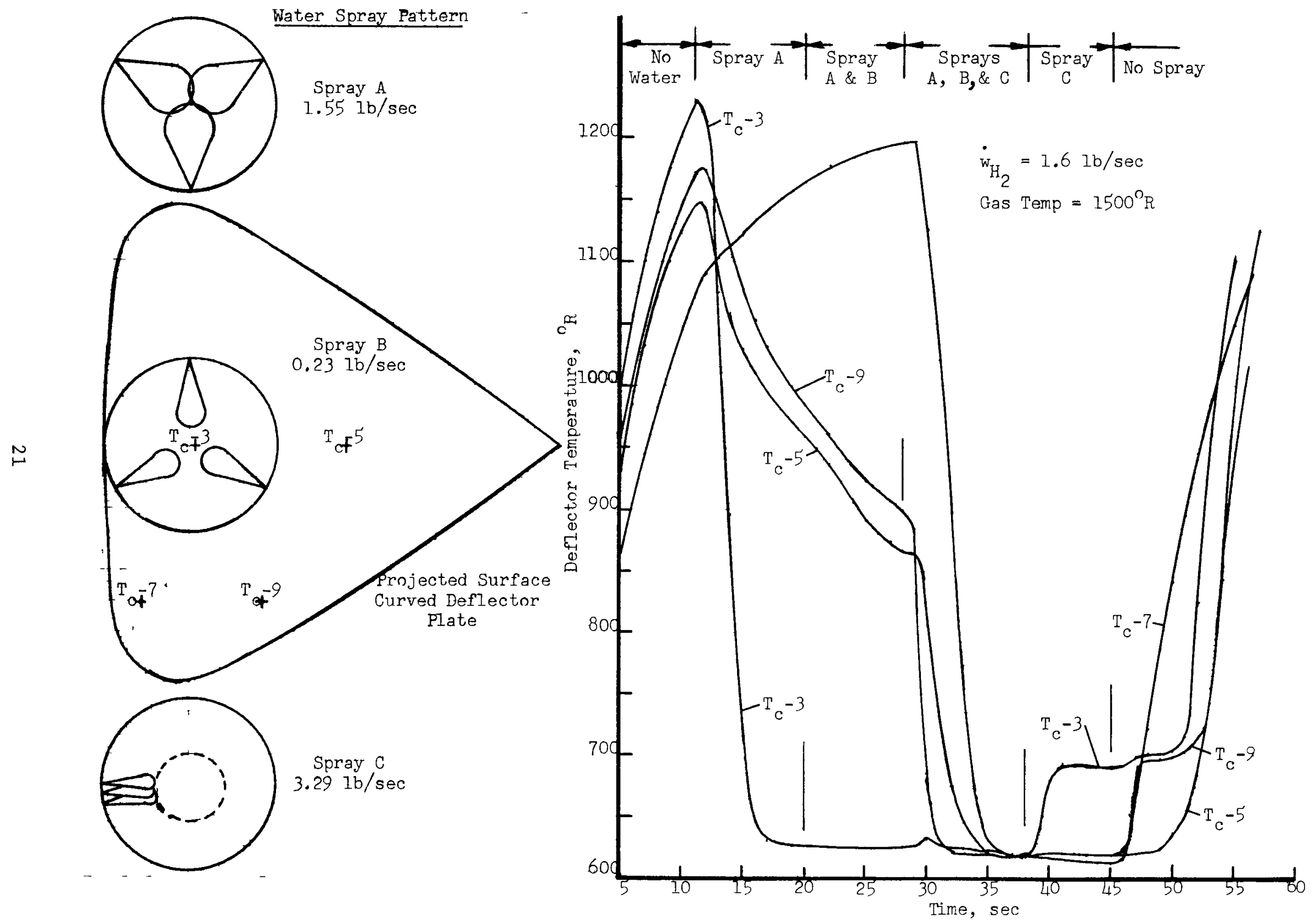

Figure 11 - Deflector-Plate Temperatures with Water Injection into Hydrogen Gas, Test 339 

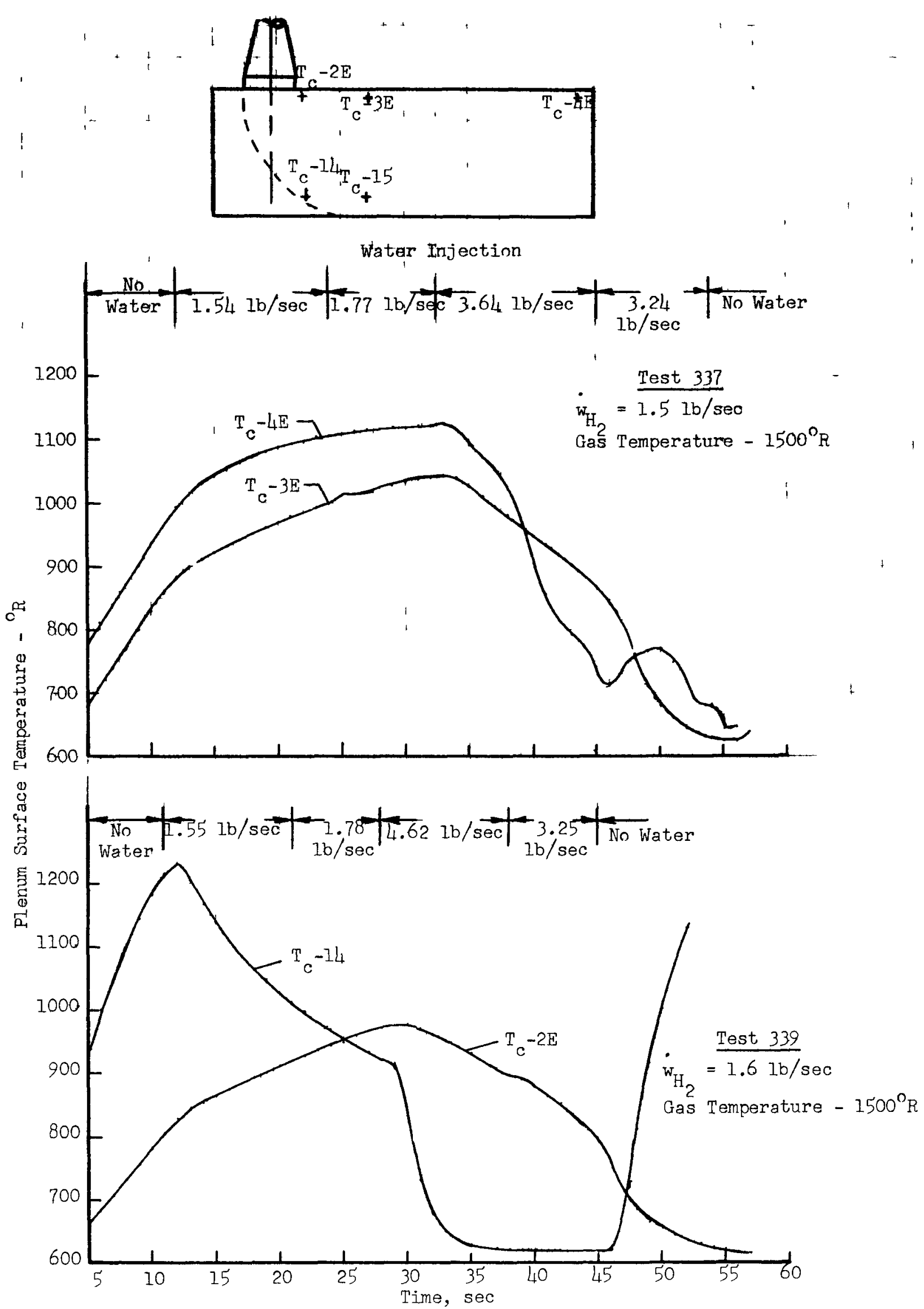

Figure 12 - Temperature on Outside of Plenum with Water Injection into Hydrogen Gas, Tests 337 and 339 
(Spray C) the temperature of the deflector plate at the lower central region (Tc-4) increased, indicating that a hot core of gas was impinging on the deflector. Figure 11 shows how the remaining thermocouples (Tc-3, $-5,-7$ and -9 ) responded with the injection of water for a similar test.

In addition to the temperatures on the deflector, thermocouples were attached to the outside of the plenum. The thermocouples indicated that in these tests, with the addition of sufficient water to saturate the gas stream, the plenum itself is cooled to the saturation temperature. This is attributed to either entrained water in the gas stream contacting the plenum walls or to nearly complete evaporation.

The scale-model hardware for these wet-elbow tests was an aerodynamic model of the flow field. Evaporation, however, which is a time-rated function, could not be scaled. Where complete evaporation is the goal in the full-scale wet elbow only a sma11 fraction of the evaporation is expected to have taken place in the subscale tests prior to impingement on the deflector plate due to the extremely short residence time of the droplets.

For the tests with heated gaseous hydrogen, approximately $4.5 \mathrm{lb} / \mathrm{sec}$ of water was required to cool the hydrogen gas to the saturation temperature. Consequently, all three of the water manifolds were flowed during the diffuser pull-in tests while flowing gaseous hydrogen. If the tests had been accurately scaled for a NERVA engine test, the gas temperature would have been $4500^{\circ} \mathrm{R}$ instead of $1500^{\circ} \mathrm{R}$ and the water injection rate to cool the $1.5 \mathrm{lb} / \mathrm{sec}$ flow of hydrogen gas would have been $20.3 \mathrm{lb} / \mathrm{sec}$. Since this is a flow rate more than four times that of the design value for the scale-model apparatus, it was impossible to achieve with existing hardware. It was, however, possible to increase the flow to $9.6 \mathrm{lb} / \mathrm{sec}$, which would be the flow necessary to $\operatorname{coo} 1.3 \mathrm{lb} / \mathrm{sec}$ from 3500 to $1000^{\circ} \mathrm{R}$ and would simulate the flow from the engine at the point of diffuser pull-in. It was, therefore, 
attempted to test the pull-in characteristics of the scale-model diffuser with this high flow rate of injected water. At a flow of $9.6 \mathrm{lb} / \mathrm{sec}$ the diffuser did not start and the cell pressure was dropped from 14.5 psia to 13 psia. The test was repeated for a water-flow rate of $61 \mathrm{~b} / \mathrm{sec}$ and the cell pressure was now reduced to 7.5 psia. Only when the flow rate was reduced to $4.75 \mathrm{lb} / \mathrm{sec}$ was diffuser pull-in achieved. In these tests the on1y way to increase the water-flow rate, without a redesign or alteration of the injector geometry, was to increase the pressure of the injected water. The resultant high-momentum jets, rather than being turned by the gas flow, may have impinged in the center of the duct resulting in a significant blockage. This difficulty, although a deviation from actual simulation, must be considered in the further scale-model studies. It is expected that by injecting the water slightly downstream in the plenum instead of into the diffuser will allow the gas to freely expand around any blockage created by impinging jets.

\section{Water Mixing and Evaporation}

A spray of water into a hot-gas stream will penetrate, break up, mix, and evaporate, thereby reducing the temperature of the gas stream. The simplicity of the approach does not indicate the complexity of the problem that has tended to discourage analytical solutions. In genera1, the design of spray coolers has proceeded in a completely empirical and conservative manner.

The concept of spray cooling as applied to a wet-elbow system is extremely promising and two experimental scale-model studies have been conducted to demonstrate that the method was feastble. In addition, analytical efforts were started to predict the duct length required to cool a hot hydrogen stream by using water droplet evaporation.

\section{a. Previous Investigations}

A serfes of spray-cooling tests were conducted by Shap1ro, et a1 (Reference 10) in an attempt to demonstrate that a stagnation 
pressure rise could be obtained by spray cooling a hot-gas stream. In this study the mechanics of the water injection, breakup, and evaporation were ignored as not significant to the basic problem. J. Rizika (Reference 11) in a paper dealing with spray cooling develops an analytical model, but indicates that verification of the model would require extensive experimental work. Evaporation of droplets has been studied experimentally, but data in the open literature were limited and no proven analytical models for spray cooling are available.

\section{b. Aerojet-General Studies}

A series of mixing and evaporation tests were performed using the basic wet-elbow, scale-model hardware, except that the gas stream leaving the diffuser was not turned $90^{\circ}$ upon entering the larger duct but was continued in the same axial direction. The purpose of the test was to obtain experimental spray-cooling data to compare with an analytical model without the perturbing influence of an elbow. The test instrumentation was designed to establish the gas-flow field, the temperature of an object in the gas stream, and the distance required for the water to evaporate.

The nozzle, nozzle enclosure, and diffuser assembly were mounted in a horizontal plane and connected to an 18-in. (0.D.) 600-in. long evaluation duct. Figure 13 is a sketch of the test assembly. Instrumentation installation ports were located along the length of the duct to permit the insertion of temperature and pressure probes (Figure 14) into the gas stream.

Total pressure rakes were designed to measure pressures at six radial positions in the stream. Static wall pressures were measured at each rake location. 


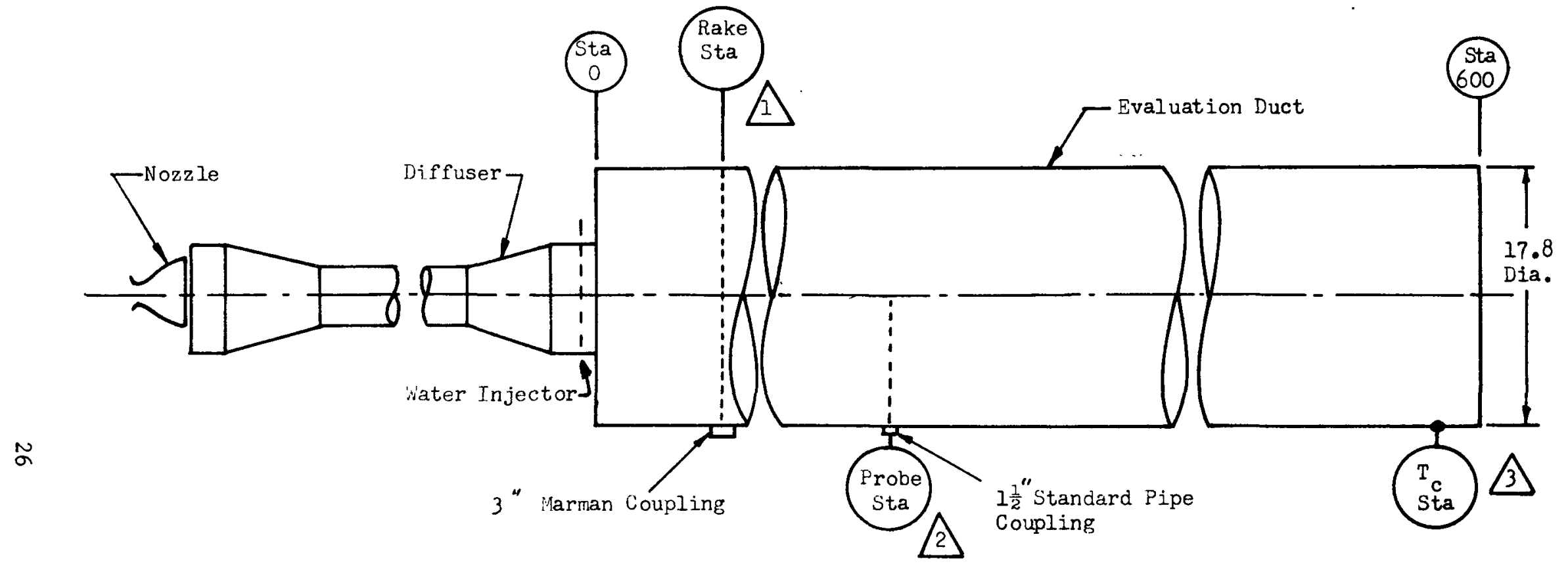

1. Instrumentation Kake Ports to be located at Stations 7, 20, 40, 80 , $120,200,300,400$, and 500 .

2 Instrumentation Probes to be located at 20-inch increments starting at Station 60 .

3 Thermocouples located on outside of duct at top and bottom on Stations 10, 50, 90, 140, 190, 290, and 490 .

Figure 13 - Mixing and Evaporation Evaluation Duct Assembly 


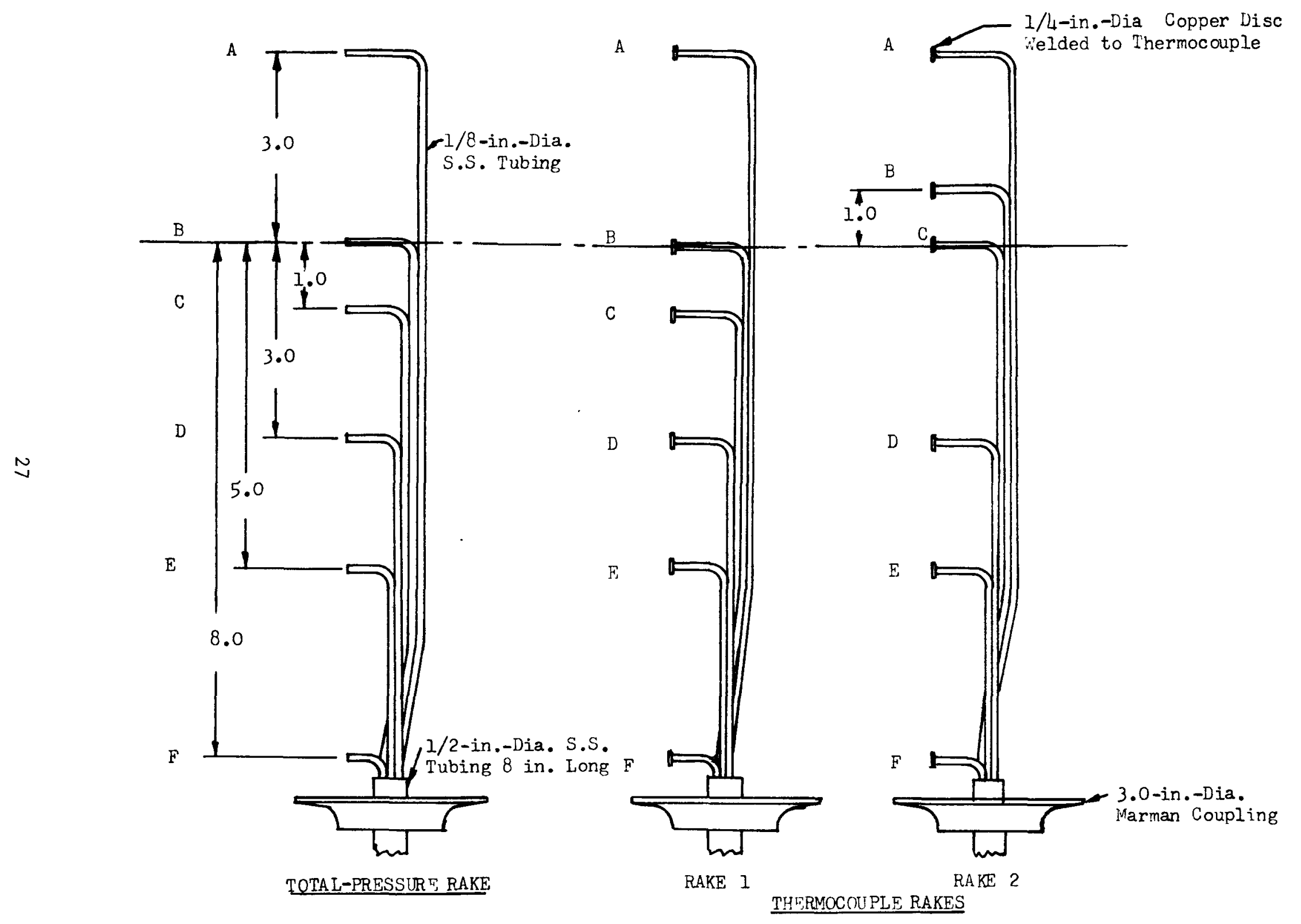

Figure 14 - Tota1-Pressure and Total-Effective-Temperature Rakes 
The temperature of the water-gas mixture was measured by a series of temperature rakes; a special moisture probe was devised to determine the point in the duct where the droplets were all evaporated. This instrument consists of two thermocouples mounted on copper blocks or discs, which in turn are located in a ceramic body as shown in Figure 15. One thermocouple measures the temperature of the stream impacting on the front of the probe and the other the temperature of the fluid aspirated in the cavity at the rear of the probe.

In designing the moisture probes it appeared that the temperature of the plate on the forward end of the probe would be film-cooled by any liquid in the gas stream and a saturation temperature would be indicated. However, the temperature of the gas flow in association with the water drops could be relatively high. In an attempt to measure the gas recovery temperature without including the influence of the water droplets, only the gas should be aspirated past a thermocouple junction. This was to be achieved by housing the thermocouple in a ceramic housing facing downstream. By placing holes in the housing between the central cavity and the outside diameter of the probe near the point of minimum static pressure, some gas flow past the rear couple will occur, resulting in a measurement of the recovery gas temperature.

\section{(1) Gaseous-Nitrogen Tests}

A series of 18 tests flowing gaseous nitrogen was conducted to map the velocities in the flow field, with and without water injection. The gases were at ambient temperatures or were heated to either 1000 or $1500^{\circ} \mathrm{R}$. The flow field from these tests is shown by Figure 16, which is a plot of the radial variation in velocity at different axial distances along the 18-in. duct.

The total effective temperature data for the $1500^{\circ} \mathrm{R}$ gas-temperature tests with no water injection and with injections of 0.2 and $1.5 \mathrm{lb} / \mathrm{sec}$ is shown in Figure 17. 


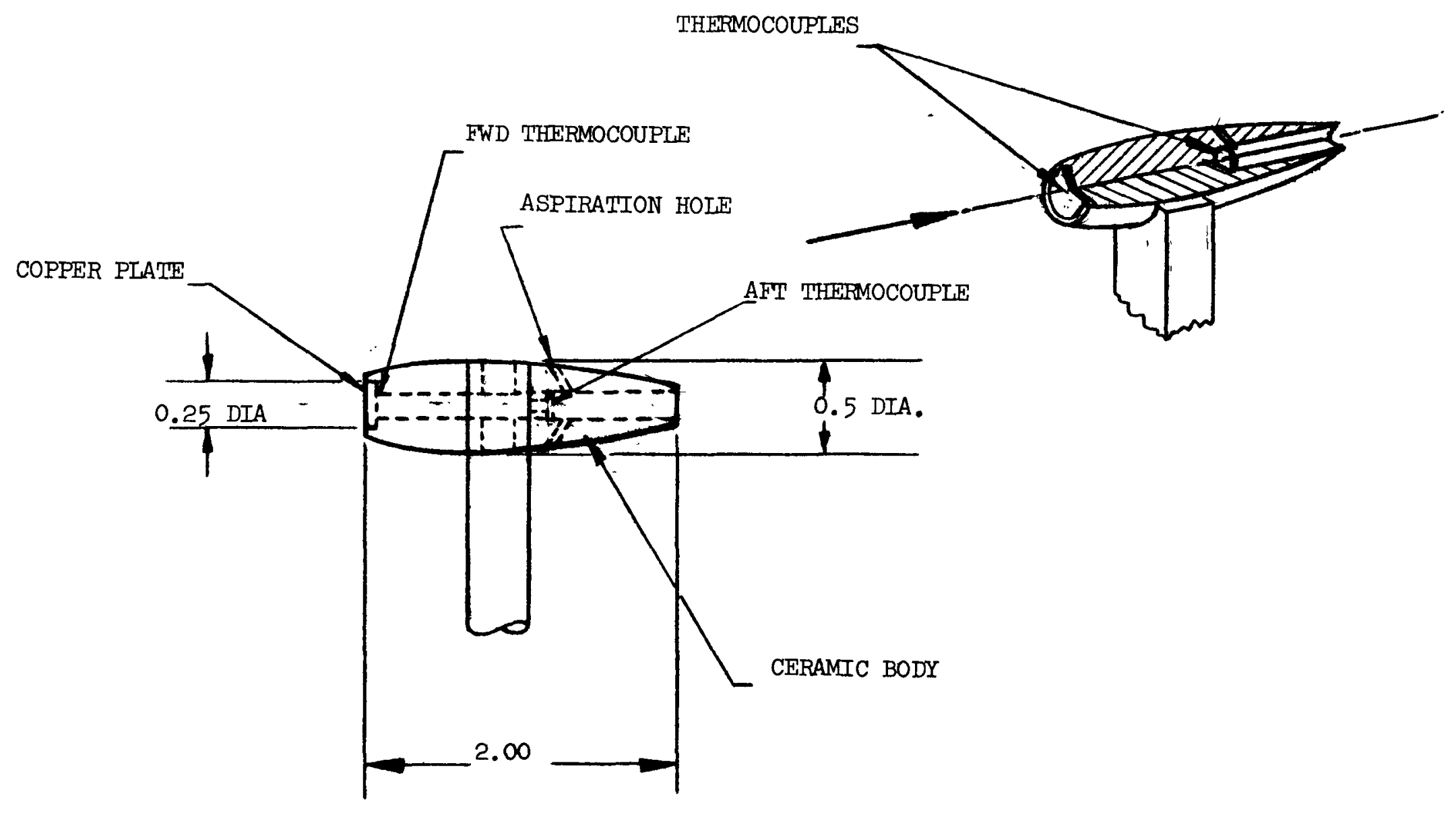

Figure 15 - Moisture-Sensor Probe 


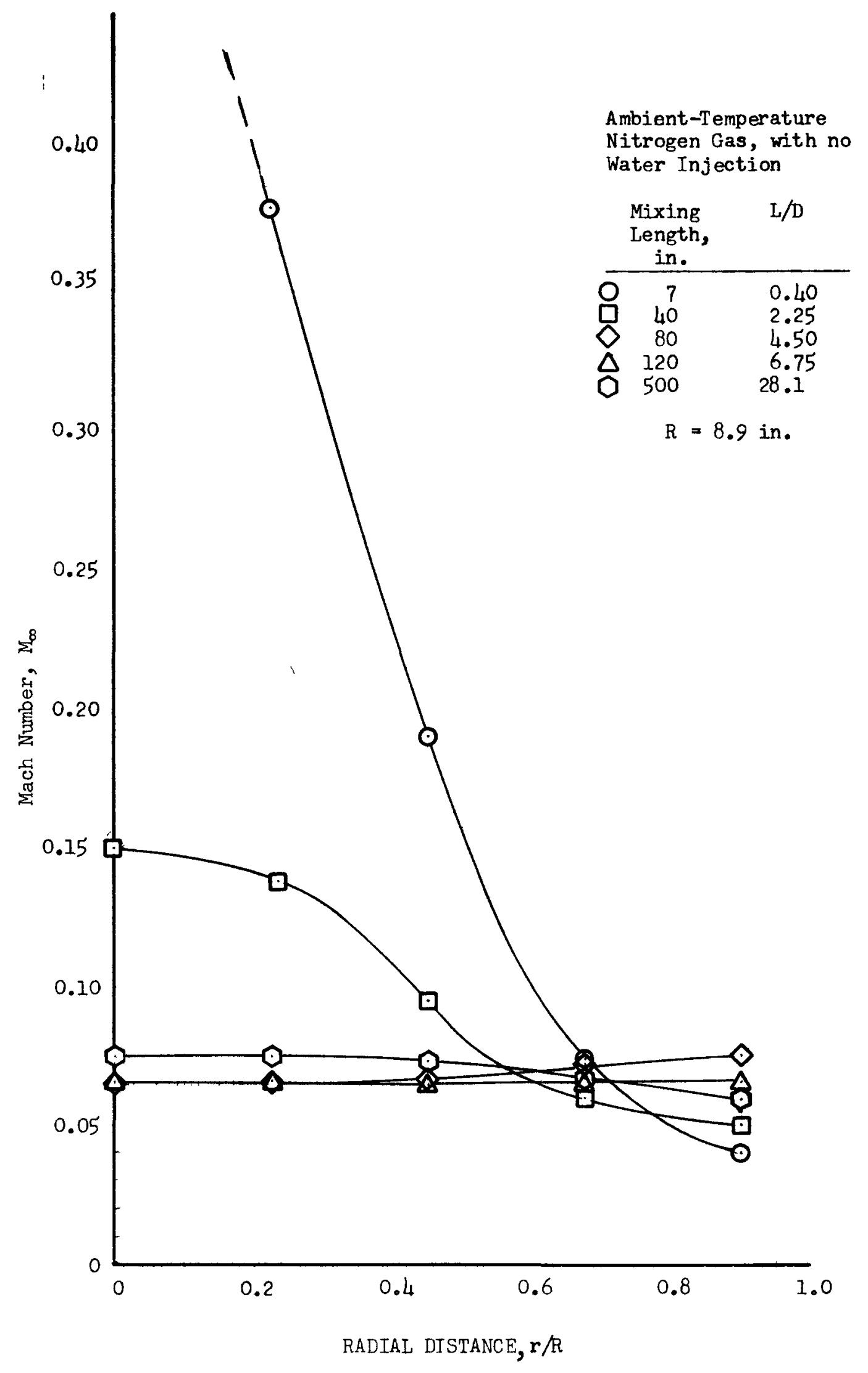

Figure 16 - Velocity Flow Field in Evaluation Duct 
Water Injection, Lb./Sec.

$\begin{array}{ll}\bigcirc & 0.0 \\ \triangle & 0.2(\text { Spray B) } \\ \triangle & 1.5(\text { Spray A) }\end{array}$

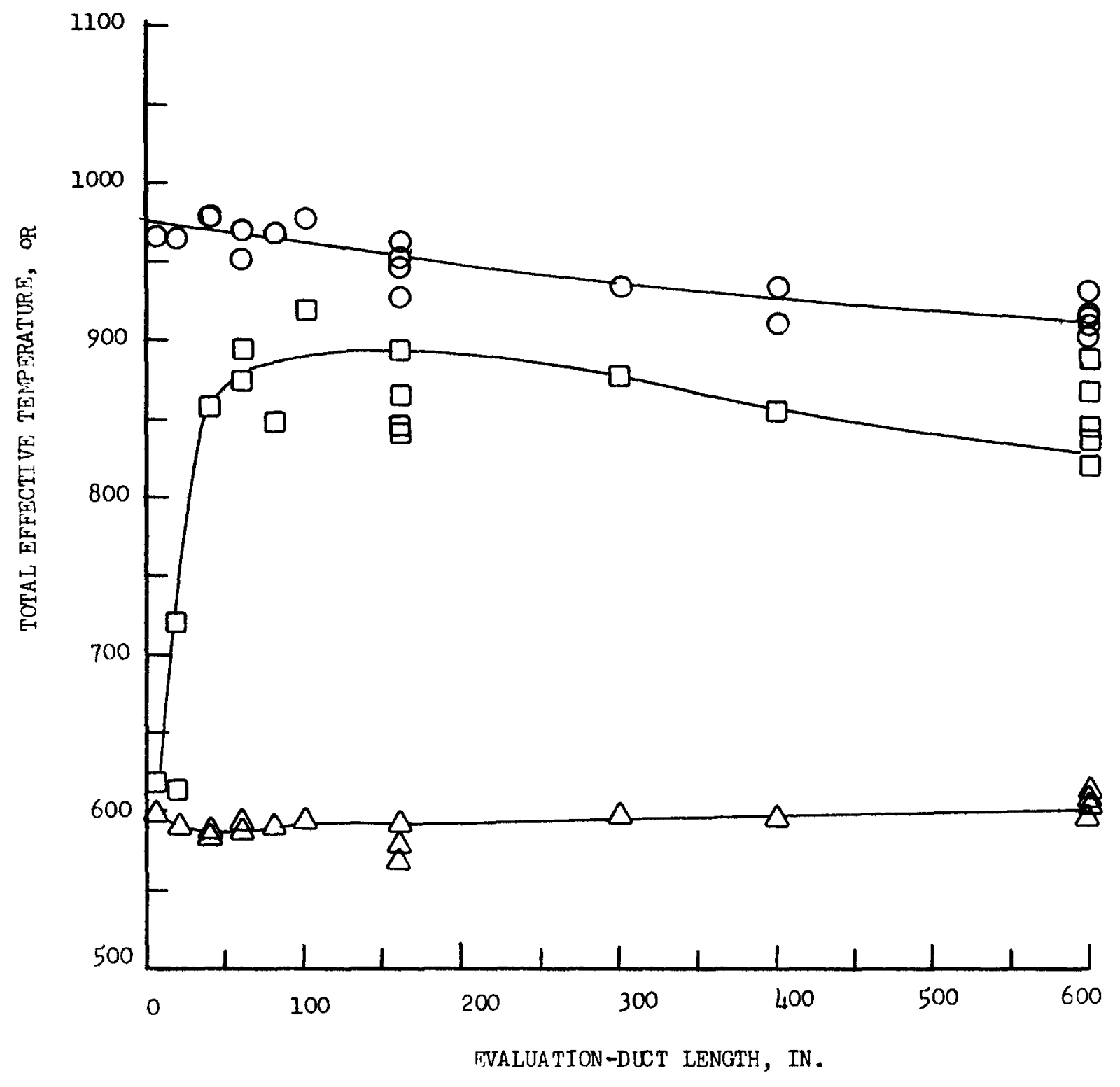

Figure 17 - Total Effective Temperature, $1000^{\circ} \mathrm{R}$ Gaseous Nitrogen with Water Injection 
The Mach No. profiles in the evaluation duct (Figure 16) show how rapidly the gas velocity decreases both along the centerline and at a radial distance beyond 6 in. At an axial distance of 80 in. $(\mathrm{L} / \mathrm{D}=11.5)$ the high-velocity core flow is depleted and the velocity profile is essentially flat. Static pressures at the wall, centerline total gas pressure, and the total effective centerline temperatures are all essentially constant after the first 80 to 120 in. or 11.5 to 17.3 duct diameters.

\section{(2) Gaseous-Hydrogen Tests}

A series of gaseous-hydrogen tests was a1so conducted using the scale-model hardware. The hydrogen gas temperature in al1 but one test was nominally $1500^{\circ} \mathrm{R}$. The total effective gas temperature along the duct centerline for the same gas-flow condition and different rates of water injection is shown in Figure 18.

Certain qualitative conclusions can be reached from these test data.

(a) Injection of water through the three manifolds reduces the centerline temperature to a temperature approaching the equilibrium temperature at the first measuring station or 7 in. from the injector (approximately one duct diameter).

(b) The total effective-temperature profiles are essentially flat in the radial direction 40 to 60 in. downstream from the point of injection.

(c) Water injected into the centerline of the gas stream by the $3-1 / 8$ in. nozzles (Spray A) results in a low centerline temperature. 


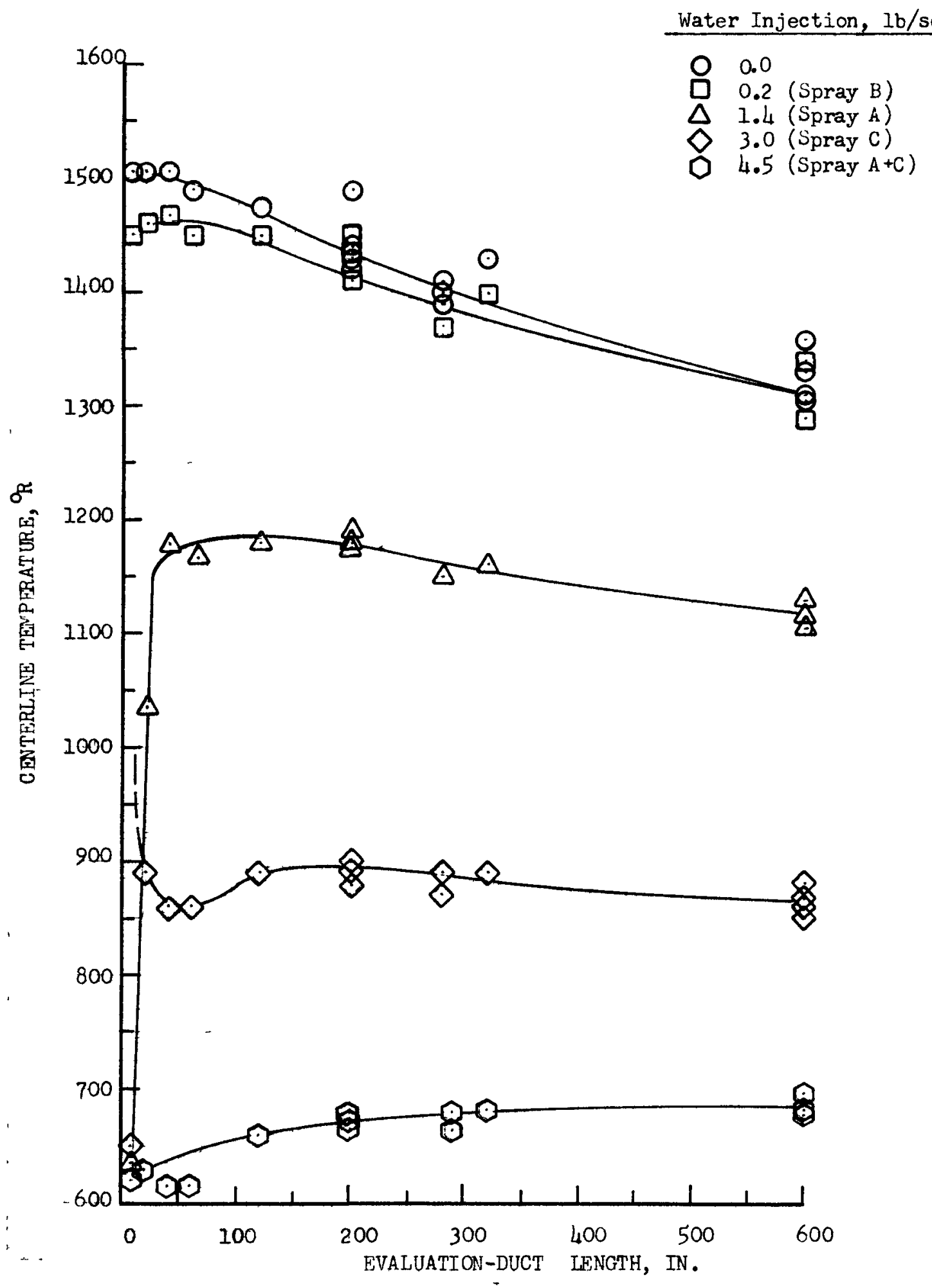

Figure 18 - Total Effective Center-Line Temperature $1500^{\circ} \mathrm{R}$ Hydrogen Gas with Water Injection 
(d) Water injection from Spray C (96 - 0.031 in. nozzles) which was designed to penetrate to within $1.5 \mathrm{in}$. of the duct centerline, appears to be completely mixed with the gas stream at an axial distance of $60 \mathrm{in}$.

\section{(3) Moisture Sensor Probes}

As the heterogenous mixture of gas-water droplets and steam progresses downstream from the water injection point, the gas temperature approaches an equilibrium temperature as the heat is transferred to the water. The time for complete evaporation is a function of the drop size. An analytical evaporation model can be used to predict the average gas temperature, and the amount of water evaporated as the gas-water'mixture moves through the evaluation duct. To evaluate the model, some means of measuring the gas temperature, and in particular the point at which the water droplets are evaporated, is necessary. The moisture probe shown in Figure 15 was used in a series of tests conducted early in 1968. The moisture probe was located along the centerline at various axial distances downstream from the point of water injection. In the tests $1.51 \mathrm{~b} / \mathrm{sec}$ of water was injected into a flow of hydrogen heated to $1500^{\circ} \mathrm{R}$. The calculated equilibrium temperature for the gas water mixture was approximately $1100^{\circ} \mathrm{R}$. The temperatures measured at the leading edge of the probe indicated a temperature generally cooler than the equilibrium temperature of the final mixture, due to film cooling by impingement of water droplets. In the base cavity, the thermocouple recorded the local vapor-gas temperature. The temperature indicated by the shrouded thermocouple was higher than that indicated by the thermocouple on the forward end of the probe, and in some cases was less than the calculated equilibrium temperature. At an axial distance beyond $80 \mathrm{in}$. from the point of water injection the temperatures of the two thermocouples were generally the same. At short mixing lengths the water that was injected from three 1/8-in.-diameter nozzles and was intended to penetrate to the centerline, did not cool the gas stream at radii of 3.5 and $8 \mathrm{in}$. ( $\frac{\mathrm{r}}{\mathrm{R}}$ ratios of 1.0 and 2.3$)$ 
as shown in Figure 19. The base temperatures in the moisture probe may be low due to the high concentration of water, which results in a significant degree of film or spray cooling, subsequent cooling of the boron nitride ceramic housing, and the possibility that some water droplets were aspirated into the cavity. Plugging of the vent holes in the probe by a water droplet would offset the aspirative feature of the probes, reducing the effectiveness of the probe and decreasing the response time by placing the thermocouple in a stagnation zone.

The effectiveness of the probe in detecting the point at which all water droplets have been evaporated is uncertain. At the point where the probe shows essentially the same temperature at the leading and trailing edge, some small droplets could exist that could effect both thermocouples to a similar degree. If this is the case, the droplets are behaving as if they are a gas or are completely evaporated. The following is a summary of the evaporation test results:

(a) Water distribution across the duct is essentially uniform at $80 \mathrm{in.}$

(b) There was no detectable evidence of water droplets in the stream beyond station 80 .

(c) After the uniform water distribution is achieved, temperatures of objects placed in the gas stream are equal to the equilibrium temperature.

\section{c. Westinghouse Studies}

WANL (Westinghouse Astronuclear Laboratory) conducted a test program in June 1966 (Reference 12). These wet-duct evaluation studies consisted of testing a model with a scaling factor of 60:1 at exhaust-gas temperatures of 1650 and $4500^{\circ} \mathrm{R}$. 

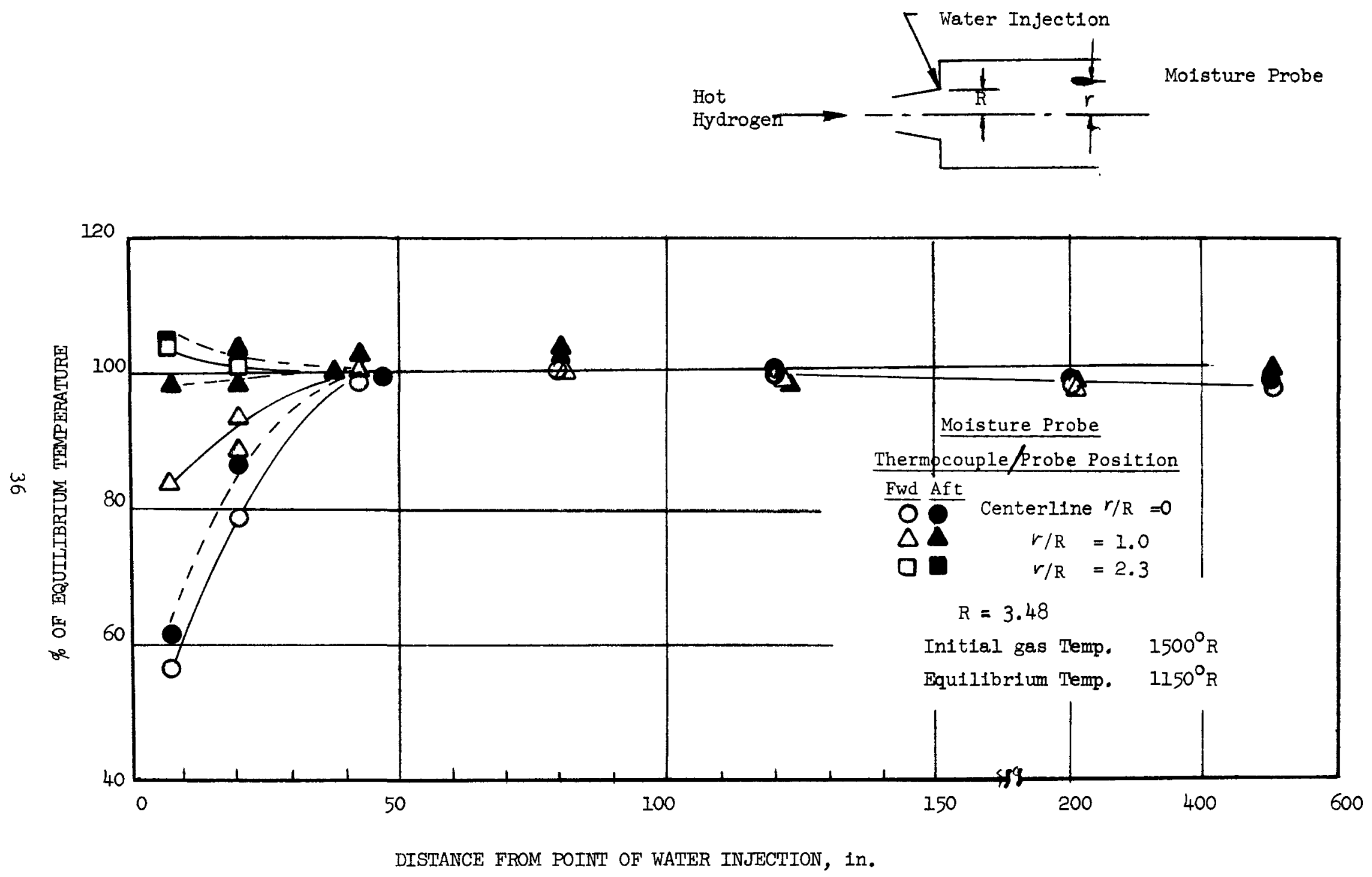

Figure 19 - Moisture-Probe Measurements, Water Injection from Spray A 
The WANL wet-duct tests were performed by exhausting hydrogen gas from a graphite heater through a scaled-down nozzle-diffuser system into a cooling chamber, where water was injected into the hot gas. The nozzle and diffuser were made from ATJ graphite coated with niobium carbide. In the first six of nine tests, the water was sprayed into the gas through 8 holes in a 2-1/2-in.-diameter annular spray ring. The holes were symmetrically placed and directed axially downstream. In the last three tests the water was injected in a single center nozzle. The cooling chamber, a 6-in. pipe 40-in. long, was lengthened to 76 inches after the fourth test to enable an increase in the residence of time of the droplets in the instrumented section. Instrumentation in addition to that necessary to measure and record gas-flow-rate pressure and temperature, included thermocouples in the cooling chamber at five duct locations.

Measurement of water concentration in the gas stream in the cooling chamber was attempted using a quality sensor. This device consisted of two thermocouples, one directly exposed to the gas stream and the other shielded from direct droplet impingement by a baffle. The drop impingement on the unshielded thermocouple indicates the saturation temperature, while the couple shielded from direct contact by water droplets should indicate the gas-recovery temperature.

Test data obtained with the eight peripheral nozzles were primarily used to establish a basis for an eddy-diffusivity analysis, and the test with center injection enabled rapid cooling of the center of the gas mass, indicating the advantage of gas-stream penetration in effecting rapid gas-stream cooling. The quality sensor measurements were apparently unsatisfactory as they were not specifically mentioned in the report. However, the test results include temperature variations in both the axial and radial direction for the tests with water injected from the eight axial nozzles in a ring pattern and from the single nozzle located at the duct centerline. 


\section{B. ANALYTICAL STUDIES}

Three analytical studies have been conducted of a wet-elbow design. One of the models was developed by Jerry Grey of the Greyrad Corporation (Reference 13) specifically for the duct-cooling problem. Another model was devised by WANL (Reference 12), and the third was developed by Aerojet-General. Aerojet's model, modified for this evaporation study, was initially intended to aid in the calculation of thrust-vector control of secondary injection into the exit cone of rocket nozzles.

\section{Water Mixing Models}

a. Greyrad Mode1

This model predicts the equilibrium temperature based on free-stream mixing, and is comprehensive in terms of the number of different parameters it can handle.

This program calculates the trajectory of the injected water into the duct, accounting for the two-dimensional-velocity distribution of the gas-flow field, assuming the injected water remains intact until it reaches a point of maximum penetration; at this point, the jet shatters.

After the jet has shattered, the Greyrad model treats the droplet and free-stream mixing using the inductive turbulent mixing mode1 of Reichardt. A review of the Greyrad model by Aerojet personnel resulted in the following conclusions: (1) that it is conservative for short distances downstream from the point of injection ( 0 to 2 diameters); (2) that it is very sensitive to an empirical turbulent-mixing constant; and (3) that its inherent complexity makes it difficult to use. These points were recognized by the author in his report, and he has subsequently proposed a study to determine the magnitude of this mixing constant. 
A comparison of analytical predictions with test data from both Westinghouse and Aerojet-General as presented in Figures 20 and 21 shows that the Greyrad predictions are conservative for short mixing lengths. In the Aerojet experiments (Figure 20), the water was injected from Spray $\mathrm{C}$ (see Figure 4), and appeared to originate at an $\frac{r}{R}$ value of 0.72 . The water spray from the Westinghouse tests was injected axially downstream at a $\frac{r}{R}$ value of 0.41 , explaining the similarity between the Greyrad analysis and the Westinghouse data. The water for the tests (Figure 21) was injected from Sprays A and C (see Figure 4) and appears to originate from two points at $\frac{r}{R}$ values of 0.1 and 0.72 .

In each of these tests the water must appear to originate from more injection points or the rate of mixing must be increased to accommodate the apparent rapid mixing noted in the Aerojet tests. The coaxial mode of injection of the water in the WANL tests indicates the time required to achieve good mixing if the water is injected from a point or ring source. The inference would be that the Aerojet spray system rapidly distributes the water in the gas stream as it would be from many jet sources. A computer experiment in which the mixing coefficients $C_{m}$ and $C_{k}$ were varied from a nominal value of 0.075 to 0.0325 and 0.15 resulted in a significant change in the calculated equilibrium temperature profile as shown in Figure 22 . One obvious way of improving the comparison between the experiment and analysis is to arbitrarily change the values of the $C_{m}$ and $C_{k}$ constraints to achieve a good correlation. Such an approach cannot be accomplished without the support of additional test data. An alternative would be to analytically increase the number of points of jet breakup.

\section{b. Westinghouse Mode1}

WANL in Reference 12 suggests a method of predicting the distance required for evaporation and mixing of water with hot hydrogen using the principle of eddy diffusion of gases. Eddy diffusion is defined as the 

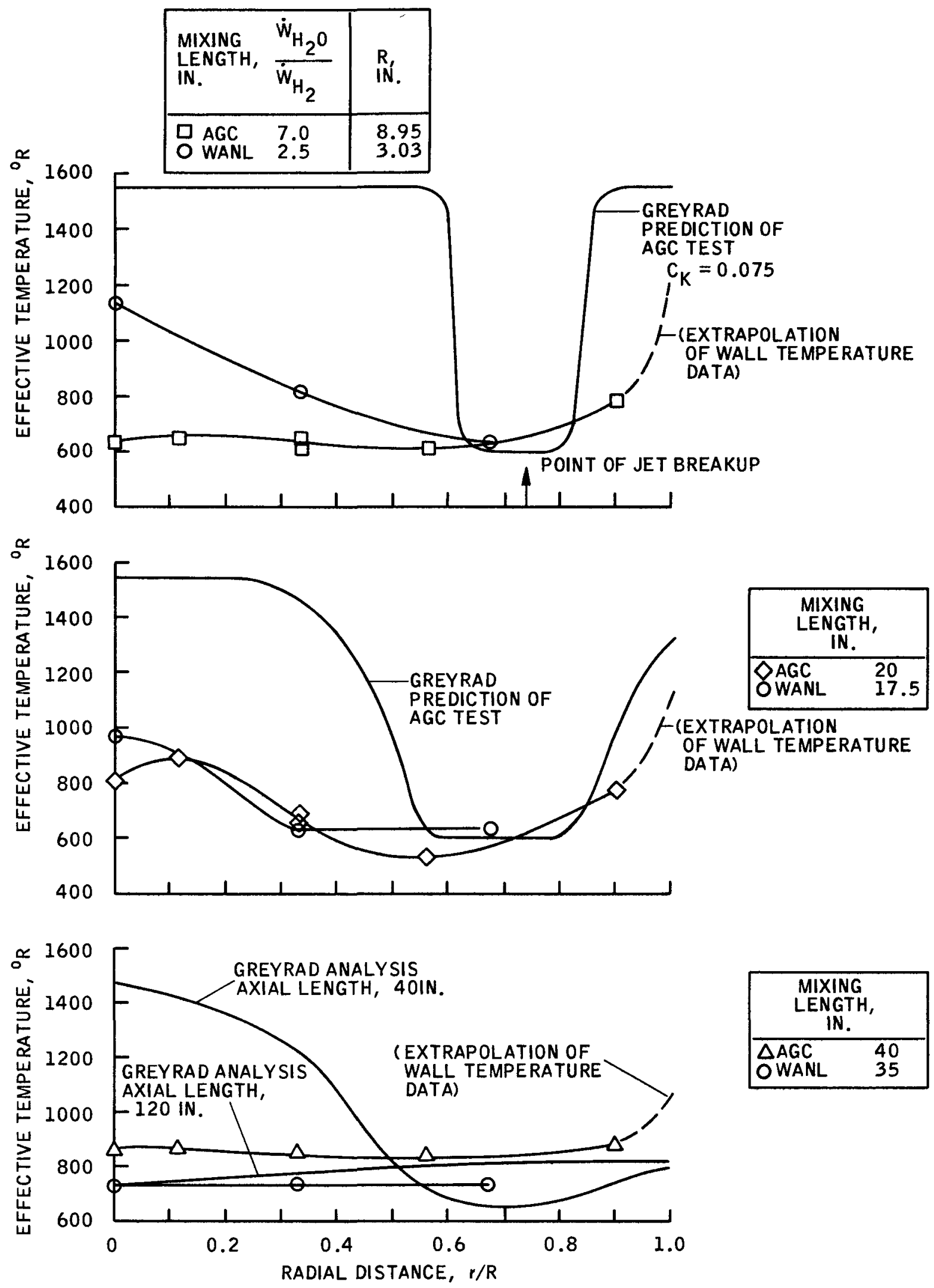

Figure 20 - Comparison of Analytical and Experimental EvaluationDuct-Temperatures; Water-to-Gas Mass Ratio $\approx 2.0$ 

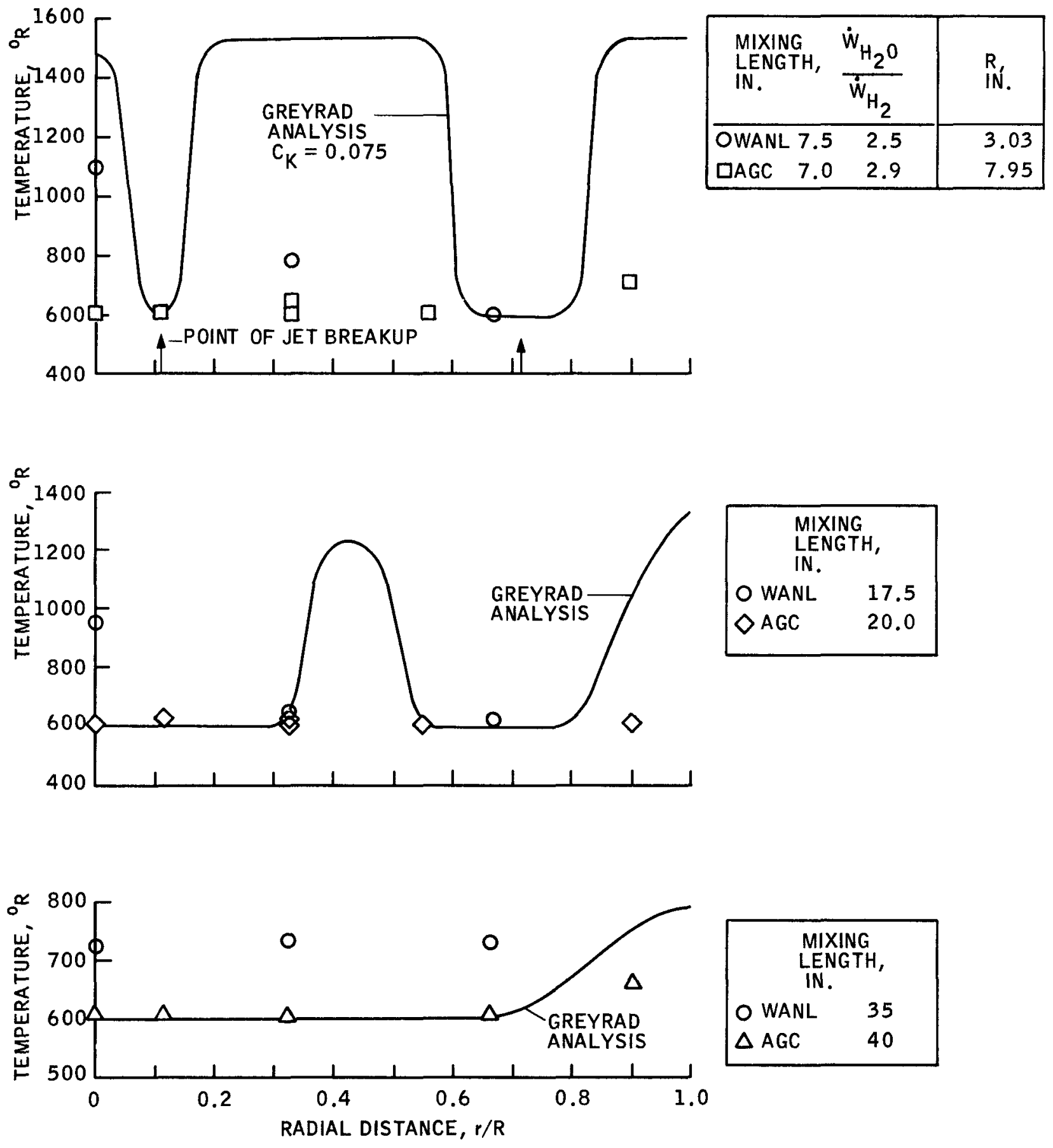

Figure 21 - Comparison of Analytical and Experimental EvaluationDuct Temperatures; Water-to-Gas Mass Ratio $\approx 2.8$ 


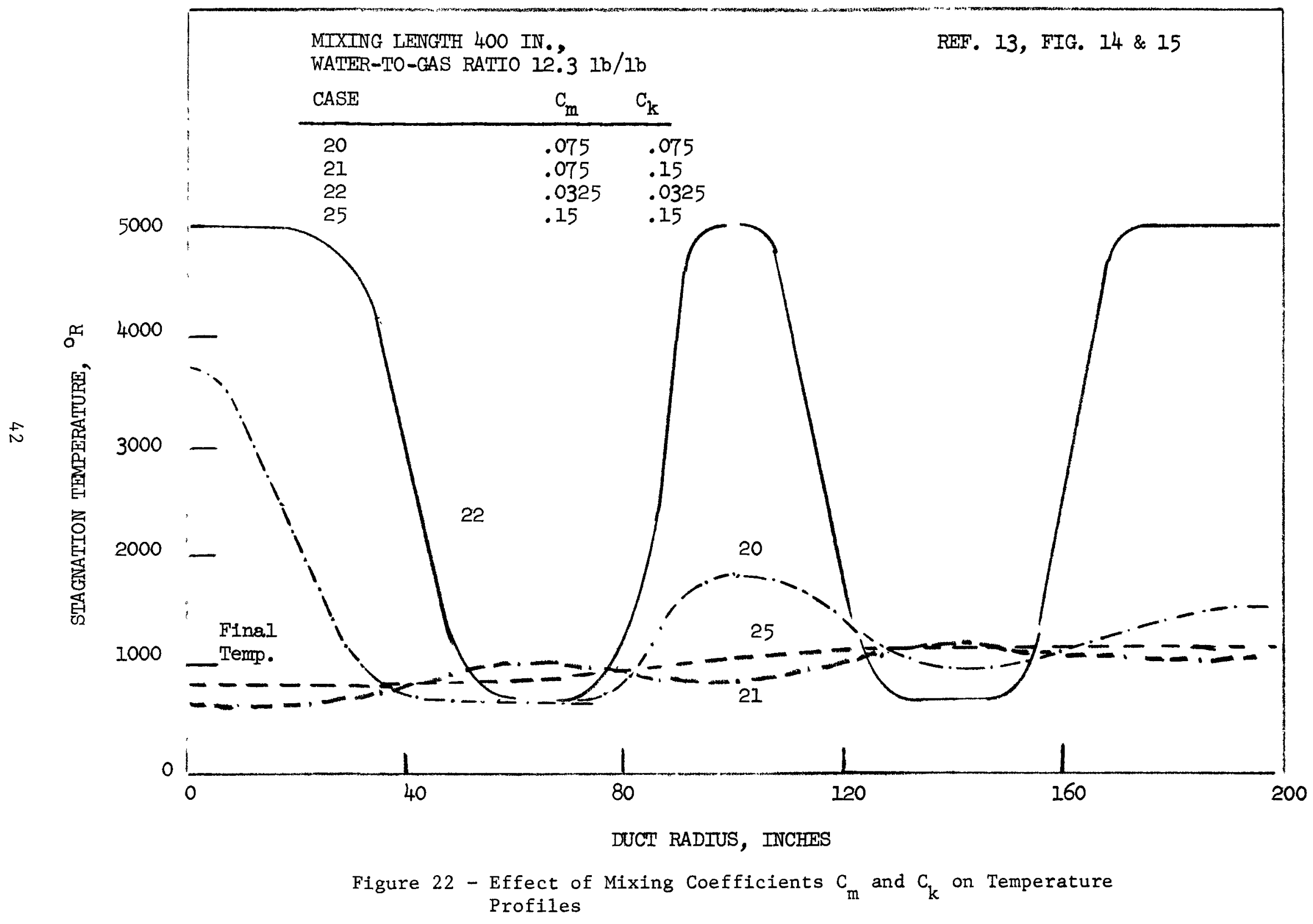


process by which concentration differences disappear in a fluid stream in turbulent motion. The WANL report considered that since data taken from the Sherwood and Woertz Study (Reference 14) of water vaporization into air, carbon dioxide, or helium were found to have a straight-line correlation, the scale model data might fit this same relationship.

Subsequently E, eddy diffusivity, was plotted as a function of the term $\frac{D U}{\mu}$, where $D$ is diameter, $U$ is velocity, and $u$ is viscosity, and $E$ was reported to be in reasonably good agreement with the Sherwood and Woertz gas data. An estimate of the duct length required to $\operatorname{cool}$ a $4500^{\circ} \mathrm{R}$ nuclear rocket exhaust to $1460^{\circ} \mathrm{R}$ using this diffusion model was $32.2 \mathrm{ft}$, which would appear to be relatively long. The report indicated that the initial distribution was particularly important, and since the only accurate measure of the degree of mixing of such a system is based on the concentration (which was not obtained), the validity of this method is questionable.

\section{Aerojet-General Water-Evaporation Mode1}

The Aerojet computer program for jet penetration and droplet vaporization was originally developed in connection with liquid-injection thrust-vector-control studies as described in Reference 15 . Since then the program has been updated to relate the behavior of the droplets and vapor to the free stream using a one-dimensional analysis as described in Chapter 8 of Reference 16 to account for:

(1) Momentum exchange due to droplet drag

(2) Energy transfer due to droplet vaporization

(3) Duct cross-sectional area change

(4) External heat source or sink

(5) Friction along the duct wall

(6) Changes in gas properties as the vapor and free-stream mix 
Also, since Reference 15 was published jet penetration and break-up models have been added to the program. A report describing the current computer program is being prepared. As the water jet penetrates into the gas stream the water jet is bent and spread by the aerodynamic force of the gas stream. After the water jet starts to spread the edges are shredded off, reducing the solid core of the jet until it is completely destroyed. The water torn from the jet forms droplets, with the size being a function of the Reynolds and Weber number ratio. Once these droplets are generated they are acted upon by the temperature of the gas and begin to evaporate.

\section{a. Liquid Trajectory}

The liquid trajectory is based on the empirical equation from Reference 6 as follows:

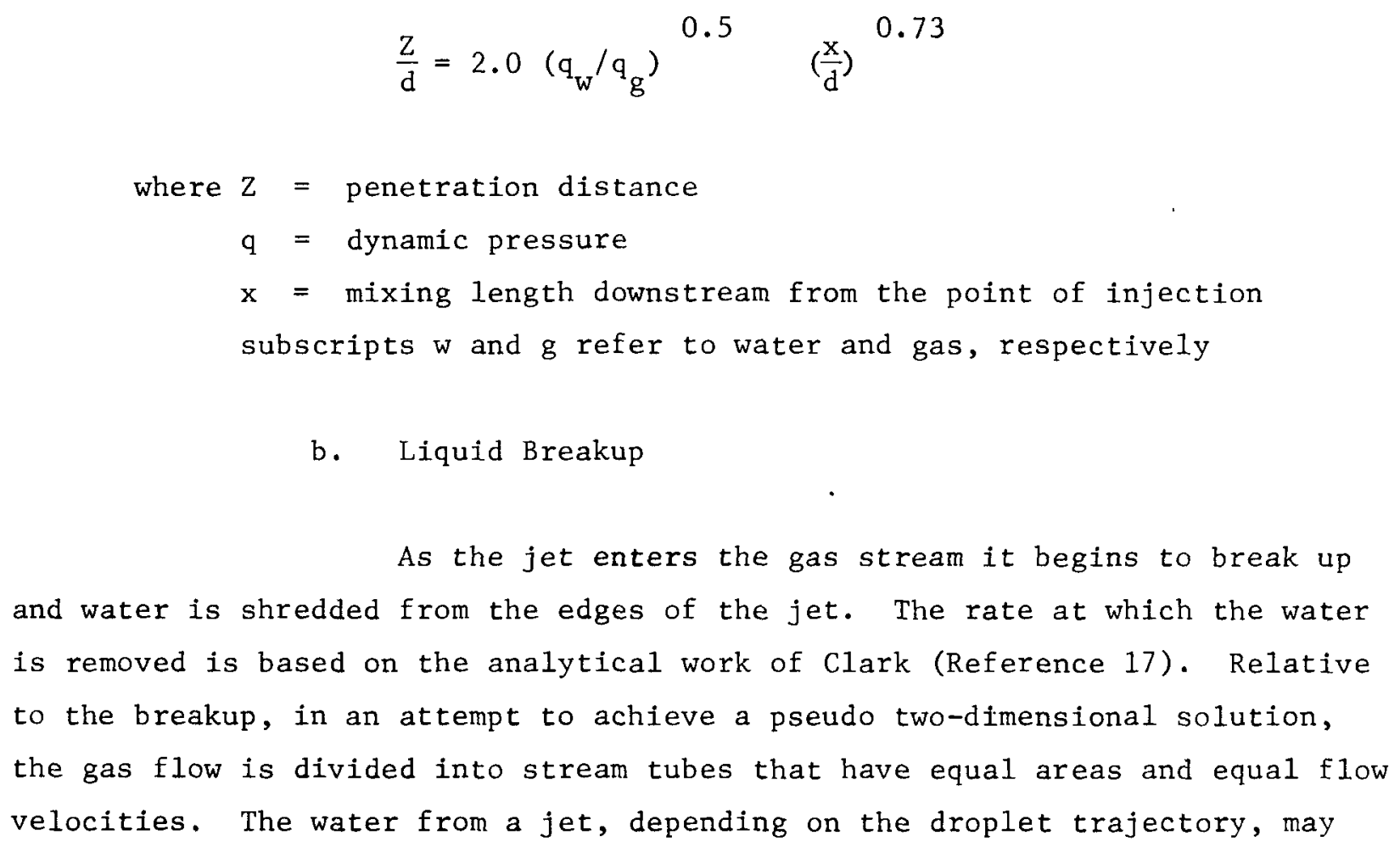$$
\frac{\mathrm{z}}{\mathrm{d}}=2.0\left(\mathrm{q}_{\mathrm{w}} / \mathrm{q}_{\mathrm{g}}\right)^{0.5} \quad\left(\frac{\mathrm{x}}{\mathrm{d}}\right)^{0.73}
$$ 
In the Clark breakup model, the important variables affecting the breakup of a jet are relative gas velocity $V$, gas density $\rho_{g}$, liquid density $\rho_{w}$, liquid jet diameter $d_{o}$, and action time $t_{x}$. $A$ dimensionless term can be devised that relates the external dynamic forces to the inertial resistance of the liquid for a given deformation rate:

$$
\frac{\rho_{g}}{\rho_{w}} \quad\left|\frac{V t}{d_{o}}\right|^{2}
$$

Experimentally, it was found that degree of breakup could be correlated with this parameter, which is referred to as the degree of $\operatorname{spreading} \varepsilon$, and since $t=L / V_{w}$ :

$$
\varepsilon=\left(\frac{\rho_{g}}{\rho_{w}}\right) \quad\left(\frac{V L}{V_{w} d_{0}}\right)^{2}
$$

The experimental results on the area change of a jet were experimentally found to be related to the spreading parameter as follows:

$$
\begin{gathered}
\left.\frac{\mathrm{A}}{\mathrm{A}_{\mathrm{O}}}=\int_{0.00392}(7.68 \varepsilon-1)(\varepsilon-1)^{2.34}+1\right\}^{-1} \\
\varepsilon \geq 1
\end{gathered}
$$

The point of complete jet breakup was found to occur at $\varepsilon=10$ to 15 , which for a uniform gas flow field permits a rapid determination of the distance a jet of liquid will travel into a gas field prior to complete breakup. 
A mean droplet size is predicted based on the empirical relation derived by Ingebo and Foster (Reference 18) for the injection of a liquid perpendicular to a subsonic free stream. According to this relationship the drop size is a function of the orifice size and the free-stream conditions.

$$
\begin{aligned}
& \frac{\mathrm{d}_{30}}{\mathrm{~d}_{0}}=3.9 \quad\left(\frac{\mathrm{We}}{\mathrm{Re}}\right) \\
& \mathrm{d}_{30}=9.3 \sqrt{\mathrm{d}_{0}}\left[\frac{\sigma_{\mathrm{W}} \nu_{\mathrm{W}}}{\rho_{\mathrm{g} \mathrm{V}} \mathrm{V}^{3}}\right]^{0.25} \\
& \text { where } \mathrm{d}_{30}=\text { mean droplet diameter } \\
& \mathrm{d}_{0}=\text { orifice diameter }
\end{aligned}
$$

The droplets formed after jet breakup can travel into the gas stream and evaporate. If the drop sizes are too large, investigators have found that they are unstable and will further subdivide. The criterion for stability is generally in terms of the droplet weber number, which relates surface forces to the dynamic forces. A Weber number of 13 is suggested as a critical number. If the Weber is greater than 13, the droplet is unstable; if less, it will not be further subdivided. Wolfe and Anderson, in Reference (19), predict a final mean-droplet diameter produced by secondary drop breakup as given by:

$$
d_{f}=\left[\frac{136 \mu \sigma^{3 / 2} d^{1 / 2}}{\rho_{g}^{2} \rho^{1 / 2} v^{4}}\right.
$$

The time for droplet breakup based also on the work of Wolfe and Anderson is:

$$
t=\frac{d}{\left(A^{2}+B P\right)^{1 / 2}-A} \text {, microseconds }
$$


where:

$$
\begin{aligned}
\mathrm{A} & =16 \mu / \mathrm{d} \rho \\
\mathrm{B} & =2 / \rho \\
\mathrm{P} & =1.2 \rho \mathrm{V}^{2} \quad-2 \sigma / \mathrm{d} \\
\mathrm{d} & =\text { original drop diameter } \\
\rho & =\text { drop density } \\
\rho_{\mathrm{g}} & =\text { gas density } \\
\mathrm{V} & =\text { velocity of gas flow } \\
\mu & =\text { liquid viscosity } \\
\sigma & =\text { surface tension }
\end{aligned}
$$

d. Droplet Trajectory and Evaporation Rate

The equation of motion for a single droplet can be written as:

$$
\left(\frac{4}{3} \pi r_{d}^{3} \rho_{L}\right) \frac{\overrightarrow{d V}}{d t}=\vec{F}_{D}=\frac{1}{2} \quad \rho_{\propto} \vec{C}_{D} \pi r_{d}^{2}\left|\vec{v}_{r}\right| \vec{v}_{r}
$$

or

$$
\frac{\mathrm{d} \overrightarrow{\mathrm{V}}_{\mathrm{d}}}{\left|\overrightarrow{\mathrm{V}}_{\mathrm{r}}\right| \overrightarrow{\mathrm{V}}_{\mathrm{r}} \mid}=\frac{3}{8} \quad / \frac{\rho_{\infty}}{\rho_{\mathrm{L}}} \quad \frac{\overrightarrow{\mathrm{C}}_{\mathrm{D}}}{\mathrm{r}_{\mathrm{d}}} \mathrm{dt}
$$

The drag coefficient $C_{d}$ for accelerating droplets is according to Ingebo (Reference 8) related to the Reynolds number based on the relative velocity between the droplets and the free stream.

$$
\vec{C}_{D}=27 \overrightarrow{R e}_{\mathrm{r}}{ }^{-0.84}=27\left(\frac{\mu_{\infty}}{\rho_{\infty} \mathrm{V}_{\mathrm{r}} \cdot 2 \mathrm{r}_{\mathrm{d}}}\right) 0.84
$$


for

$$
6<\left|(\operatorname{Re})_{\mathrm{r}} \quad\right|<400
$$

An expression for the vaporization rate of a spherical droplet in quiescent or stagnant atmosphere by williams in Reference 9, where the rate of vaporization is assumed to be proportional to the surface area of the droplet.

$$
\begin{aligned}
& \beta=-\frac{d\left(r_{d}{ }^{2}\right)}{d t}=-2 r_{d} \frac{d r_{d}}{d t} \\
& \beta=\frac{2 \lambda_{V}}{C_{\rho v} \rho_{L}} \text { ln }\left[1+\frac{T_{\infty}-\frac{T_{L}}{L_{v} / C}}{1+C_{\rho}}\right]
\end{aligned}
$$

Where there is relative motion between the fluid and the droplet, Williams applies an empirical correction.

$$
\beta=\beta_{0}\left(1+0.276 \operatorname{Re}_{\mathrm{r}}^{1 / 2} \mathrm{Pr}^{1 / 3}\right)
$$

The trajectory equations are arranged in component form and the evaporation equation is rewritten as

$$
2 r_{d} d r_{d}=-\beta d t
$$

$$
\begin{gathered}
\frac{d u}{\left(U_{\infty}-u\right)^{2}}=-\frac{3}{4} \frac{\rho_{\infty}}{\rho_{L}} \frac{\left(C_{D}\right)_{x}}{\beta} d r_{d} \\
\frac{d v}{v^{2}}=\frac{3}{4} \\
\frac{\rho_{\infty}\left(C_{D}\right)_{y}}{\rho_{L} \beta} d r_{d}
\end{gathered}
$$


These equations form a set of simultaneous ordinary differential equations to be solved for the droplet radius, $r_{d}$, and the droplet velocity component $U$ and $V$ as a function of time, $t$.

e. Comparison of Evaporation Model with Experimenta1 Data

A series of experiments was conducted by injecting water into a flow of heated hydrogen gas. The temperature and pressure of the resultant gas-1iquid system were measured as it passed through an evaluation duct. The evaporation model has been used to calculate the gas temperature and pressure for certain of these experiments.

The analytical model calculates the water-jet trajectory, and the degree of breakup of the jet along this trajectory. As the jet is broken up, droplets are generated and evaporation is initiated. The droplet trajectory is now modified, since the droplets can be acted upon by the gas stream, and secondary breakup can take place together with an alteration in the droplet trajectory. Prior to the application to this study, the model assumed one-dimensional and uniform flow of the water-gas mixture, and the resultant temperature was the average gas temperature of the mixture. To determine the radial variation in gas temperature, a method of using the program to calculate temperatures and pressures along equal area annular rings or circular stream tubes was devised. The gas flow was divided into five equal flow-area stream tubes, assuming that the mass flow in each stream tube was constant and that no mixing occurred between stream tubes. The analytical procedure was to calculate the jet trajectory and determine the degree of jet breakup in each stream tube until liquid jet breakup was complete. The result was a distribution of water along the trajectory of the solid liquid stream. A redistribution of the water then occurs due to the action of the gas on the resultant droplets. Once the water-droplet distribution is determined by the particle trajectory calculations, the water is permitted to evaporate and the gas temperature in each stream tube can be computed. Figures 23 through 25 show the calculated trajectory and water distribution for each stream tube for the scale-model evaporation tests. 


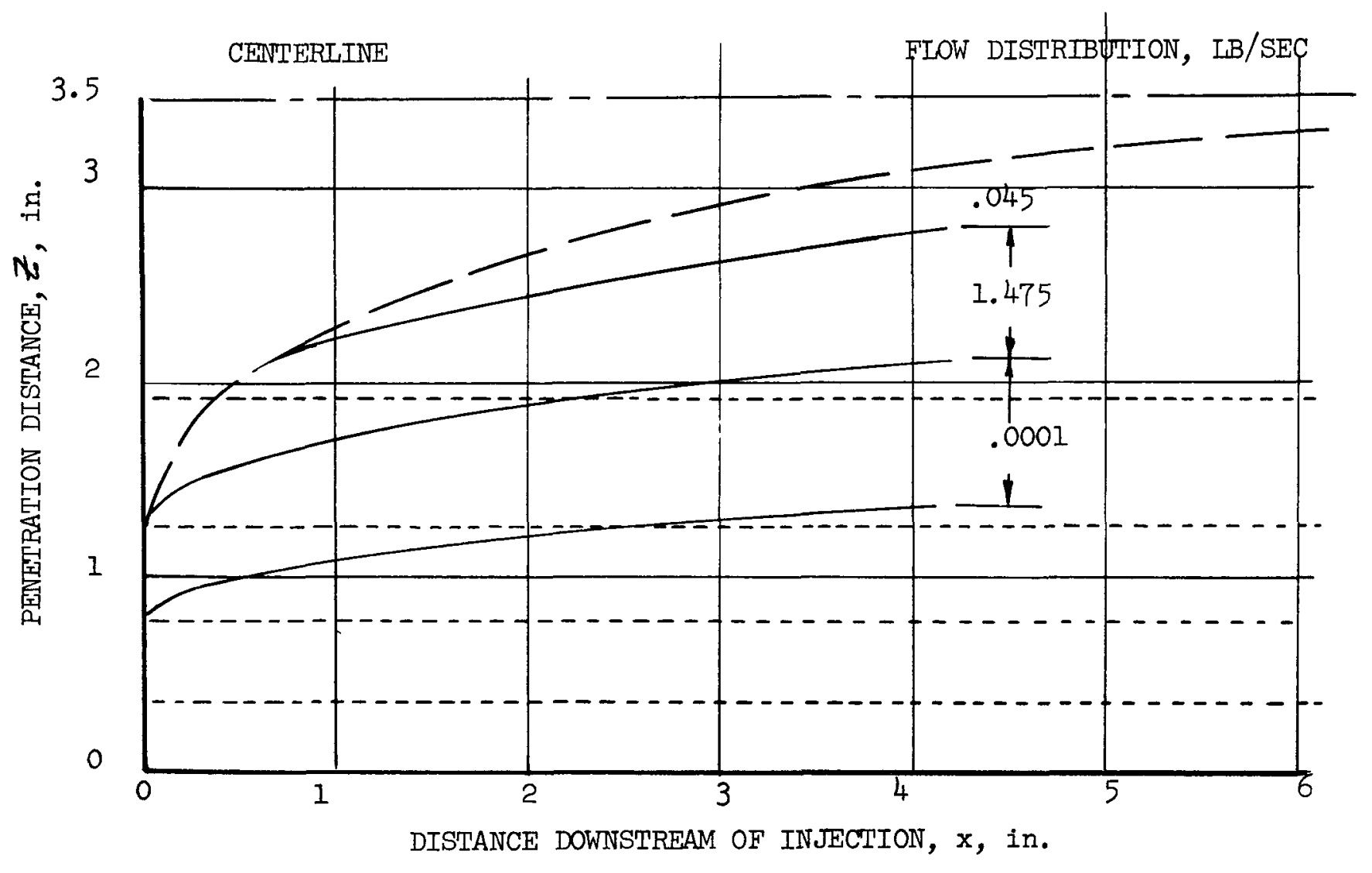

STREAM TUBE

(I)

Figure 23 - Calculated Trajectory of Droplets and Water Distribution for Scale-Model Tests; Three 1/8-in.-dia Nozzles (Spray A) 


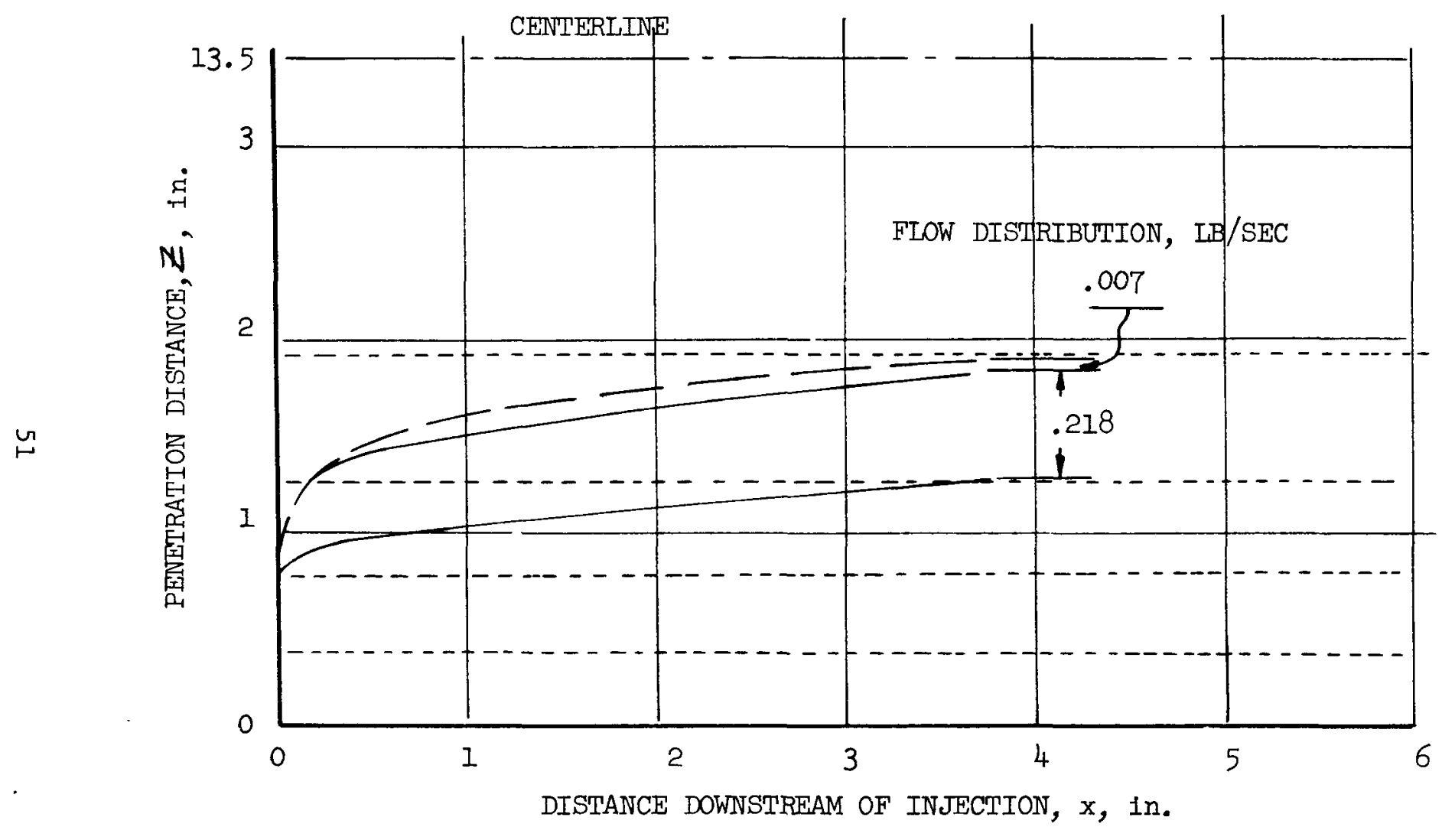

STREAM TUBE

(1)

Figure 24 - Calculated Trajectory of Droplets and Water Distribution for Scale-Mode1 Tests; Three 1/20-in.-dia Nozzles (Spray B) 


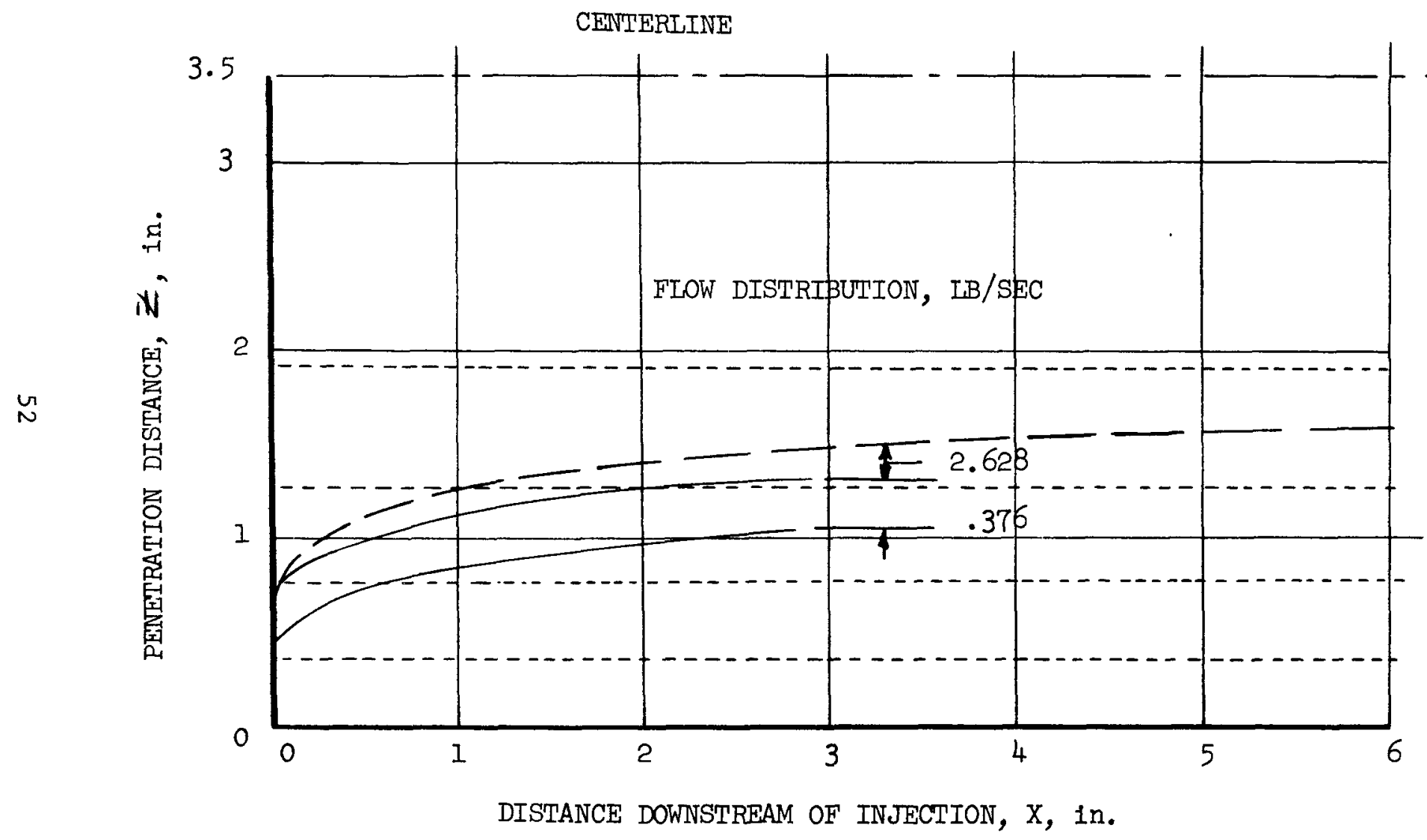

STREAM TUBE

(1)

Figure 25 - Calculated Trajectory of Droplets and Water Distribution for Scale-Model Tests; 96 1/32-in.-dia Nozzles (Spray C) 
The water injected into the heated-hydrogen gas flow from the three $1 / 8$ in. nozzles (Spray A) was intended to penetrate to the centerline and cool the central portion of the gas flow or stream tube (1). From the measured temperatures along the centerline, as shown in Figure 19, it appears that the water from these nozzles penetrates to the centerline and immediately begins mixing with the gas until at an axial distance of 40 in. there is essentially no measured difference in the temperature across the duct. The predicted equilibrium gas temperatures based on the Aerojet model for each of the stream tubes are finally restricted by the amount of water deposited in the stream tube. The model shows that essentially all the water from Spray $A$ is deposited in stream tube (1) and when evaporated would cool the gas stream to a temperature below the measured or equilibrium temperature. Neither the Aerofet nor the Greyrad model show significant quantities of water from Spray A deposited in any stream tube other than stream tube (1) prior to the occurrence of mixing.

Injection of water from all the sprays (A, B and $C$ ), according to the experimental data, should result in a uniform distribution of water and consequently a uniform temperature across the duct. The thermocouple measurements indicate essentially uniform distribution. The water distribution curves (Figures 23 through 25) were summed, and the result is presented in Figure 26. Figure 26 indicates that stream tubes (1) and (2) should be cooled to the saturation temperature and only in stream tubes (3), (4), and (5) will the gas be essentially uncooled. Again, secondary mixing has been ignored in the analysis, which precludes any change in the water-gas composition after the droplets are generated and deposited in a stream tube. Only very small quantities of water are required in these stream tubes to cool the gas. As a result, the calculated water distribution based on this model indicates an excess of water in stream tube (2), and insufficient water in the other stream tubes (3), (4), and (5). Evaporation of a mean diameter droplet according to this computer model can take place within the 
INITIAL WATER DISTRTBUT'TON

RESULTING FROM BREAKUP OF

WATER JET

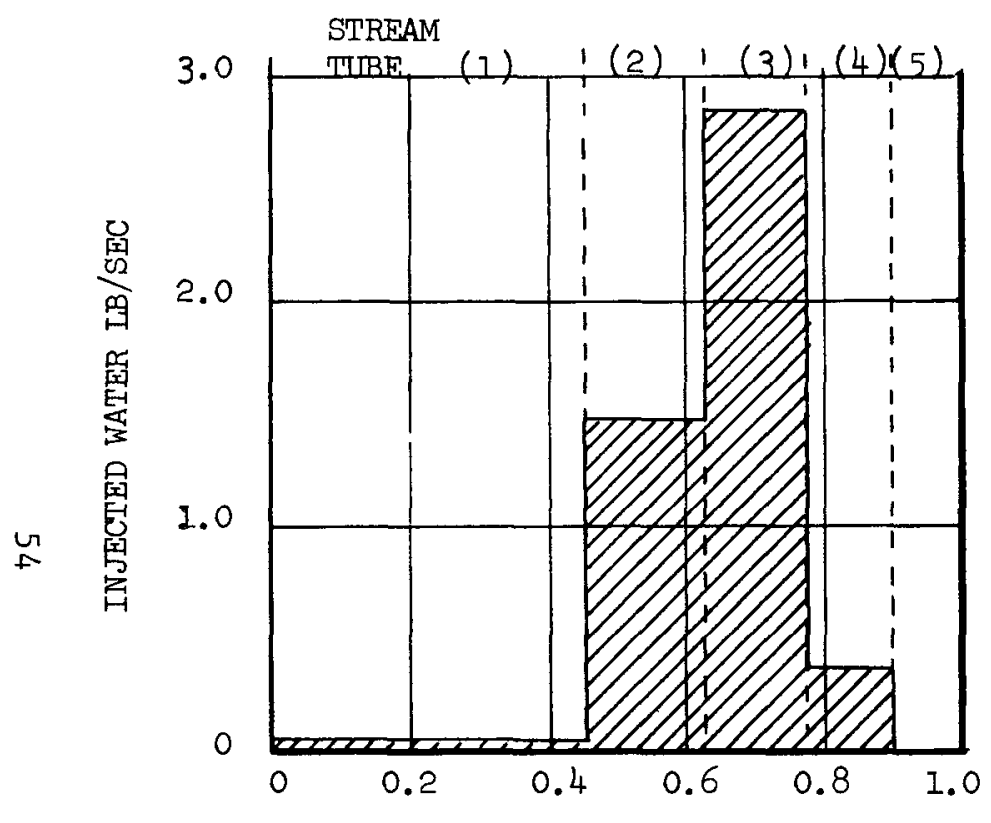

WATER DISTRTBUTTON ACROSS DUCT AFTER DROPLET RE-DISTRIBUTION AT AXIAL DISTANCE > 3 IN.

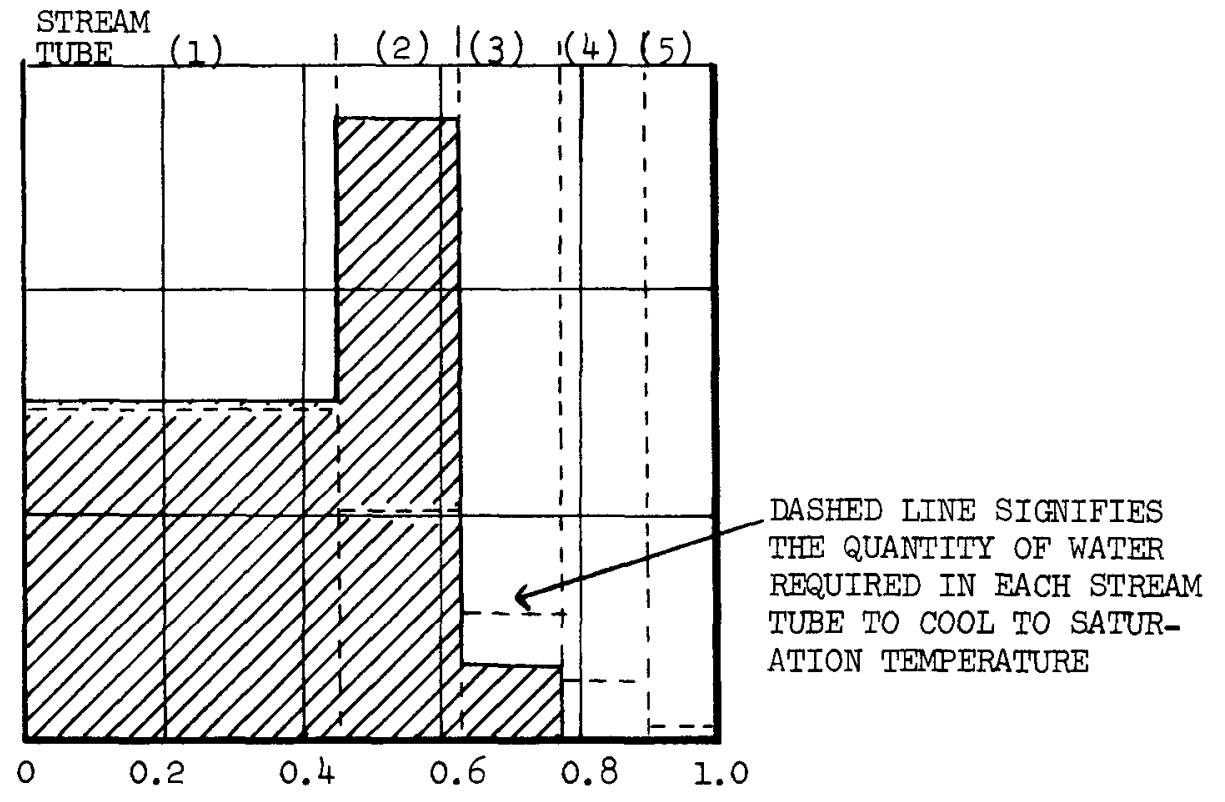

RADIAL DISTANCE, $r / R$

CALCULATED STATIC PRESSURE IN EQUAL-

$R$, DIFFUSER - $3.5 \mathrm{IN}$.

AREA STREAM TUBES AT (3) INLET DIAMETERS

R, EVALUATION DUCT $=8.9 \mathrm{IN}$ $\approx 21.0$ INCHES

\begin{tabular}{c} 
TUBE \\
\hline 1 \\
2 \\
3 \\
4 \\
5
\end{tabular}

\begin{tabular}{c}
$P_{s 2}$ PSIA \\
\hline 21.9 \\
18.0 \\
14.9 \\
13.7 \\
13.6
\end{tabular}

Figure 26 - Calculated Water Distribution in Scale-Model Evaporation Studies; Flow from all Nozzles $1.4 \mathrm{lb} / \mathrm{sec}$ Hydrogen Gas Initially at $1450^{\circ} \mathrm{R}$ 
first 40 in. from the point of injection at a rate fast enough to cool the gases to a temperature very nearly that measured. The as-measured temperature is considered as being the temperature of a film-cooled solid. When a significant fraction of the water in the water-gas mixture has evaporated, the measured temperature and calculated temperature should agree. In these tests, when the measured temperatures remain low and the model indicates little or no water in the stream tube, it can be concluded that either mixing occurs in the stream particularly near the duct wall, or the model does not adequately predict the water shredded from the jet in the initial phase of injection. If the quantity of water deposited in each stream tube was equal, and the flow field uniform, then the resultant static pressure across the duct would be uniform. In this analysis, each stream tube is treated separately independent of the adjacent tubes; therefore, the calculated static pressure in each stream tube may differ from that in the others. In the actual tests the static pressure across the flow field cannot vary. The calculated static pressures for the analysis included in Figure 26 are for an axial distance of $21 \mathrm{in.}$ The nonuniformity of the pressure across the duct indicates the inadequacy of the analysis at axial distances greater than three or four exit duct diameters. The effect of the radial pressure gradient would be an increase in the flow area of stream tubes (1) and (2), with a corresponding decrease in the flow area of stream tubes (3), (4), and (5) until an ambient static pressure of 14.5 psi occurs in each stream tube. Adjusting stream tube areas to eliminate pressure gradient would in effect increase the radial mixing and result in a more uniform radial-temperature distribution or one approaching the measured temperatures.

The hot temperatures in the outer stream tubes indicated by this analysis were not measured in the experiments. This was attributed in part to an exclusion from the model of any radial-velocity component in the gas stream. In the expansion section of the evaluation duct, the gas flow expands outward and has a significant outward radial-velocity component, particularly in the outer stream tubes, which would react on any droplets in the gas stream causing them to either stay in the gas stream or possibly be accelerated directly to the wall. 
The analytical solution was subsequently changed to include the influence of the expanding gas-flow field on the droplets at the instance of droplet generation. The result was some slight change in the calculated water-distribution system for the scale-model tests.

The conclusions regarding the evaporation model at this time are: (1) the model is not able to predict two-dimensional results beyond an axial distance of three duct diameters, as a result of a constraint against stream tube mixing; (2) the predicted gas temperatures within the first three duct diameters will approximate the measured temperatures where sufficient water to cool the gas is predicted to be present; (3) sufficient evaporation can take place within the first $40 \mathrm{in}$. of duct length to result in a gas temperature as low as the saturation temperature; and (4) by proper selection of the size and number of spray nozzles, it is possible to design a spray system which will cool a gas stream in an expanding flow field using this analytical model. 
IV. PREDICTION OF TEST RESULTS FOR HIGH-TEMPERATURE TESTS AT SACRAMENTO FACILITY

A series of high-temperature-gas large-scale tests with a rocket engine used as the hot-gas source have been devised as a direct test of our analytical gas cooling models. The high-temperature gas comprises the combustion products of a liquid-fluorine-mixed-hydrazine-fueled rocket engine. The combustion temperature at a mixture ratio of $2: 1$ is about $7000^{\circ} \mathrm{R}$. The tests are to be conducted at the Propulsion Division's high-altitude test facility (Test Cell $\mathrm{J}-4$ ). The test facility consists of an engine test compartment and an exhaust-duct system to scrub the exhaust gases prior to release to the atmosphere. The exhaust duct consists of essentially three sections, a cylindrical supersonic diffuser $30 \mathrm{in.}$ in diameter and $24 \mathrm{ft}$ long, which is convectively cooled and discharges into a 6-ft-diameter, uncooled, carbon-steel duct, which in turn leads to a long 12-ft-dia scrubber. Spray nozzles in the 6-ft-dia duct normally discharge water into the exhaust gases to cool them. The cool exhaust gases and steam are then discharged into the 12-ft-dia duct, where scrubbing of the gases can take place. The fluorine engine operates at a chamber pressure of $100 \mathrm{psi}$, and the exhaust duct must be evacuated by steam ejectors during an engine test.

The test program will consist of six tests as shown in the Test Plan in Appendix A. The first two tests, of 10-sec duration, will establish the nature of the gas flow field, and subsequent 60-sec-duration tests will use a water-spray system specifically designed to cool the exhaust gases. An instrumentation rake will supply measurements of temperatures and pressures in the duct at various axial stations downstream from the water injector during the long-duration tests.

\section{A. GAS FLOW FIELD}

Prior to designing a water-injection system to cool the hot exhaust gases, the nature of the flow field leaving the exhaust duct must be 
established. Two tests of approximately 10-sec duration each and flowing $18.8 \mathrm{lb} / \mathrm{sec}$ of propellant at a mixture ratio of 1.6 permitted a measure of the gas flow field.

The measurements made in the first test, which utilized the original facility water-cooling system, consisted of five total and two static pressures measured across the duct exit, four static wall pressures in the cooling plenum, and three thermocouple temperatures near the wall in the quiescent region at the junction of the 30-in.- and 72-in.-dia ducts. An uncooled pressure-measurement rake (AGC Drawing ST-7033) was fabricated and installed across the exit plane of the 30-in. diffuser. Pressure measurements of the first test indicated that the gas flow exiting from the diffuser was supersonic. The exit pressure or static pressure in the 72-in. duct was approximately $1.5 \mathrm{psia}$. It was apparent that, to achieve subsonic flow from the diffuser, either the back pressure in the 72-in. duct had to be increased or engine flow reduced, with the former being the accepted solution. On the basis of estimates of the static pressure needed at the diffuser exit to achieve subsonic flow, a preliminary water-injection system was devised for injecting water to penetrate and saturate the exhaust gases. Included as Appendix $B$ are sketches of the new water-injection system. A second test was conducted with this new NERVA water system, and with the steam flow to the steam ejectors was throttled to result in an increased back pressure of between 4 and 7 psia.

The second test was to determine the effects of the operational modifications on reducing the gas velocity at the point of water injection and to see if the flow field was adversely affected by the water-injection system. The steam ejectors were turned on, and, when the static pressure in the duct and engine compartment reached approximately 7.0 psia, the engine was fired. The test-compartment pressure immediately started to fail and became stable at a cell pressure of 1.5 psia after some 10 sec of run time. 
During this firing, the duct pressure was fluctuating around 6.5 psia at a steam-ejector flow of approximately $100 \mathrm{lb} / \mathrm{sec}$. The Mach-number profile at the diffuser exit at three different times during the test is shown on Figure 27. Initial attempts to confirm the flow, based on an average Mach number, indicated a mass flow rate in excess of the $18.59-1 \mathrm{~b} / \mathrm{sec}$ propellant flow. Further examination of the test data revealed that, in addition to the propellant flow, a significant flow of air was being removed from the test compartment after engine ignition.

From analysis of Test -002 pressure data and the investigation of possible pressure-probe anomalies, the following conclusions were reached:

1. Steady diffuser flow was never achieved during Test -002 because of varying diffuser flow, which results from the test-cell evacuation. The test-cell pressure-decay data indicate that approximately $15 \mathrm{sec}$ are required to reach steady flow with an initial system pressure of 6.7 psia. The data show that the Mach-number profiles will vary during the 15-sec flow transient and that core flow approaching supersonic velocity will occur during the transient.

\section{A diffuser back pressure of approximately 6.5 psia will} produce a subsonic flow, whereas a back pressure of approximately 4 psia will produce a supersonic gas core. Although the test data were inadequate to calculate the steady-flow Mach-number profile, it will be reasonably flat and have a core Mach number between 0.62 and 0.46 , the theoretical one-dimensional steady-state value.

With the maximum Mach number now 0.62 rather than 0.75 , the water pressure or nozzle size required to achieve penetration can be relaxed. 


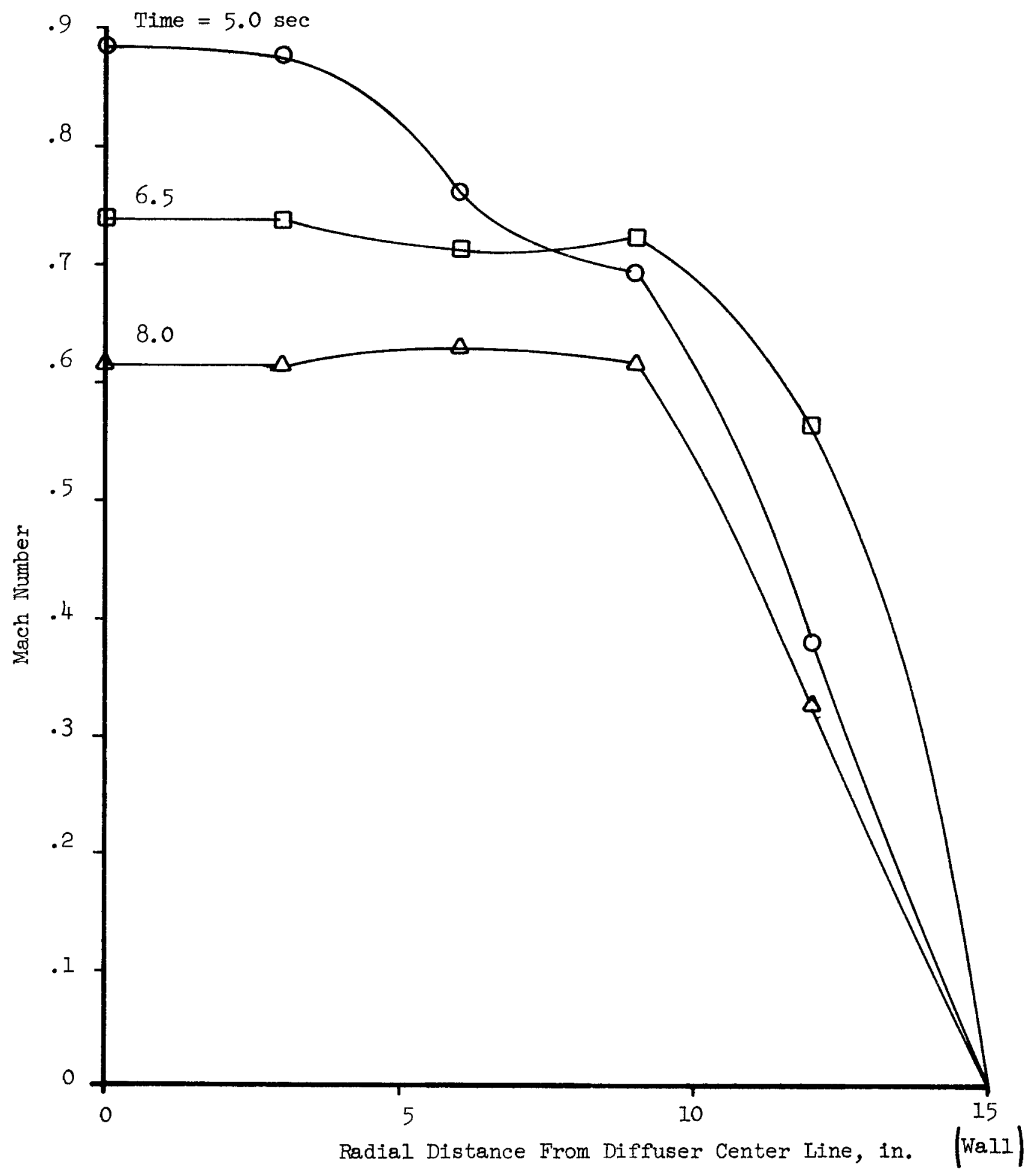

Figure 27 - J-4 Test No. 1186-X01-DJ-002, Mach Number Profiles 


\section{B. WATER-SPRAY SYSTEM}

A water-injection system was devised based on the following assumptions made for purposes of predicting the quantity of water required to cool the gas stream and size the water nozzles.

1. Frozen flow exists at an area ratio of 2.0 .

2. Combustion efficiency is equivalent to a mixture ratio of $1.6: 1$.

3. Propellant flow is $18.8 \mathrm{lb} / \mathrm{sec}$.

The test plan for the $\mathrm{LF}_{2}$ TCA high-temperature tests (Appendix A) calls for two different quantities of spray water:

1. Water to cool to a saturation temperature of $157^{\circ} \mathrm{F}$ (saturation at 6.5 psia)

2. Water flows to simulate the NERVA wet-elbow system (10 to 12 lb of coolant per pound of gas).

The water flow to cool the exhaust gases to saturation (initially determined to be $3.3 \mathrm{lb}$ water/1b exhaust gas) assumes no energy loss from the gases to the diffuser and no chemical reaction with the water. This corresponds to a total gas water flow rate of approximately $465 \mathrm{gpm}$.

A water injection system to cool the gas stream was subsequently designed to consist of 40 stainless-steel nozzles. The recommended nozzle is the Spraying Systems Company Vee-jet nozzle with a spray angle of $0^{\circ}$ and with the required pressure and flow schedule as follows: 


\begin{tabular}{|c|c|c|c|c|c|c|}
\hline Case II & $\begin{array}{l}\text { Nozzle } \\
\text { Code } \\
\end{array}$ & $\begin{array}{c}\text { Nozzle Press. } \\
\text { Drop, psi } \\
\end{array}$ & $\begin{array}{l}\text { Nozzle } \\
\text { Flow, gpm } \\
\end{array}$ & $\begin{array}{l}\text { No. of } \\
\text { Nozzles } \\
\end{array}$ & $\begin{array}{c}\text { Tota1 } \\
\text { Flow, gpm } \\
\end{array}$ & $\begin{array}{c}\text { Cum. } \\
\text { Flow, gpm } \\
\end{array}$ \\
\hline & A & 140 & 37.5 & 2 & 75.0 & 75.0 \\
\hline & B & 100 & 31.6 & 4 & 126.4 & 201.4 \\
\hline & C & 75 & 27.4 & 4 & 109.6 & 311.0 \\
\hline & D & 10 & 10.0 & 20 & 200.00 & 511.0 \\
\hline & $*_{\mathrm{A}}$ & 55 & 116.9 & 5 & 584.5 & 584.5 \\
\hline & $*_{B}$ & 15 & 61.2 & 5 & 306.0 & 890.5 \\
\hline
\end{tabular}

*Additional water spray ring to simulate 10 to $12 \mathrm{lb}$ of coolant/lb of gas.

Water nozzles A through D will be spaced radially $12^{\circ}$ apart and directed normal to the gas stream at the exit of the diffuser. The ends of the nozzles from sprays A through D will be coplanar with the circumference of the diffuser and 1 to 2 in. downstream from the end of the diffuser, and will be flowed during Tests $2,3,4,5$, and 6 . The 1-in. nozzles, $A^{*}$ and $B^{*}$, will be arranged downstream of the 1/2-in. nozzle in a plane 5 to 6 in. from the diffuser exit and will be flowed during Test 5 only. The nozzle exits will be coplanar with the diffuser circumference and will be spaced $36^{\circ}$ apart. A sketch of these nozzle arrays is included in Appendix B.

The water manifold supplying water to the water sprays will include a flowmeter to record the water delivery rate for each test.

The predicted spray patterns for the water-spray nozzles at an axial distance of 15 in. are shown in Figures 28 and 29.

\section{Instrumentation}

The principal means of measuring test parameters will be through the use of a special instrumentation rake. The measurements to be 


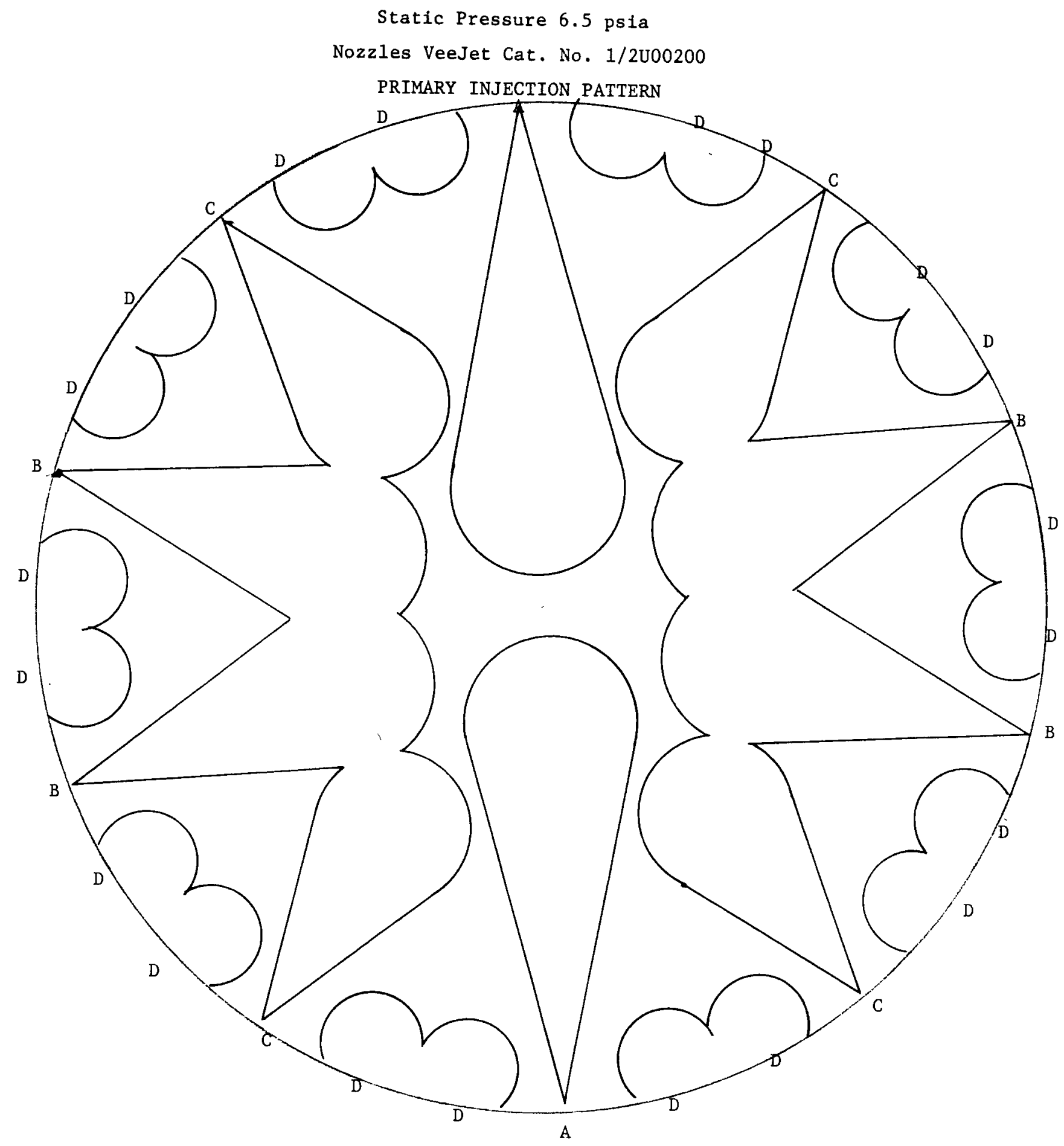

Figure 28 - Water-Spray Pattern in Duct, Case II 


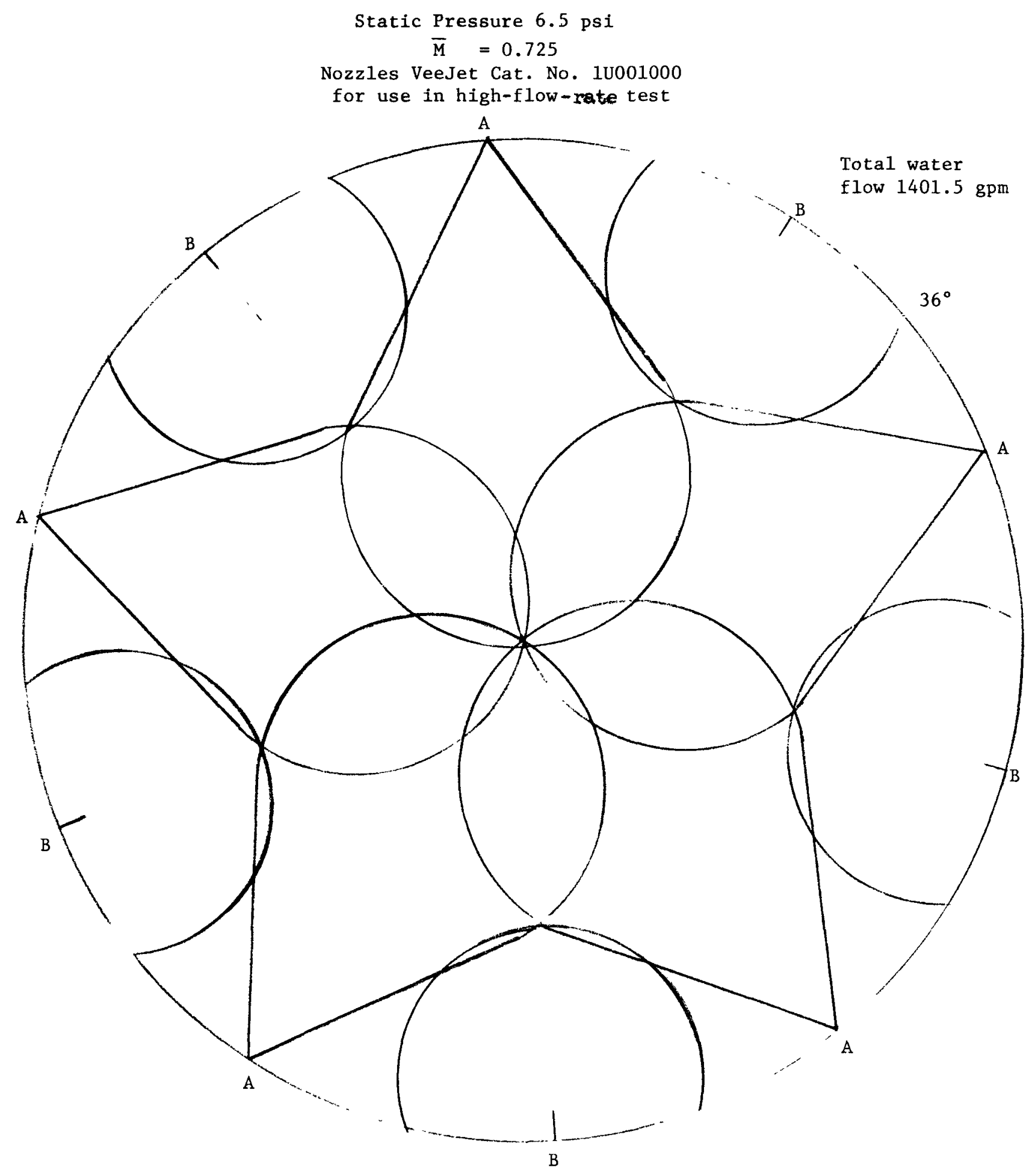

Figure 29 - Water-Spray Pattern in Duct, Case III 
made with the rake are all indicated in Figure 30. The rake was fabricated in accordance with AGC Drawing 1104118. Measurements will include three total pressures, six temperatures (at five radial locations), and three moisture levels by means of probes at the radial locations shown. This rake will be located at three different axial locations in the 6-ft duct: 30,60 , and 90 in. from the diffuser exit. In addition to the rake, wall static pressures will be measured at the diffuser exit and at four places along the 6-ft duct wall. Three thermocouples will be located in the stagnation region radially outward from the end of the diffuser and along the wall of the 6-ft-dia duct.

\section{Gas-Stream Temperatures and Pressures}

a. Mixing Model (Greyrad)

The asymmetric wet-duct mixing analysis and computer program of Reference 13 was modified so it would analytically simulate the high-temperature tests. One of the major modifications was to accommodate the flow of the fluorine-hydrazine gas blend. This modification involved changing the gas property and state calculations from a one-component gas flow to a multiple-component composition. The flexibility and analytical simulation of the water-penetration calculation were also improved. The program was modified to accommodate individual jet flow rates and pressures. Also, the number of rows of jets used to simulate injection was changed.

After the program modification, two cases of different injection patterns were run for four different Reichardt momentum mixing coefficients equal to $0.0375,0.075,0.10$, and 0.15 . The output was for stream properties at axial and radial locations corresponding to the rake measurement locations. Two radial planes were computed for $\theta-0$ and $\theta-$ 90 degrees. The rake position at a horizontal plane corresponds to $\theta-$ 0 degrees. 


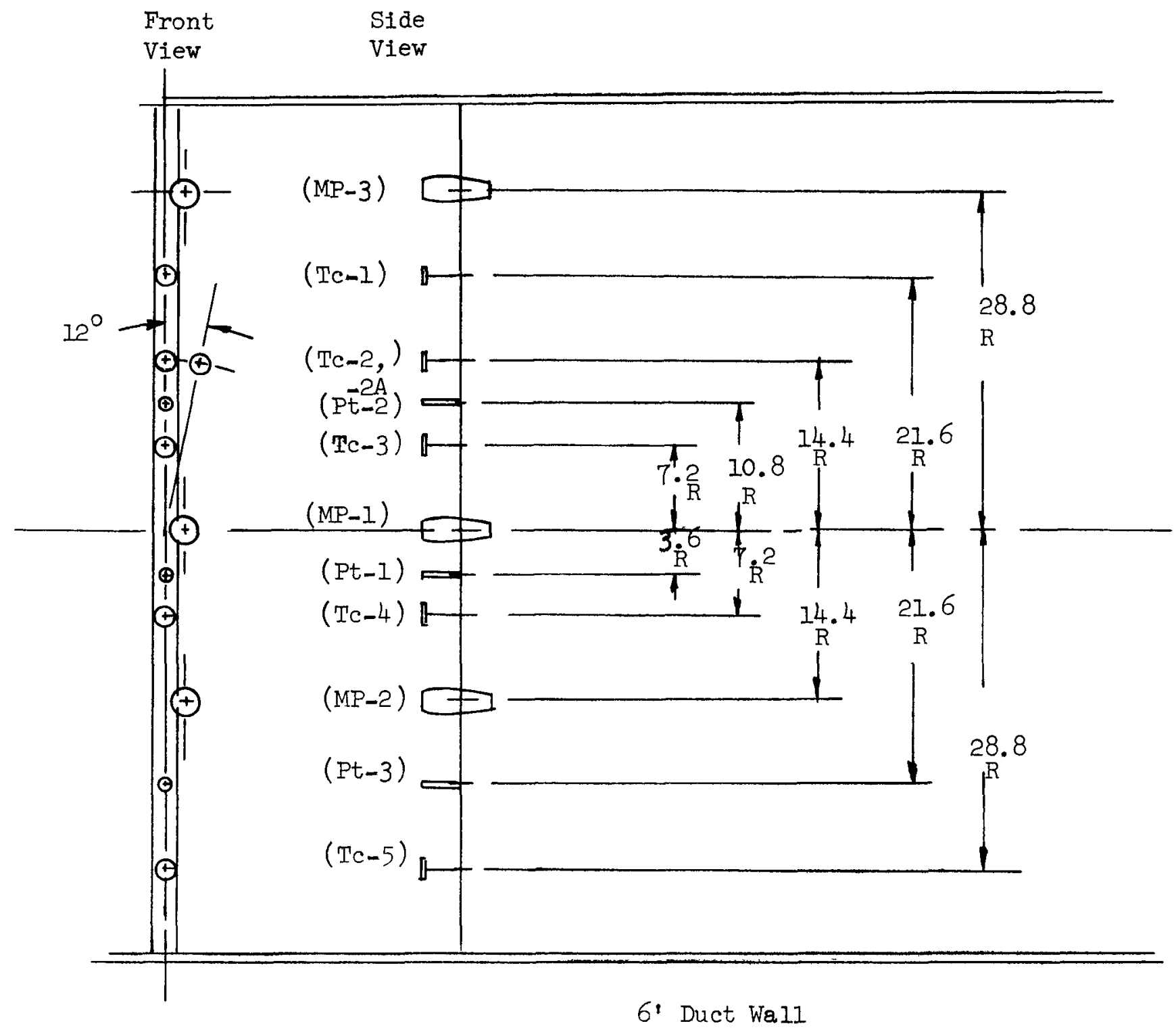

Figure 30 - High-Temperature Water-Penetration Tests, Instrumentation Rake 
In all the calculations, the inlet Mach No. was 0.75 and the inlet duct diameter was adjusted to 22.4 in. to permit a match of static pressures in the duct of $6.5 \mathrm{psia}$. Without this area change, the continuity equation could not be satisfied at a static pressure of 6.5 psia as established in the initial duct tests. (Subsequent analysis indicates the error was due to the mass of entrained air from the test cell in the exhaust gas.)

The input conditions for the cases are as follows:

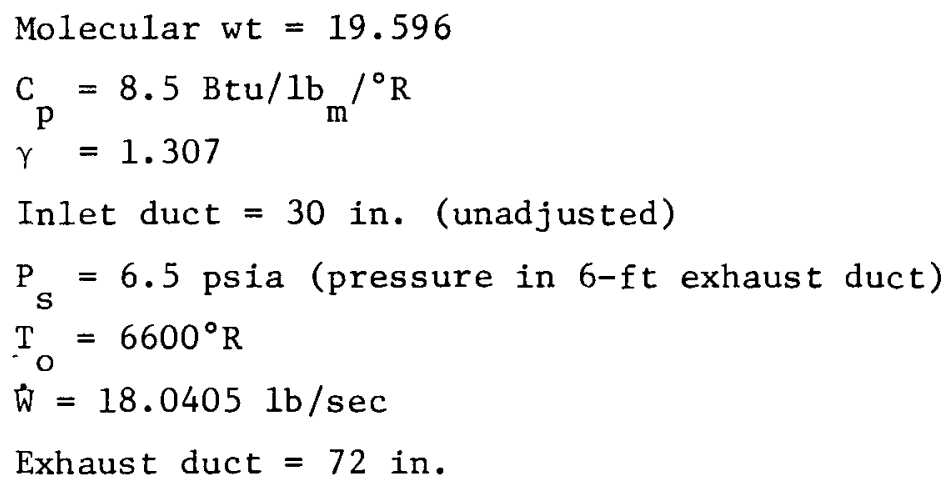

The predicted gas temperatures for water injection from the thirty 1/2-in. nozzles at axial distances of $30,60,90$, and 100 in. downstream from the point of injection are shown in Figures 31 through 34 and for injection from the 1/2- and 1-in. nozzles in Figure 35. The influence of the mixing coefficient $\mathrm{C}_{\mathrm{m}}$ on the predicted temperatures is clearly evident in the three plots for Case II.

The total pressures and wall static pressures computed from this model are listed in Table 2 . 
Axial Distance, in.

○ 30

$\square \quad 60$

$\triangle 90$

$\diamond 150$

잉

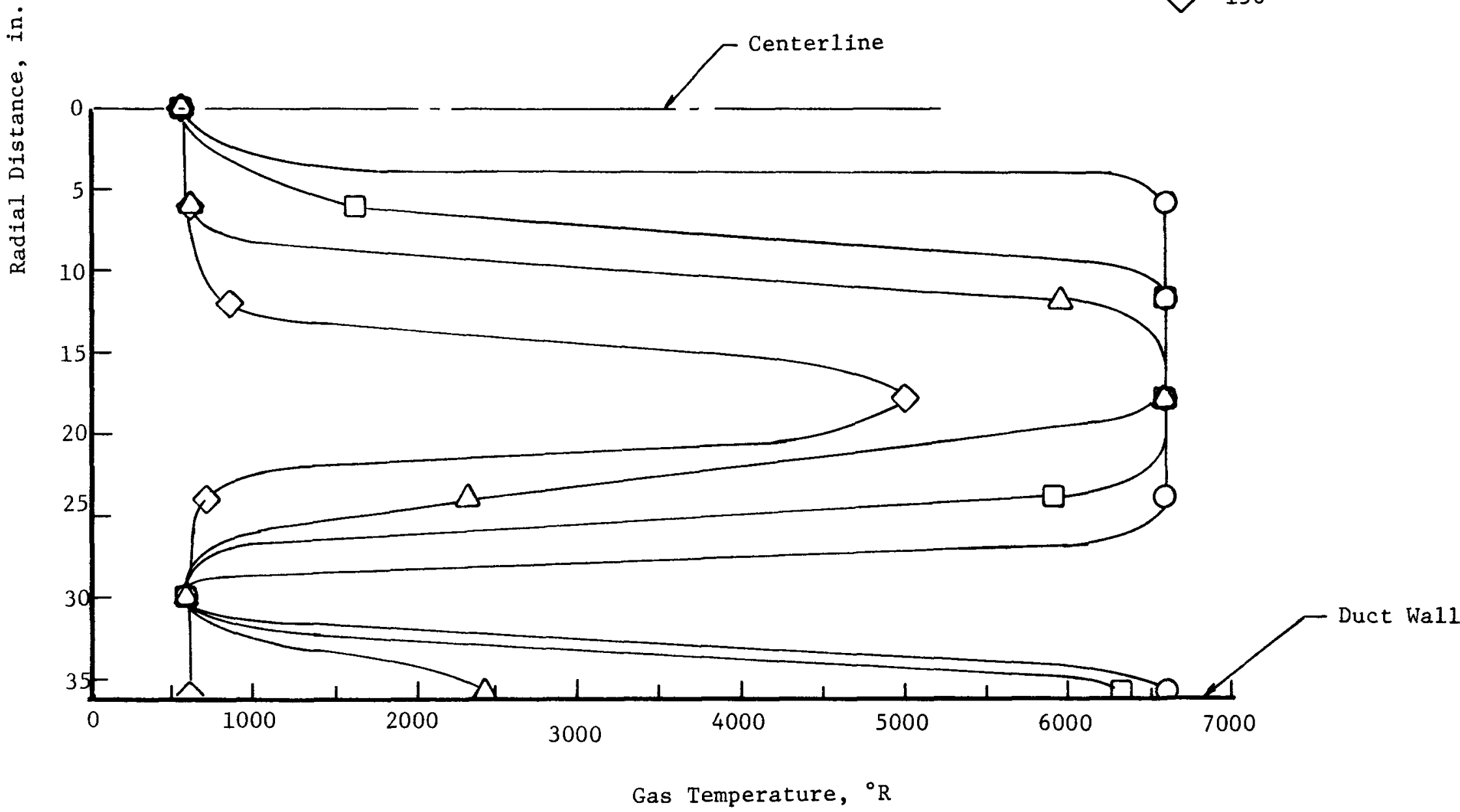

Figure 31 - Exhaust-Gas Cooling, Case II; Azimuth $0^{\circ}, C_{m}=0.0375$ 
Axial Distance, in.

O 30

$\square \quad 60$

$\triangle 90$

$\diamond 150$

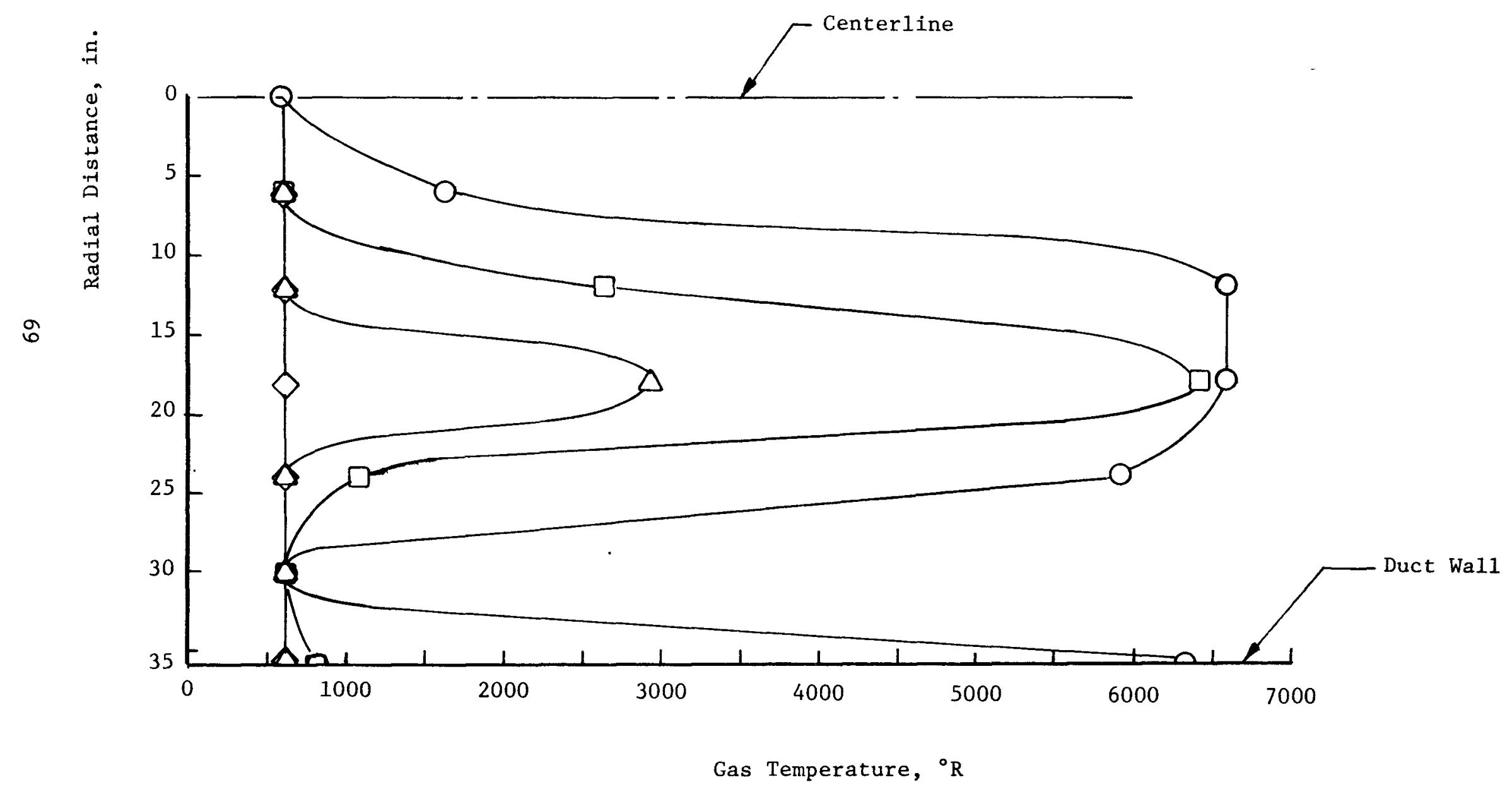

Figure 32 - Exhaust-Gas Cooling, Case II; Azimuth $0^{\circ}, \mathrm{C}_{\mathrm{m}}=0.075$ 
Axial Distance, in.
O 30
口 60
$\triangle 90$

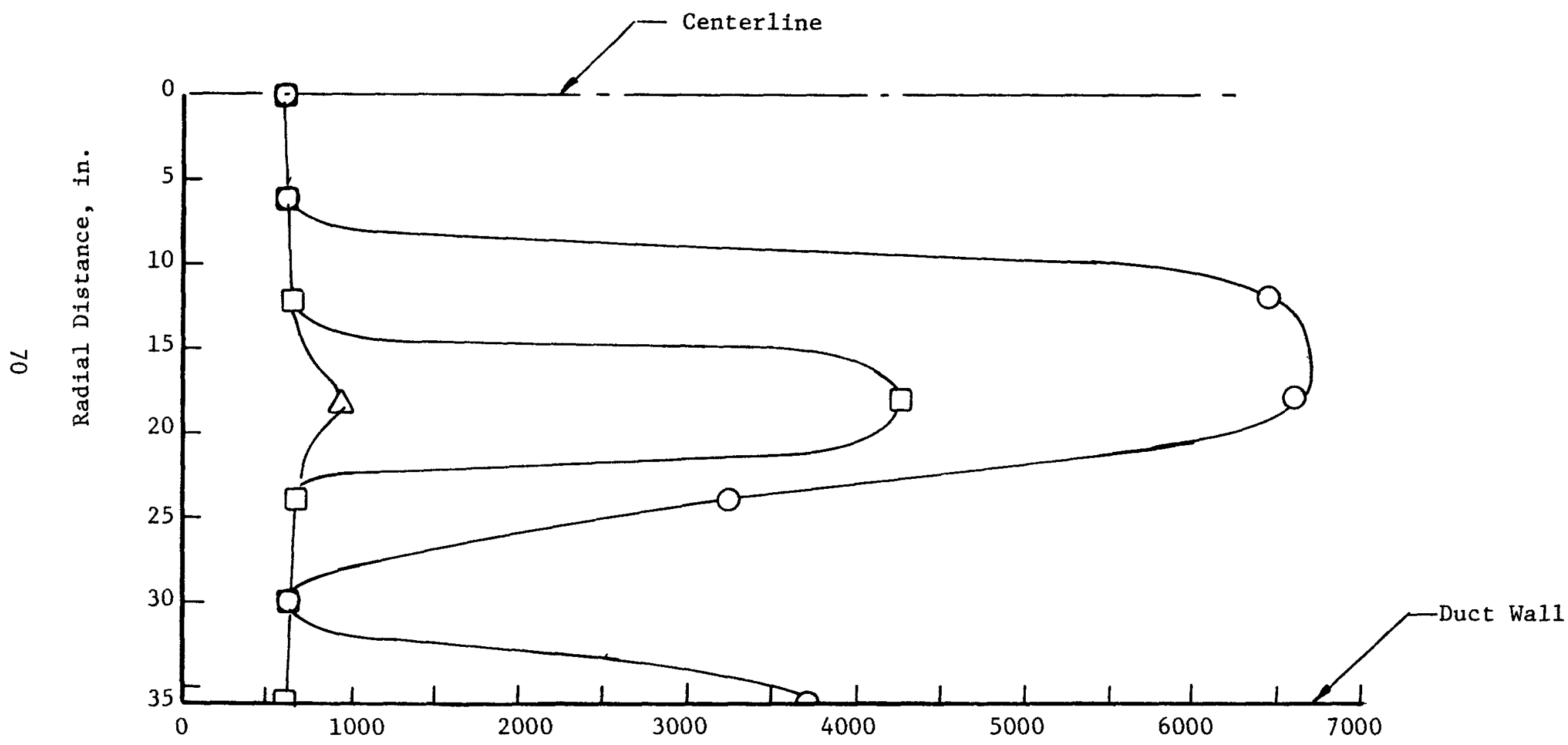

Gas Temperature, ${ }^{\circ} \mathrm{R}$

Figure 33 - Exhaust-Gas Cooling, Case II; Azimuth $0^{\circ}, \mathrm{C}_{\mathrm{m}}=0.10$ 
Axial Distance, in.

O 30

$\square \quad 60$

$\triangle 90$

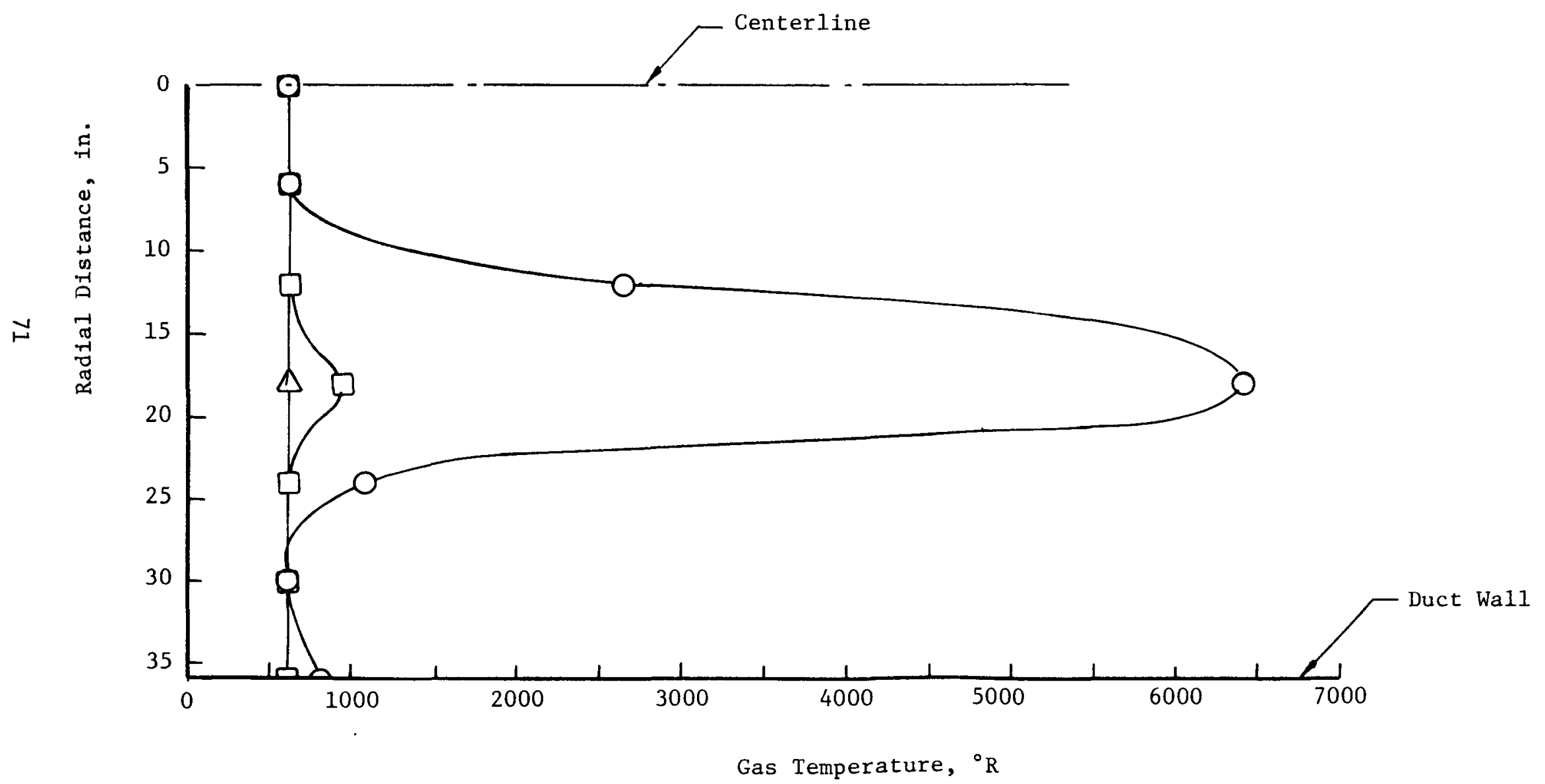

Figure 34 - Exhaust-Gas Cooling, Case II; Azimuth $0^{\circ}, \mathrm{C}_{\mathrm{m}}=0.15$ 
Axial Distance, In.
O 30
口 60
$\triangle 90$

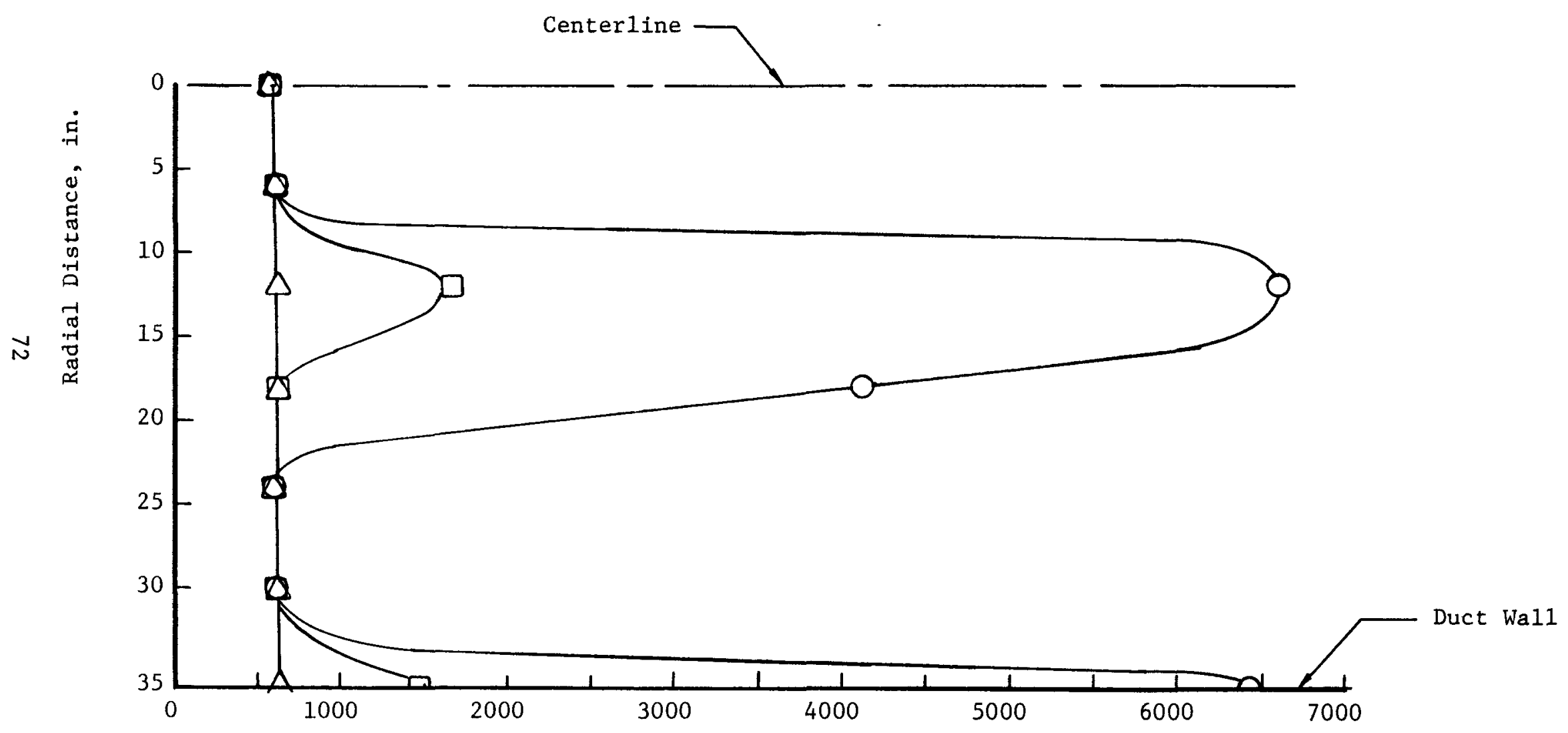

Gas Temperature, ${ }^{\circ} \mathrm{R}$

Figure 35 - Exhaust-Gas Cooling, Case II and Case III; Azimuth $0^{\circ}$, $\mathrm{C}_{\mathrm{m}}=0.075$ 


\section{TABLE 2}

STATIC AND TOTAL PRESSURES;

EXHAUST-GAS COOLING MIXING PROGRAM

Case II, $C_{m}=0.0375$

\begin{tabular}{|c|c|c|c|}
\hline $\begin{array}{c}\text { Axial } \\
\text { Distance, } \\
\text { in. }\end{array}$ & $\begin{array}{c}\text { Radius, } \\
\text { in. } \\
\end{array}$ & $\begin{array}{r}\mathrm{P}_{t,} \\
\text { psia }\end{array}$ & $\begin{array}{r}\mathrm{P}_{\mathrm{s}} \\
\text { psia } \\
\end{array}$ \\
\hline 30 & $\begin{array}{r}0 \\
6 \\
12 \\
18 \\
24 \\
30 \\
36\end{array}$ & $\begin{array}{r}10.6 \\
6.95 \\
6.95 \\
6.95 \\
6.95 \\
7.53 \\
6.95\end{array}$ & 6.941 \\
\hline 60 & $\begin{array}{r}0 \\
6 \\
12 \\
18 \\
24 \\
30 \\
36\end{array}$ & $\begin{array}{l}7.65 \\
6.95 \\
6.94 \\
6.94 \\
6.94 \\
7.09 \\
6.94\end{array}$ & 6.923 \\
\hline 90 & $\begin{array}{r}0 \\
6 \\
12 \\
18 \\
24 \\
30 \\
36\end{array}$ & $\begin{array}{l}7.25 \\
6.97 \\
6.94 \\
6.94 \\
6.94 \\
7.00 \\
6.94\end{array}$ & 6.912 \\
\hline 150 & $\begin{array}{r}0 \\
6 \\
12 \\
18 \\
24 \\
30 \\
36\end{array}$ & $\begin{array}{l}7.08 \\
7.01 \\
6.95 \\
6.94 \\
6.95 \\
6.97 \\
6.97\end{array}$ & 6.920 \\
\hline
\end{tabular}




\section{TABLE 2 (cont.)}

\section{Case II}

$$
\underline{\mathrm{C}_{\mathrm{m}}=0.10 \quad \underline{\mathrm{C}_{\mathrm{m}}=0.15}}
$$

Axial

Distance,

in.

30

60

90

150

\begin{tabular}{c}
$\begin{array}{c}\text { Radius, } \\
\text { in. }\end{array}$ \\
\hline 0 \\
6 \\
12 \\
18 \\
24 \\
30 \\
36
\end{tabular}

0

6

12

18

24

30

36

\section{0}

6

12

18

24

30

36

0
6
12
18
24
30
36

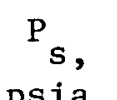

psia

6.915

7.33

6.96

6.94

6.94

6.94

7.02

6.94

7.07

7.01

6.95

6.94

6.95

6.97

6.96

7.02

7.00

6.97

6.95

6.96

6.96

6.96

6.98
6.98
6.97
6.96
6.96
6.96
6.96

$$
6.922
$$

$$
6.924
$$

$\mathrm{P}_{\mathrm{t}}$,

psia

7.13

7.00

6.94

6.94

6.95

6.98

6.95

7.02

7.00

6.97

6.95

6.96

6.96

6.96

6.99

6.98

6.97

6.96

6.96

6.96

6.96

6.97

6.97

6.96

6.96

6.96

6.96

6.96
6.923

psia

6.914$$
6.923
$$

$$
6.924
$$

6.924 
TABLE 2 (cont.)

\begin{tabular}{|c|c|c|c|}
\hline $\begin{array}{c}\text { Axial } \\
\text { Distance, } \\
\text { in. }\end{array}$ & $\begin{array}{c}\text { Radius, } \\
\text { in. } \\
\end{array}$ & $\begin{array}{r}P_{t,} \\
\text { psia } \\
\end{array}$ & $\begin{array}{r}P_{\text {s, }} \\
\text { psia }\end{array}$ \\
\hline 30 & $\begin{array}{r}0 \\
6 \\
12 \\
18 \\
24 \\
30 \\
36\end{array}$ & $\begin{array}{l}7.54 \\
7.00 \\
6.94 \\
6.94 \\
7.19 \\
7.00 \\
6.94\end{array}$ & 6.910 \\
\hline 60 & $\begin{array}{r}0 \\
6 \\
12 \\
18 \\
24 \\
36\end{array}$ & $\begin{array}{l}7.28 \\
7.06 \\
6.94 \\
6.95 \\
7.00 \\
6.94\end{array}$ & 6.900 \\
\hline 90 & $\begin{array}{r}0 \\
6 \\
12 \\
18 \\
24 \\
30 \\
36\end{array}$ & $\begin{array}{l}7.14 \\
7.05 \\
6.96 \\
6.95 \\
6.97 \\
6.95 \\
6.94\end{array}$ & 6.905 \\
\hline 150 & $\begin{array}{r}0 \\
6 \\
12 \\
18 \\
24 \\
30 \\
36\end{array}$ & $\begin{array}{l}7.02 \\
7.00 \\
6.97 \\
6.95 \\
6.95 \\
6.95 \\
6.95\end{array}$ & 6.901 \\
\hline
\end{tabular}




\section{b. Evaporation Mode1}

The water injection system of Figure 28 was evaluated by using the evaporation model.

The stream tube profiles used for the J-4 test predictions are shown in Figure 36 as five stream tubes. As the water jets from each of the nozzles penetrate the stream tubes, a fraction of the water is shredded into droplets. The droplets have some mean diameter and radial velocity component at the time or origin, hence they continue to penetrate the gas stream and enter other stream tubes. Curves in Figures 37 through 40 show the flow distribution from each of the different flow-rate nozzles. The radial gas-velocity component due to expansion of the gas was not included in the calibration of water distribution for Figures 37 through 40 . The resultant water distribution establishes the quantity of water in each stream tube, and the equilibrium temperature can be calculated if one assumes: (1) no radial mixing and (2) uniform circumferential mixing.

Figure 41 shows the equilibrium-temperature calculations for this water-injection system. In stream tubes 1,3 , and 5 , the final equilibrium temperature is higher than desired. At the present state of model development, demonstration of cooling in the outer $10 \%$ of the duct radius (stream tube 5) is not indicated, but the spray pattern can be changed to resolve the hot central core (stream tube 1) and the hot zone at a radial distance of 25 in. (stream tube 3 ).

The water-distribution system was subsequently altered to improve the distribution and to incorporate the revised estimate of the maximum expected gas Mach No. of 0.62 rather than 0.75 . The revised water spray pattern (Case IV) is shown in Figure 42. This nozzle array is shown in Table 3 . 


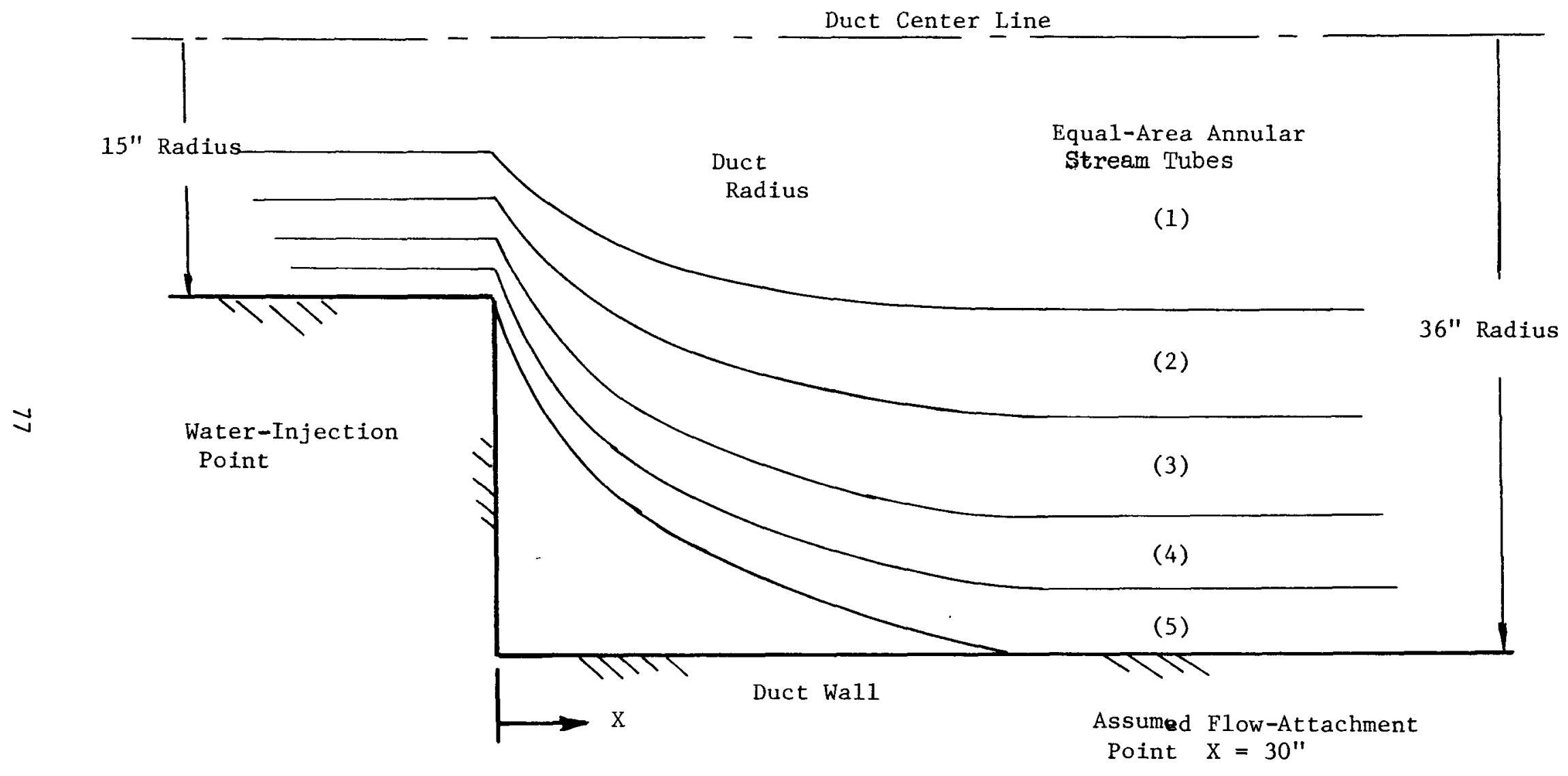

Figure $36-$ J-4 Test Stand; Stream Tube Profile 


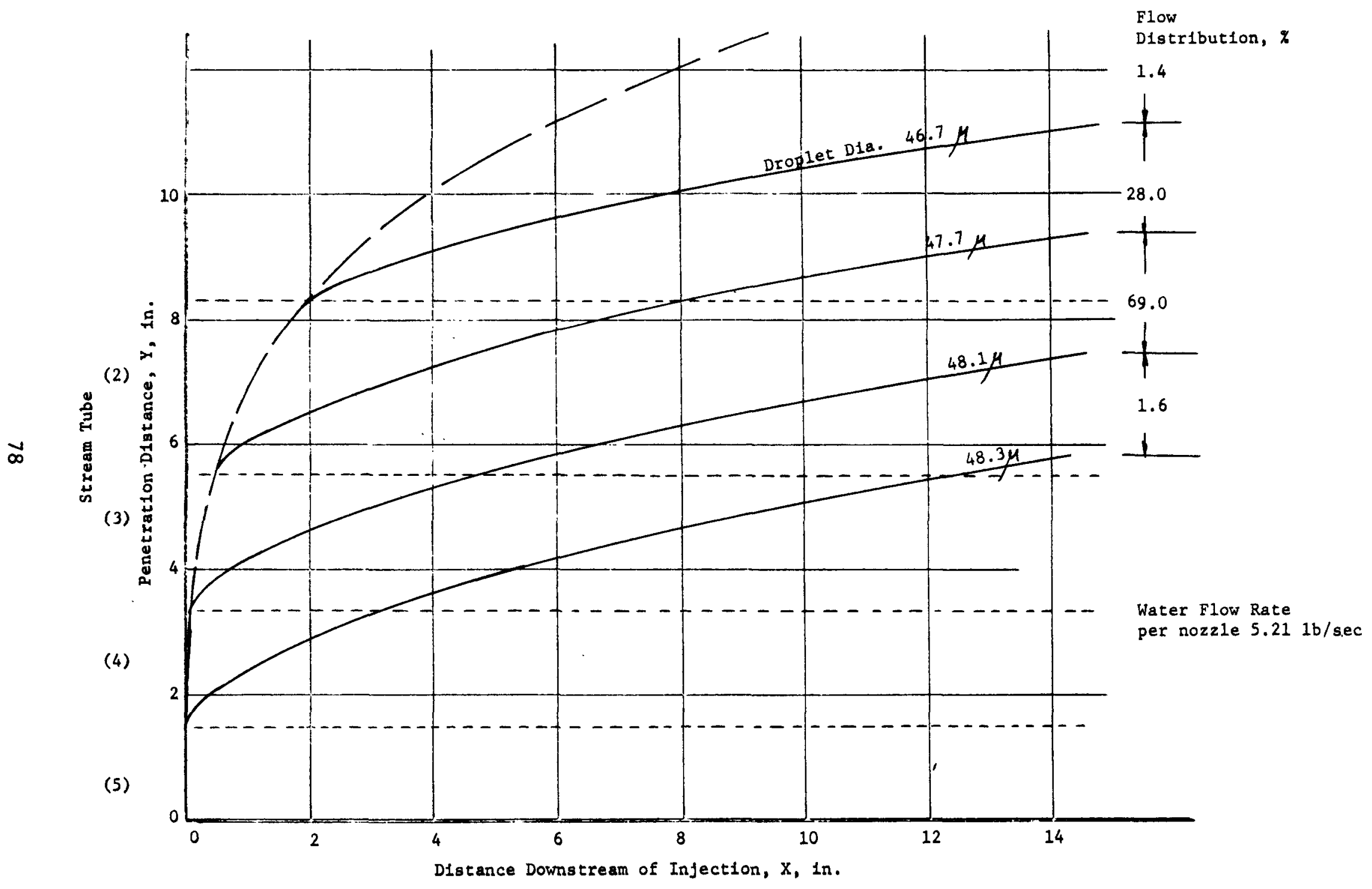

Figure 37 - Trajectory of Droplets and Water Distribution, J-4 Nozzle A 


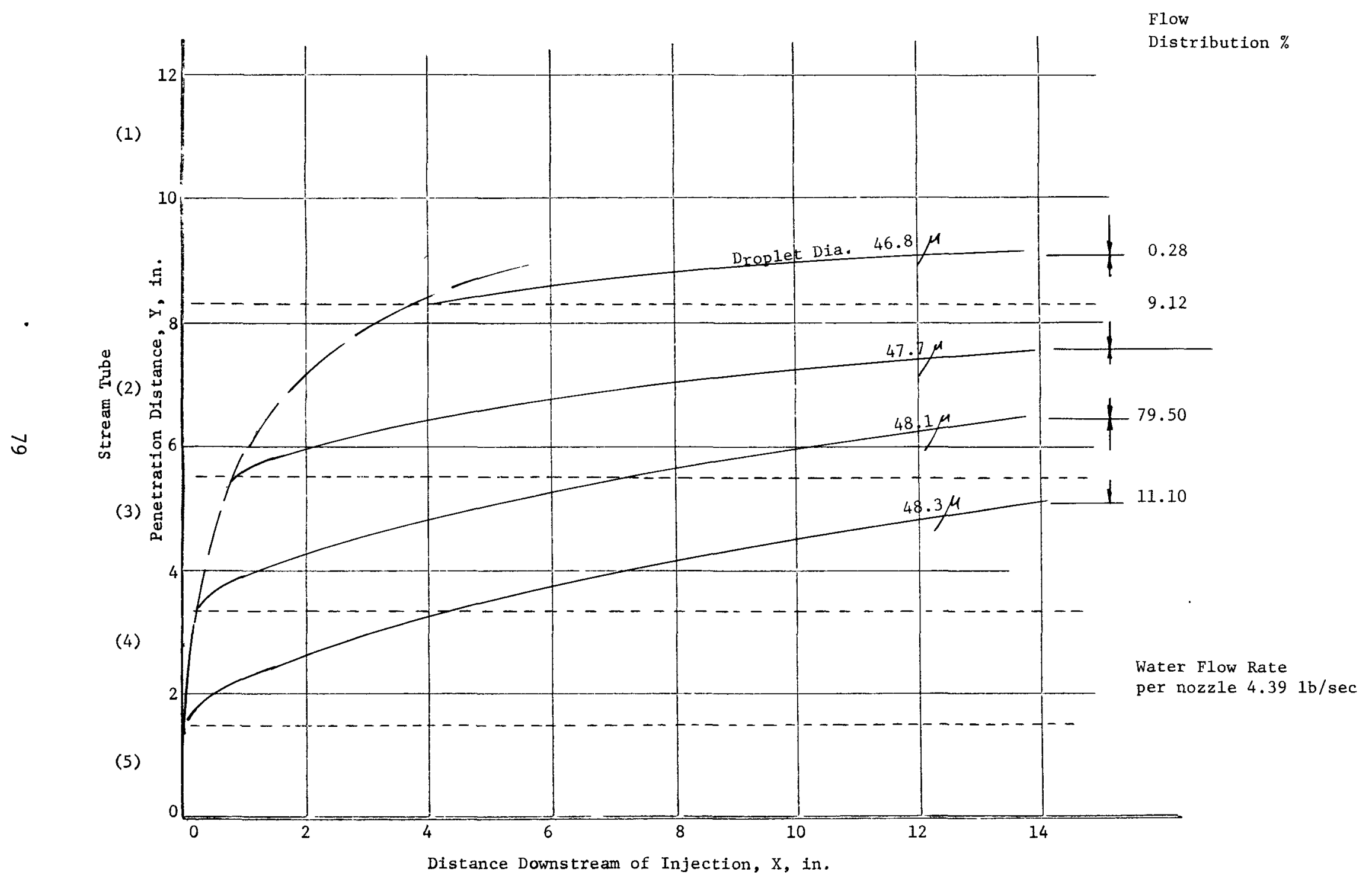

Figure 38 - Trajectory of Droplets and Water Distribution, J-4 Nozzle B 
(1)

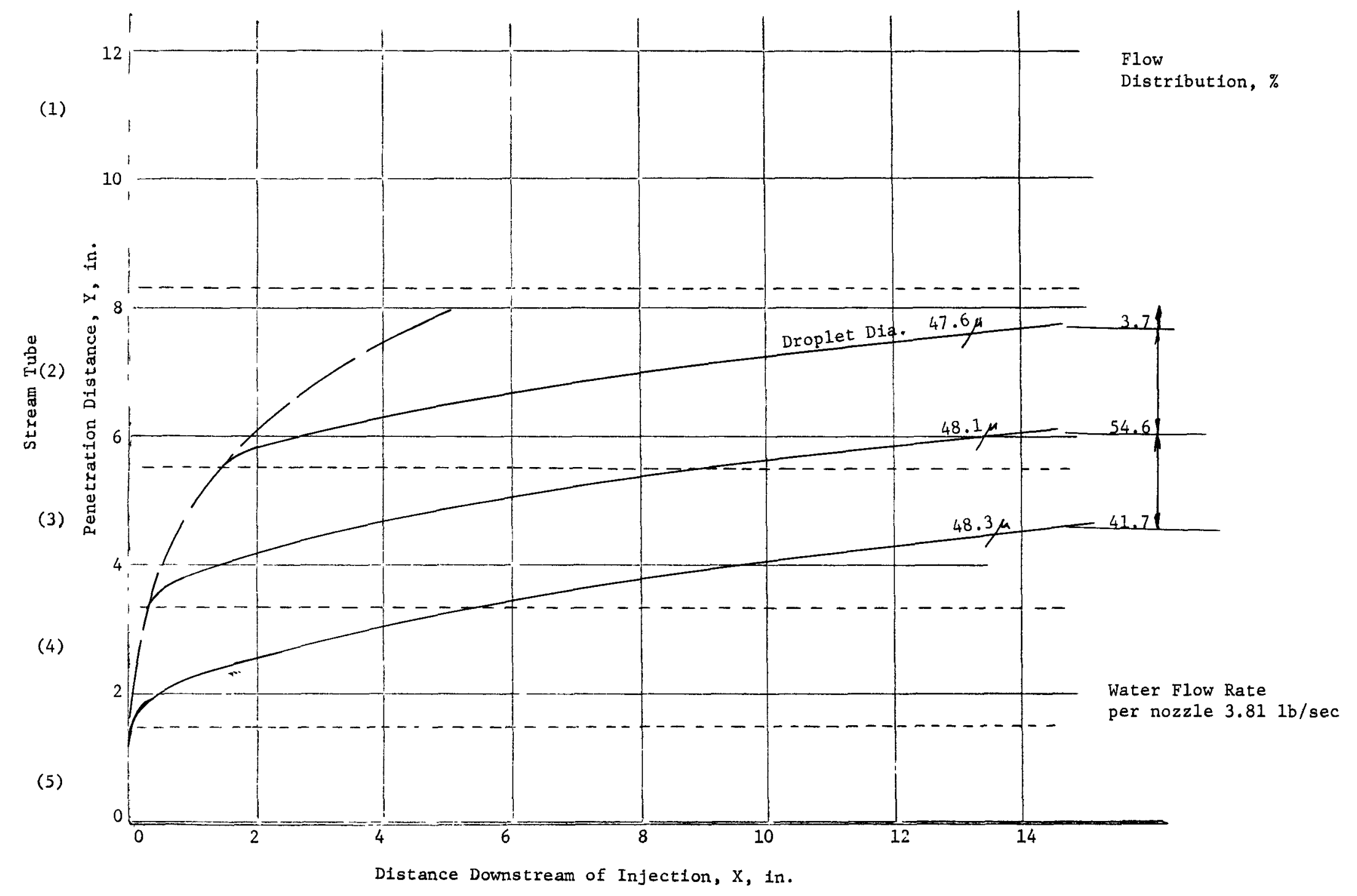

Distribution, \%

Figure 39 - Trajectory of Droplets and Water Distribution, J-4 Nozzle C 


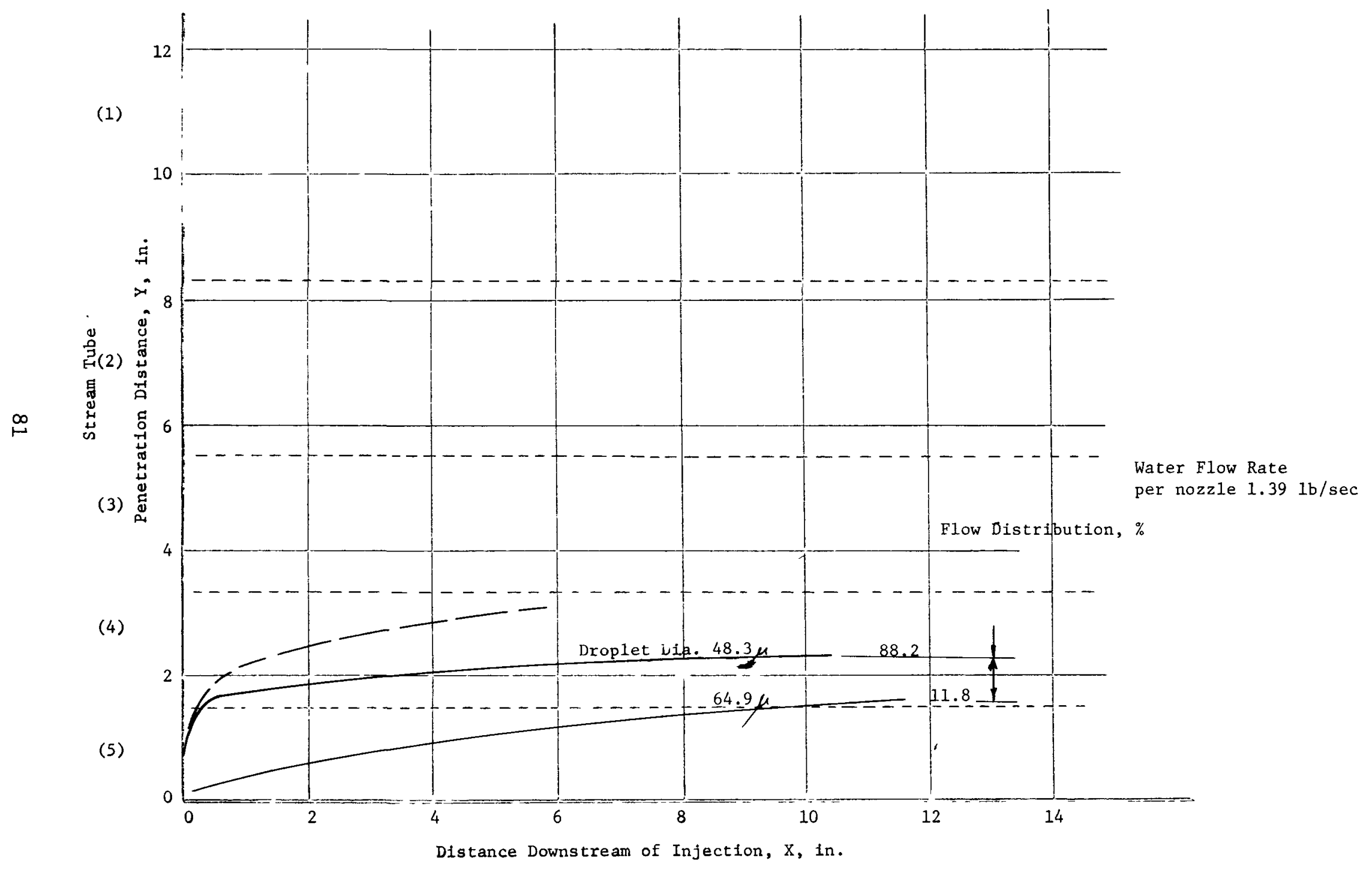

Figure 40 - Trajectory of Droplets and Water Distribution, J-4 Nozzle D 


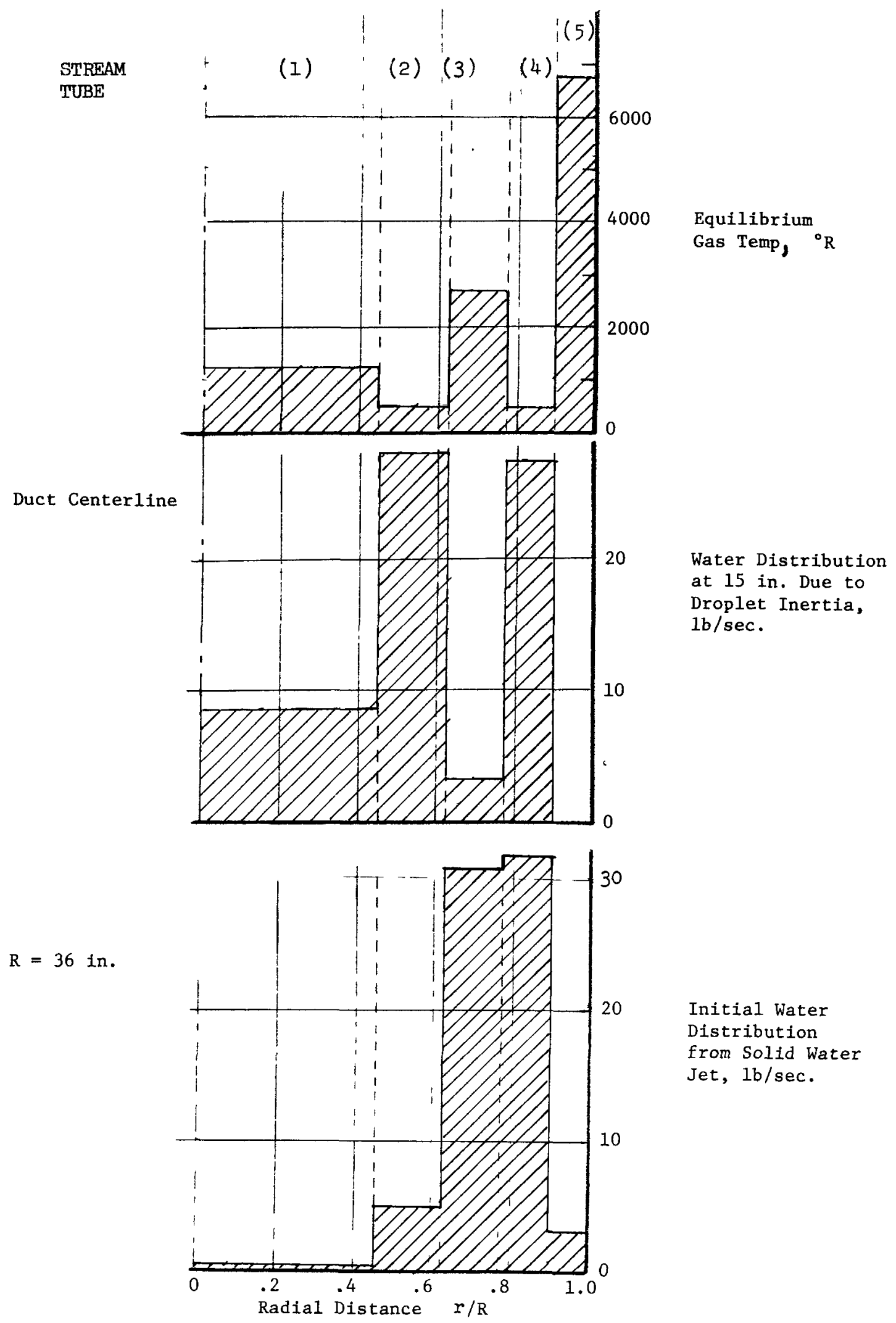

Figure 41 - J-4 Water Nozzles, Case II 


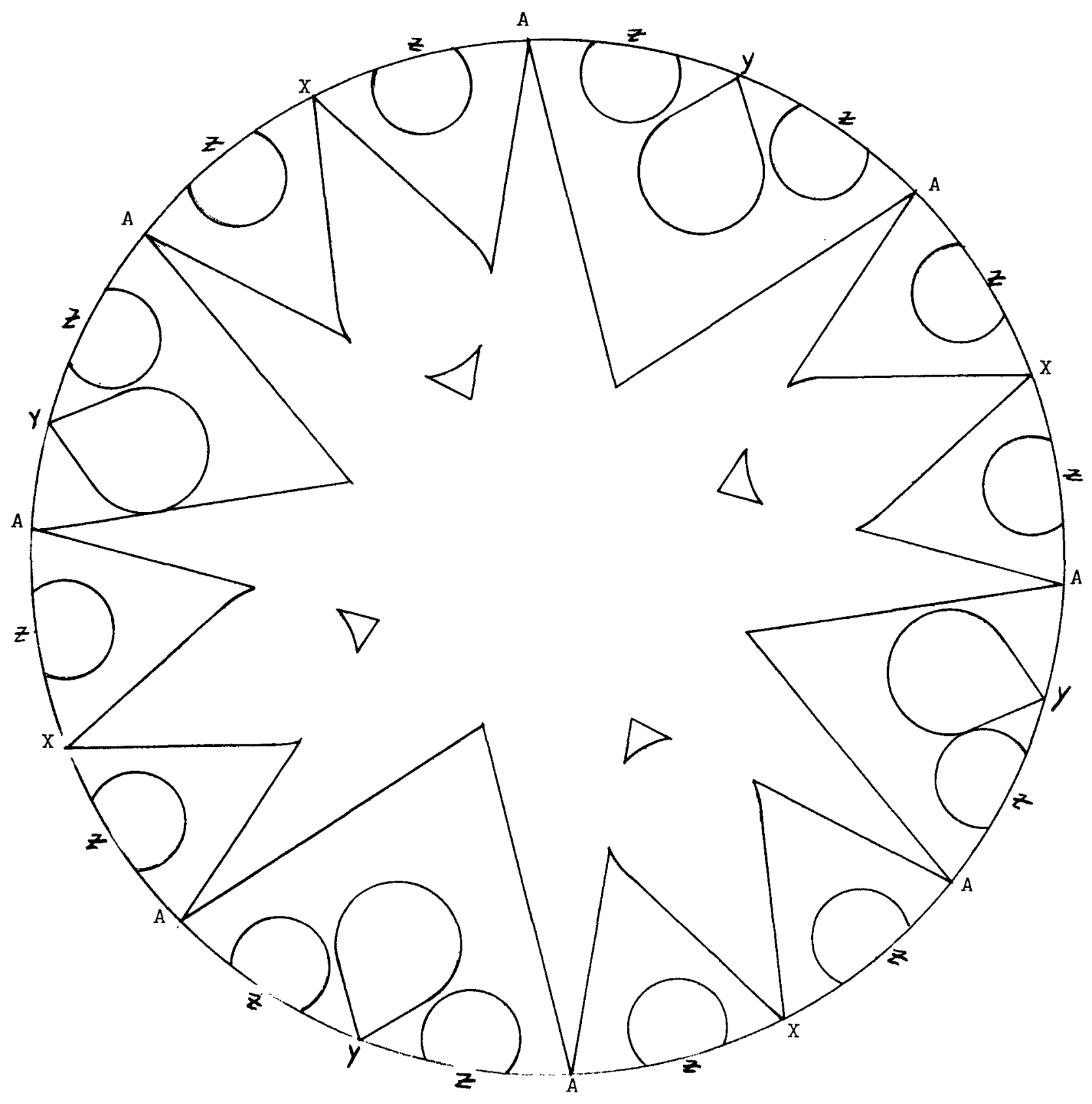

Figure 42 - Water-Spray Pattern in Duct, Case IV; Static Pressure 6.5 psia, Average Mach No. 0.62 
TABLE 3

NOZZLE ARRAY FOR CASE IV

\begin{tabular}{|c|c|c|c|c|c|c|}
\hline Case IV & $\begin{array}{c}\text { Nozzle } \\
\text { Code } \\
\end{array}$ & $\begin{array}{c}\text { Pressure } \\
\text { Drop, psia }\end{array}$ & $\begin{array}{l}\text { Flow, } \\
\text { gpm }\end{array}$ & $\begin{array}{l}\text { No. of } \\
\text { Nozzles }\end{array}$ & $\begin{array}{l}\text { Total } \\
\text { Flow } \\
\end{array}$ & $\begin{array}{l}\text { Cum. } \\
\text { Flow }\end{array}$ \\
\hline & $W-2$ & 140 & 37.5 & 8 & 300.0 & 300.0 \\
\hline & $\mathrm{x}$ & 50 & 22.2 & 4 & 88.8 & 388.8 \\
\hline & $\mathrm{Y}$ & 20 & 14.16 & 4 & 56.6 & 445.4 \\
\hline & $\mathrm{z}$ & 7 & 8.38 & 14 & 117.2 & 562.6 \\
\hline
\end{tabular}

The water distribution for these nozzles is shown in Figures 43 through 46 , and the new water distribution is shown in Figure 47. The changes in the water-spray system and gas Mach No. have resulted in an increase in the quantity of water in Zones 1 and 3 and a reduction in the quantity in Zones 2 and 4. The droplets generated in the various stream tubes for the initial evaporation calculations (Case II) had a mean droplet size of approximately 50 microns, and the one-dimensional gas temperature and static and total pressures were calculated for this droplet-gas system with radial and circumferential variations in water distribution and secondary droplet breakup ignored. The redesigned water-spray system has resulted in the droplet size decreasing to 15 microns; the gas temperatures and total and static pressures for various distances from the ejector are listed in Table 4 . It is apparent that the gas temperature based on these calculations will be rather moderate at a distance of $100 \mathrm{in.}$ and that the water available in the gas stream as based on the distribution calculations has little potential for further cooling the gas stream. The calculated static pressure in the duct decreases from the initial value of 6.5 psia to approximately 6.0 psia. This decrease was not evident in Test 2 and therefore indicates that the evaporation may not proceed at a rate as rapid as this analysis presently predicts.

\section{PRETEST PREDICTIONS}

The calculated temperatures and pressures for the high-temperature tests based on the Greyrad mixing model and the AGC evaporation model differ because of the manner in which the water-jet breakup is treated in each 


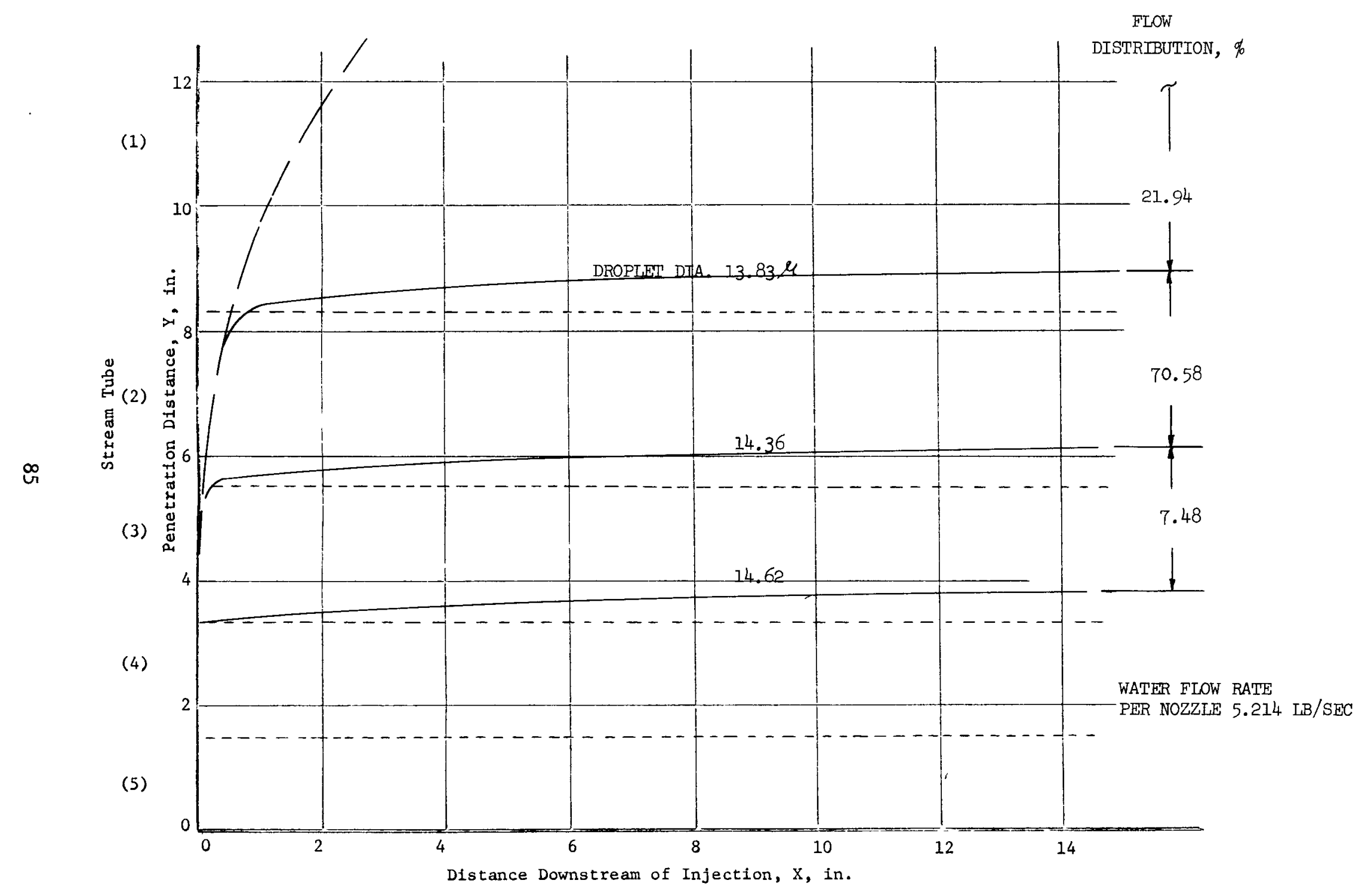

Figure 43 - J-4 Trajectory of Droplets and Water Distribution in an Expanding Flow Field, Nozzle W-2 


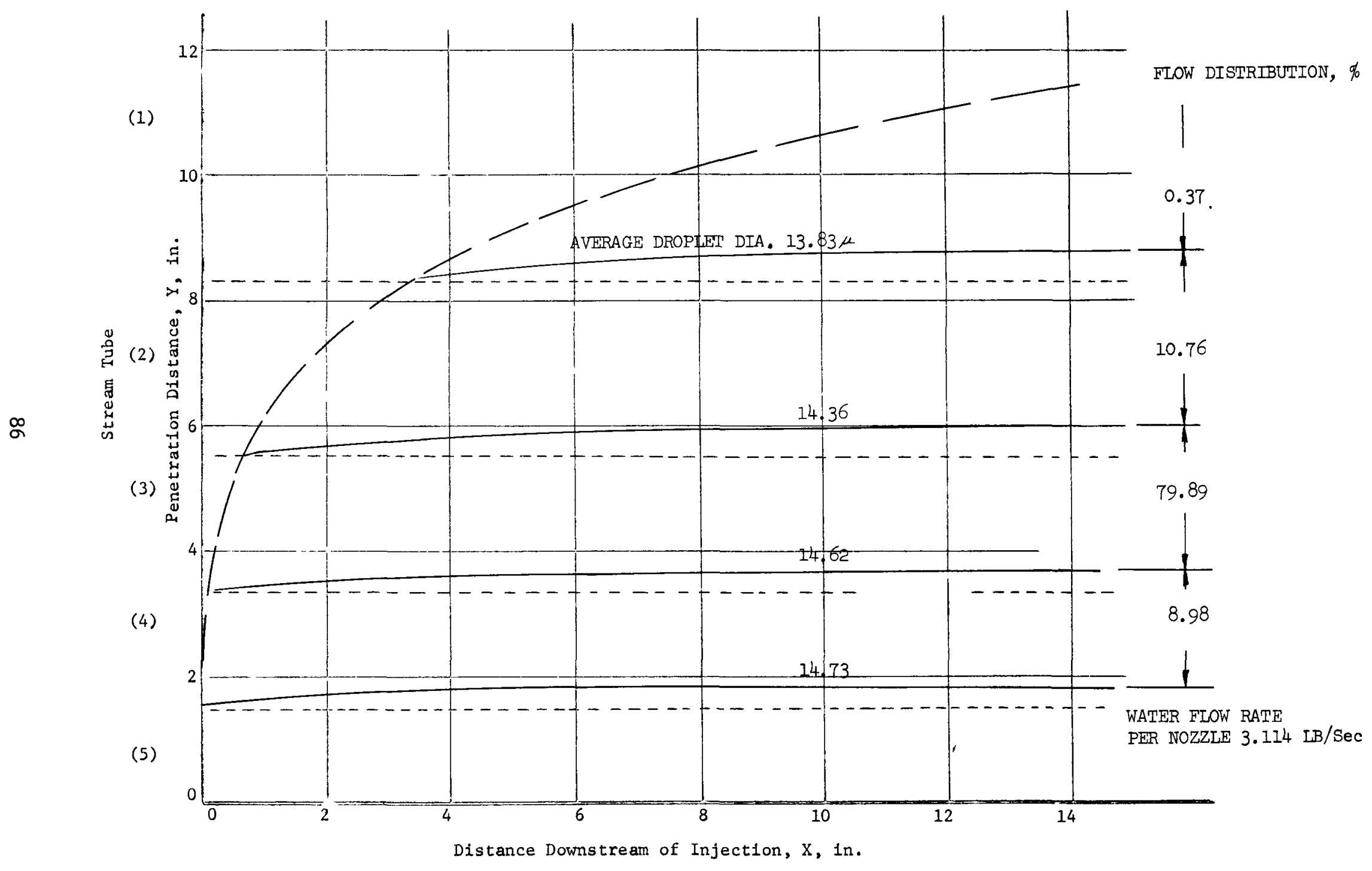

Figure $44-J-4$ Trajectory of Droplets and Water Distribution in an Expanding Flow Field, Nozzle X 


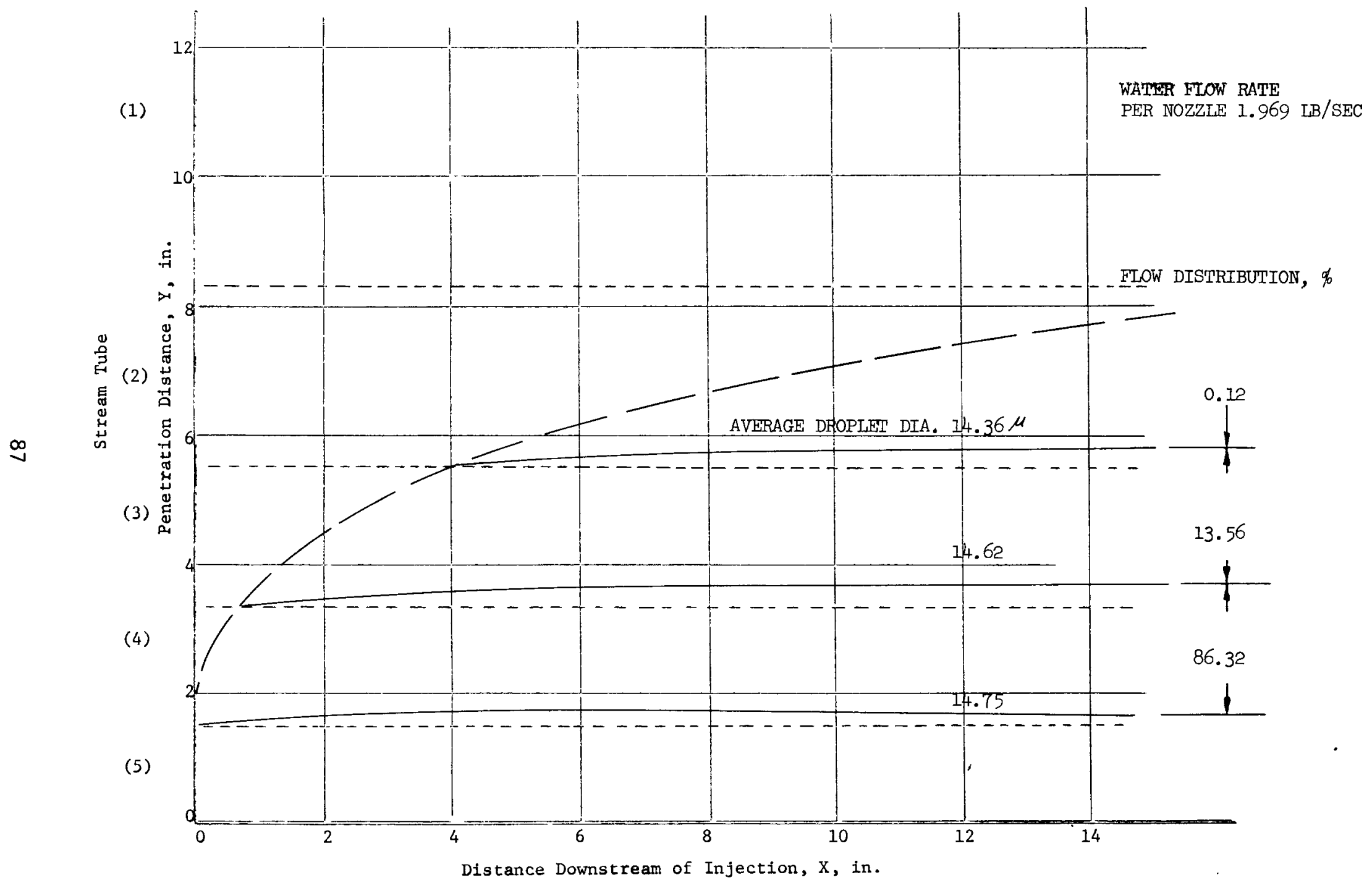

Figure 45 - J-4 Trajectory of Droplets and Water Distribution in an Expanding F1ow Fie1d, Nozzle Y 


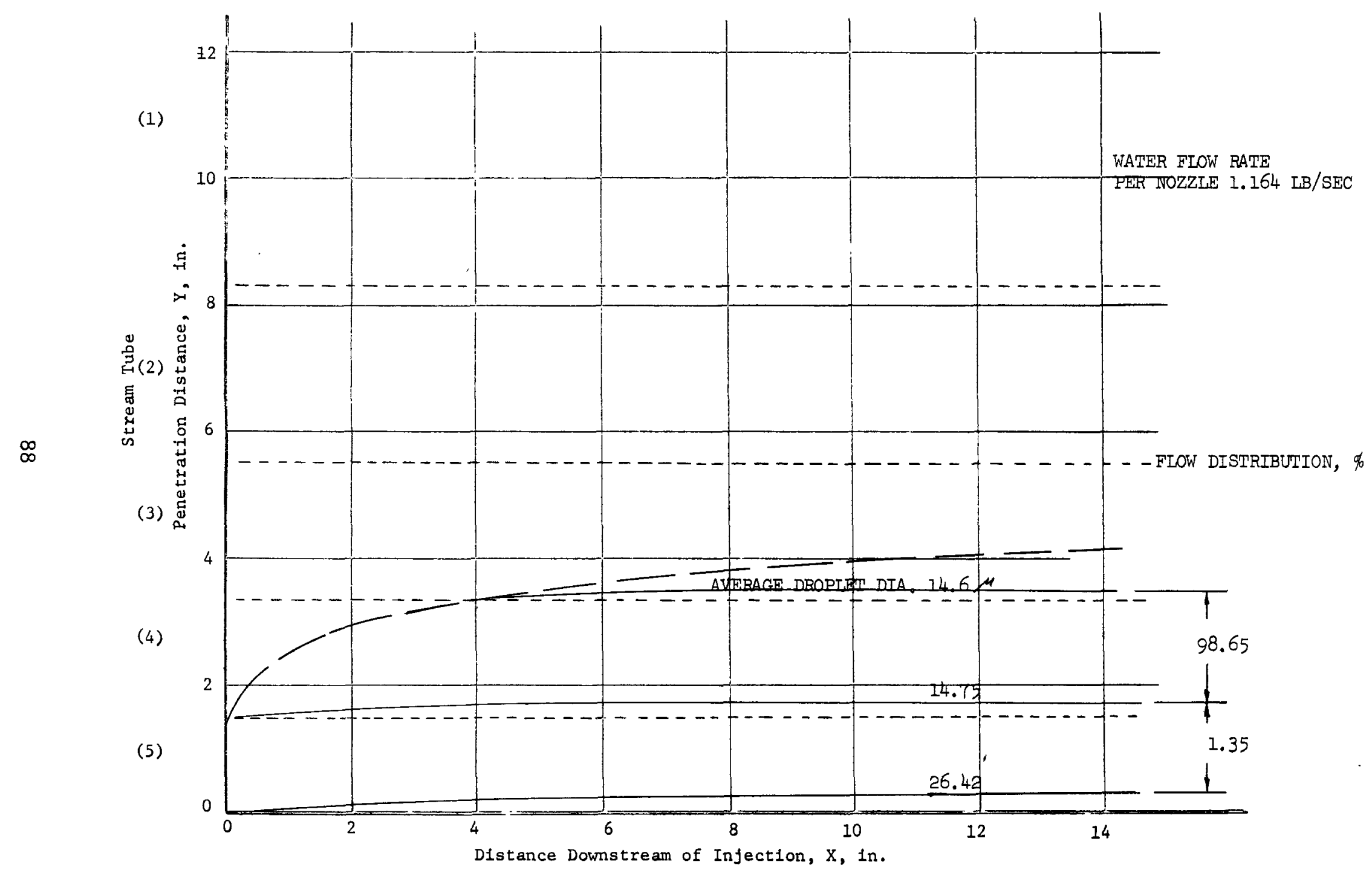

Figure 46 - J-4 Trajectory of Droplets and Water Distribution in an Expanding Flow Field, Nozzle Z 


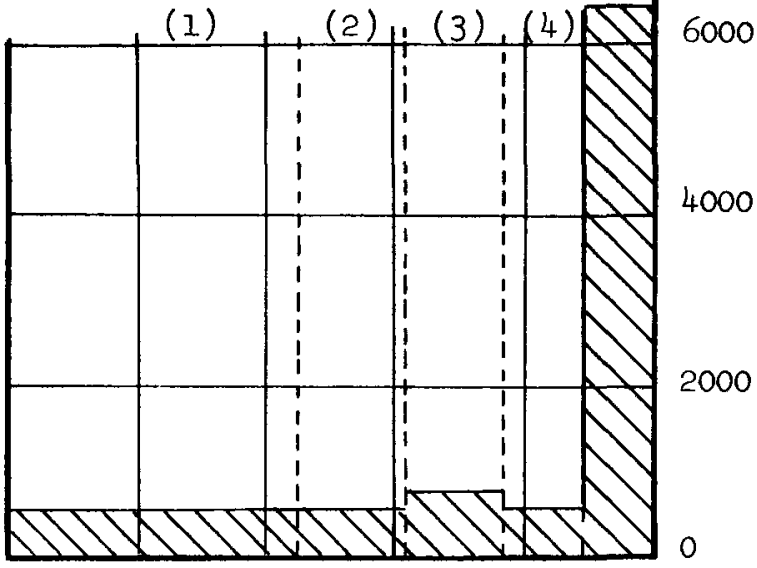

CALCULATED EQUITIBRIUM

GAS TEMPERATURE, ${ }_{R}$

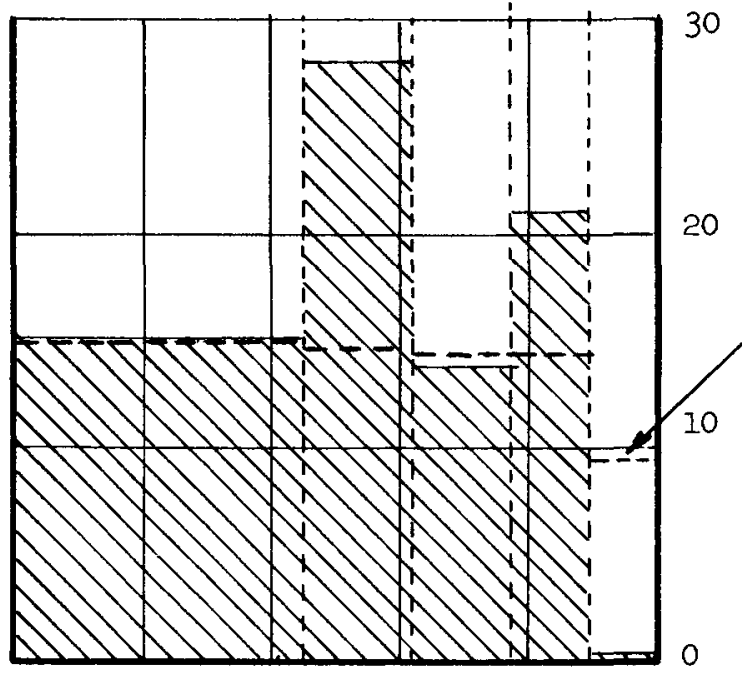

WATER DISTRIBUTION ACROSS DUCT AFTER DROPLET RE-DISTRIBUTION AT AXIAL DISTANCE OF 15 IN., $\mathrm{IB} / \mathrm{SEC}$ $R=36$

WATER REQUIRED IN FACH STREAM TUBE TO COOL TO SATURATION TEMPERATURE

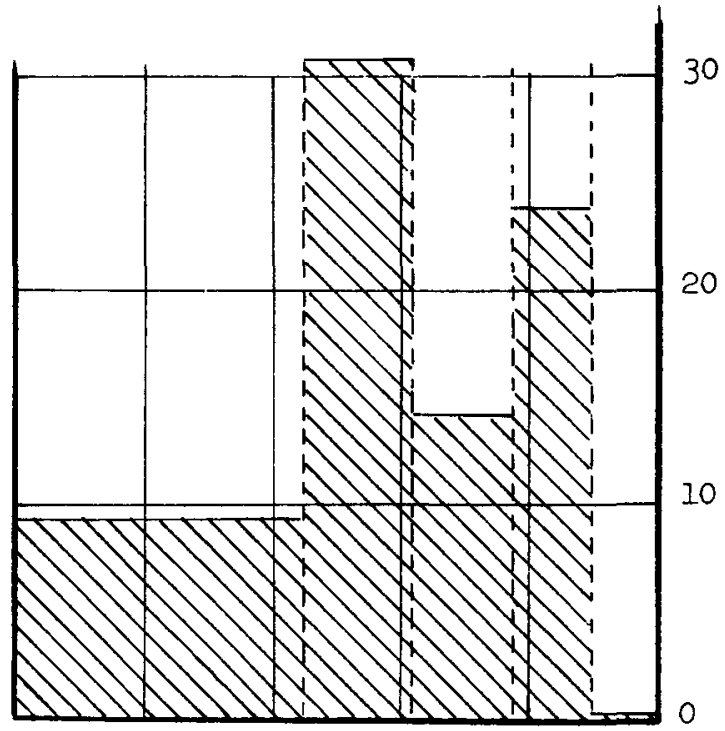

INITIAL WATER DISTRIBUTION RESULTING FROM BREAKUP OF WATER JET, IB/SEC

$R=15$
0
0.2
0.4
0.6
0.8
Radial Distance, $r / R$

Figure 47 - Calculated Water Distribution for J-4 Test Using Spray Nozzles $\mathrm{W}-2, \mathrm{X}, \mathrm{Y}$ and $\mathrm{Z}$, Case IV 
TABLE 4

TEMPERATURES AND PRESSURES AT

VARIOUS DISTANCES FROM EJECTOR

\begin{tabular}{cccc}
$\begin{array}{c}\text { Duct } \\
\text { Length } \\
\text { X, in. }\end{array}$ & $\begin{array}{c}\text { Fraction } \\
\text { Water } \\
\text { Evaporation, \% }\end{array}$ & Temperature, ${ }^{\circ} \mathrm{R}$ & $\begin{array}{c}\text { Static } \\
\text { Pressure, psia }\end{array}$ \\
\cline { 2 - 2 } & 47.9 & 1602. & 5.95 \\
60 & 69.0 & 909. & 6.00 \\
90 & 75.0 & 750. & 6.04
\end{tabular}


program. Other reasons for variation exist because the Greyrad program calculates an effective gas temperature by assuming the gas and water are in equilibrium, whereas the AGC model calculates a gas temperature resulting from evaporation of some fraction of the water. A temperature measurement from a thermocouple immersed in the stream could indicate the temperature calculated by the Greyrad but not by the AGC model. The moisture probe is designed to measure the gas temperature in the mixture directly; however, tests to data have not indicated that it performs as intended.

At the present state of development, the Greyrad program lacks definition of the mixing rate coefficients $\left(C_{m}\right)$, which limits the applicability of the program to predict results near the injector. The AGC program does predict a distribution of water in the gas stream independent of mixing; and, a1though the actual quantity of water that is evaporated and, consequent1y, the gas temperature may be in question, the temperature recorded by a thermocouple immersed in the stream should indicate the saturation temperature if the concentration of water present is sufficient to cause saturation. Since the application of the program is the prediction of temperatures within three duct diameters, the initial water distribution is important. Designing by using the AGC model depends less on mixing as a method of achieving water distribution and is thus more applicable to this problem; therefore, although the AGC analytical model does not necessarily offer the best means of predicting the system temperatures and pressures, it has been selected as the basic tool for predicting the test results. The gas temperatures predicted by using the AGC model are based on a mean droplet diameter, which may be either too large (resulting in slow evaporation and high gas temperatures) or too small (resulting in rapid evaporation and low gas temperatures); however, the temperature measured will be an equilibrium temperature or the saturation temperature if the water is adequately dispersed in the gas stream. The following temperatures and pressures are based on a one-dimensional solution of the water-gas mixture made by using the AGC analytical model for the Case IV water-injection scheme of Figure 42 and assuming a droplet diameter 
of approximately 15 microns distributed uniformly throughout the gas flow. The temperatures and pressures are for the noted rake positions during the respective tests.

\section{PRETEST PREDICTIONS}

\begin{tabular}{|c|c|c|c|c|}
\hline & $\begin{array}{c}\text { Test } \\
3 \\
\end{array}$ & $\begin{array}{c}\text { Test } \\
4 \\
\end{array}$ & $\begin{array}{c}\text { Test } \\
5 \\
\end{array}$ & $\begin{array}{c}\text { Test } \\
6 \\
\end{array}$ \\
\hline Rake position, in. & 90 & 60 & 60 & 30 \\
\hline Water injection rate, gpm & 562 & 562 & 1452 & 562 \\
\hline Gas temperature, ${ }^{\circ} \mathrm{R}$ & 750 & 909 & 900 & 1602 \\
\hline Equilibrium temperature, ${ }^{\circ} \mathrm{R}$ & 620 & 620 & 620 & 620 \\
\hline Total pressure, psia & 6.00 & 6.04 & 6.04 & 6.08 \\
\hline Static pressure, psia & 5.95 & 6.00 & 6.00 & 6.04 \\
\hline
\end{tabular}

The gas temperatures for Tests 4 and 5 will be essentially the same because the large nozzles will result in the generation of large droplets approximately 70 microns in diameter. With no secondary breakup assumed, these large droplets would not evaporate significantly in the first 60 in. and, consequently, would not reduce the gas temperature. The water will serve to film-cool any solid exposed to the flow.

The thermocouples on the rake should all read essentially the same temperature except for the aft thermocouples on the moistures probes. The temperature indicated by the aft thermocouples should correspond to the calculated gas temperatures. The region in the duct where water is not predicted (specifically, stream tube 5) is the region at a radial distance of 32.4 in. from the duct center line. The rake, as constructed, has no sensing elements in this region; hence, no test data would be recorded for this suspect region. It may be necessary to insert thermocouples through the duct wall to a depth of 1 to 3 in. and paint the rake so either the thermocouples or a discoloration of paint can substantiate the temperature calculations. 


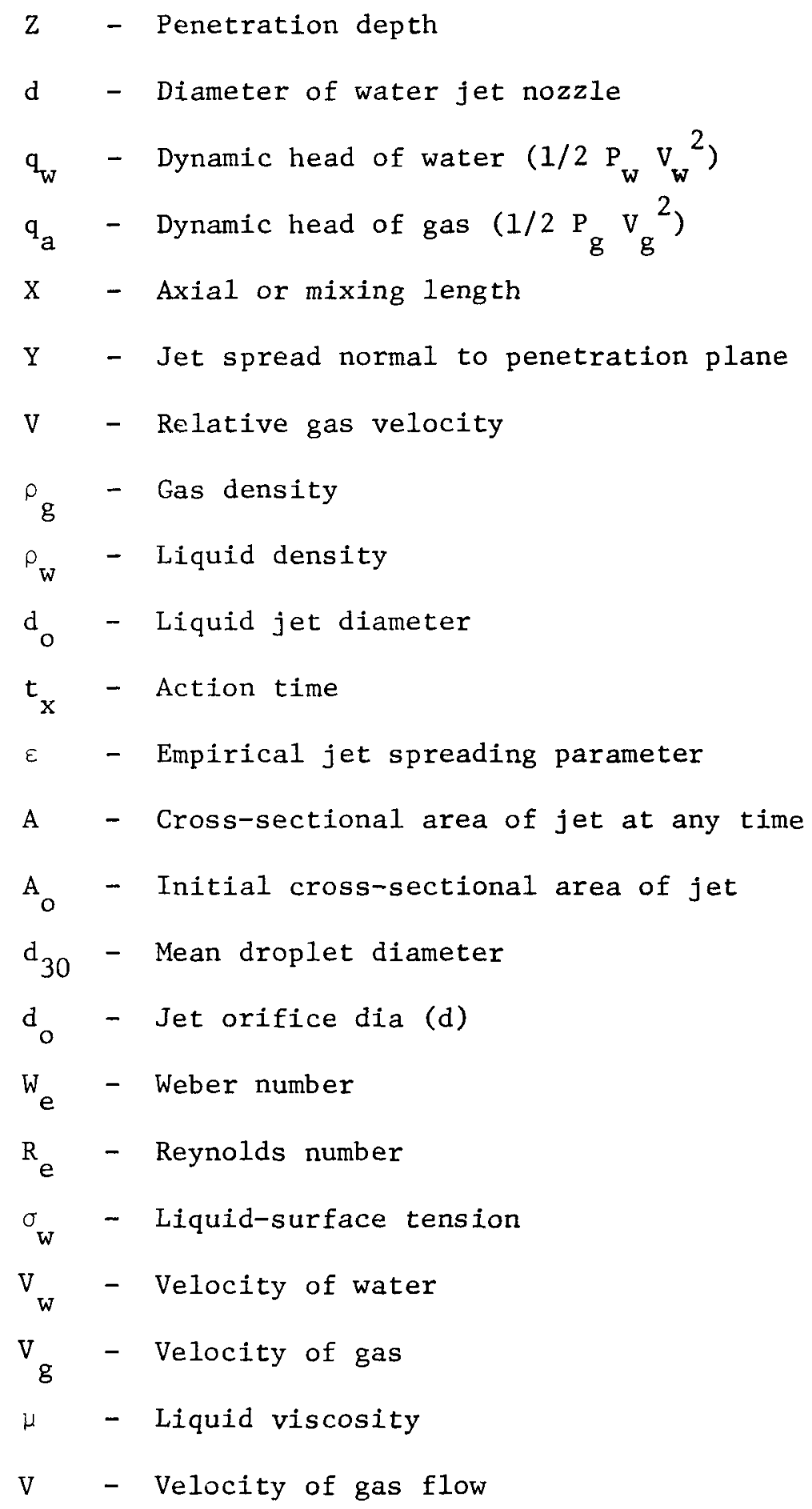




\section{LIST OF SYMBOLS (cont.)}

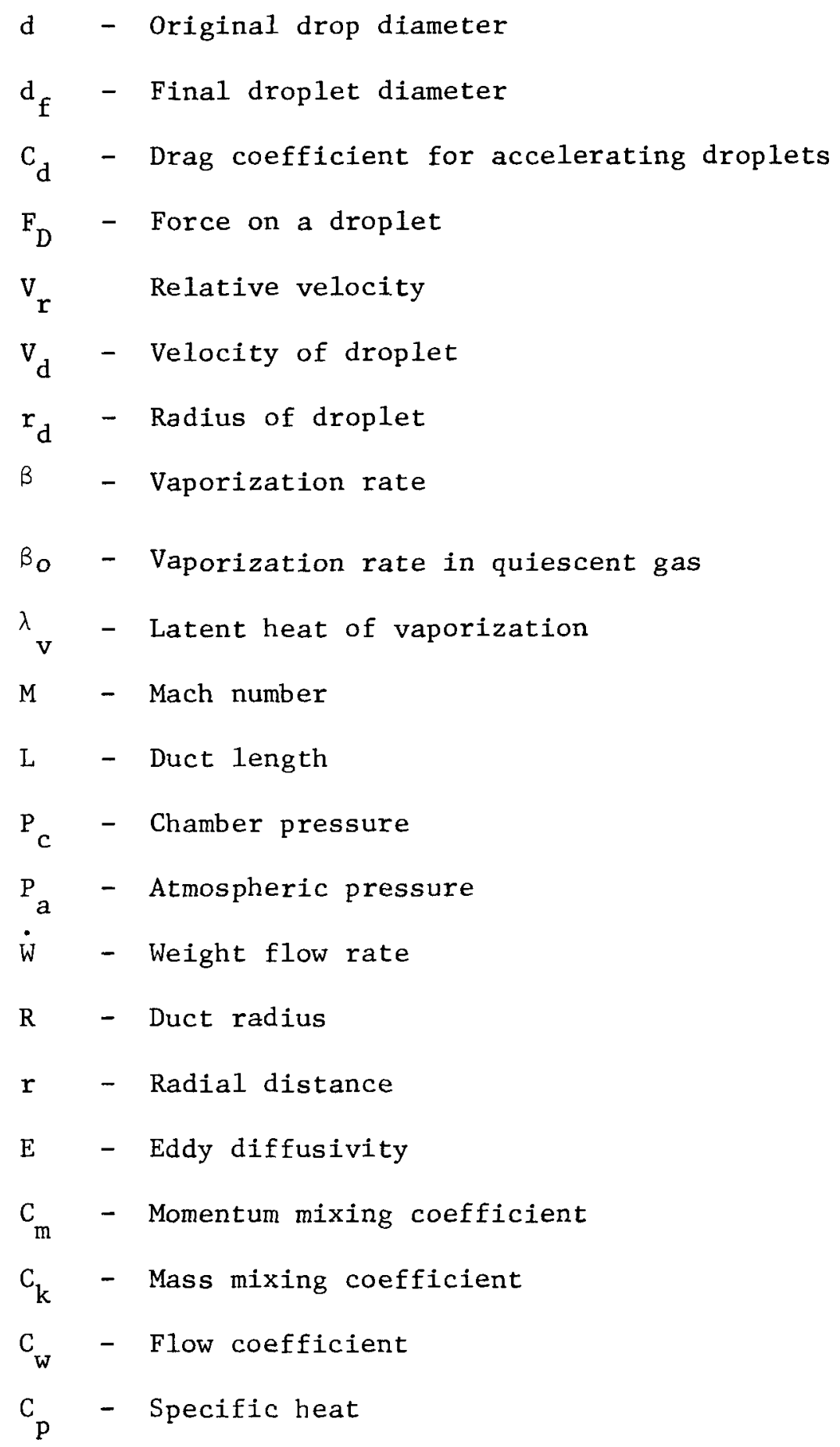




\section{REFERENCES}

1. L. J. Chelko, Penetration of Liquid Jets into a High Velocity Air Stream, NASA Research Memorandum RME50F21, 14 August 1950.

2. D. B. Fenn, Correlation of Isothermal Contours Formed by Penetration of Jet of Liquid Ammonia Directed Normal to an Air Stream, NASA Research Memorandum, RME53J08, February 1954.

3. J. M. Forde, S. Molder, and E. J. Szpiro, "Secondary Liquid Injection into a Supersonic Air Stream," J Spacecraft \& Rockets, Vol. 3 August 1966, pp 1172-1176.

4. R. D. Ingebo, Penetration of Drops into High Velocity Airstreams, NASA TMX-1363, Apri1 1967.

5. E. L. Geery and J. J. Margetts, "Water Jet Penetration of a High Velocity Gas Stream in Crossflow," Aerojet-General Corporation, Report No. RN-TM-0559, December 1967.

6. Experimental Investigation of Fire Monitors and Nozzles, ASCE Vol. 117, No. 2529 (1952), p 1147.

7. G. O. Patmor, R. E. Nelson, B. Mande11, and B. L. McFarland; A Heat Transfer Investigation of Ejector Systems with $90^{\circ}$ Turns, AIAA Space Simulation Testing Conference, Pasadena, Calif., November 1964, AIAA Press, New York, N. Y.

8. R. D. Ingebo, Drag Coefficients for Droplets and Solid Spheres in Clouds Accelerating in Air Streams, NACA TN3762 (1956).

9. F. A. Williams, "Progress in Spray Combustion Analyses," Eight International Symposium on Combustion, Williams \& Wilkins, Baltimore, 1962 .

10. A. H. Shapiro, et. al., "The Aerothermopressor - A Device for Improving the Performance of a Gas-Turbine Power Plant," TRANS ASME Vol. 78, 1956.

11. J. W. Rizika, "Droplet Evaporation in a High Temperature Turbulent Gas Stream," ASME Paper 54-A-141, Dec 1954.

12. M. C. Gilchrist, "Evaluation of Wet Duct System for E/STS 2-3 Test Stands," Westinghouse Astro-Nuclear Laboratory, WANL-TME-1603, April 1967.

13. "Analytical Investigation of Key Problems in the Water Injection Cooled Diffuser for Nuclear Rocket Engine Stage Test Stands 2 - 3," Greyrad Corporation Report SNP-3, September 1967. 


\section{REFERENCES (cont.)}

14. T. K. Sherwood and B. B. Woertz, "Mass Transfer Between Phases," Industrial \& Engineering Chemistry, Vol. 31, No. 8, pp 1034-1041, August 1939.

15. V. D. Mockenhaupt, "Performance Characteristics and Analysis of Liquid Injection Thrust Vector Control," Aerojet-General Corporation, TM-16-SRO, 15 March 1965.

16. A. H. Shapiro, The Dynamic and Thermodynamics of Compressible Fluid Flow, The Ronald Press, 1953.

17. B. J. Clark, Breakup of a Liquid Jet in a Transverse Flow of Gas, NASA TND-2424.

18. R. D. Ingebo and H. H. Foster, Drop Size Distribution for Crosscurrent Breakup of Liquid Jets in Airstreams, NASA TN4087, October 1957.

19. H. E. Wolfe and W. H. Andersen, Kinetics, Mechanism, and Resultant Droplet Sizes of the Aerodynamic Breakup of Liquid Drops, Aerojet-General Corporation Report 0395-04 (18) SP, April 1964. 


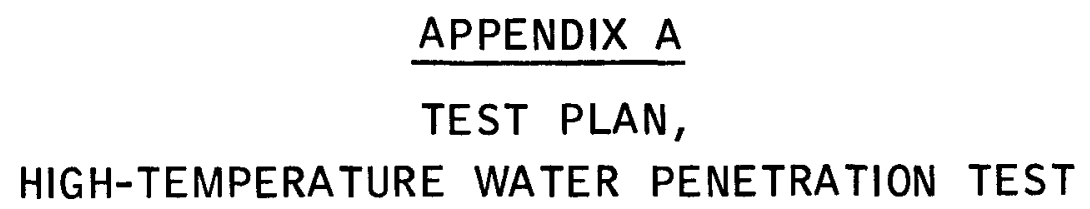


I. TEST

A. Duration $\approx 10 \mathrm{sec}$.

B. $F / 0 \approx 1.9$.

C. NERVA water system out; use facility cooling.

D. Instrumentation (NERVA, see Figure 1) to be recorded as follows (ranges indicated in parentheses):

$$
\begin{aligned}
& \mathrm{P}_{\mathrm{S}}-\mathrm{A}(0-10 \mathrm{psia}) \mathrm{P}_{\mathrm{T}}-1 \text { (0-10 psia) Pressure channels: } 13 \\
& \mathrm{P}_{\mathrm{S}}-\mathrm{B} \text { (0-10 psia) } \mathrm{P}_{\mathrm{T}}-2 \text { (0-10 psia) } \\
& \mathrm{P}_{\mathrm{S}}-2 \text { (0-10 psia) } \mathrm{P}_{\mathrm{T}}-3(0-10 \mathrm{psia}) \text { Temperature channels: } 3 \\
& P_{S}-5 D(0-10 \text { psia) } \\
& \mathrm{P}_{\mathrm{S}}-1 \mathrm{C}\left(0-10 \text { psia) } \mathrm{P}_{\mathrm{T}}-4(0-10 \text { psia) Water flow channels: } 1\right. \\
& \mathrm{P}_{\mathrm{T}}-5(0-10 \text { psia) } \\
& \mathrm{P}_{\mathrm{S}}-1 \mathrm{~B}(0-10 \mathrm{psia}) \mathrm{T}_{\mathrm{C}}-8\left(0-2000^{\circ} \mathrm{F}\right) \\
& \text { Tota1 NERVA channe1s: } \overline{17} \\
& \mathrm{P}_{\mathrm{S}}-1 \mathrm{~A}(0-10 \mathrm{psia}) \mathrm{T}_{\mathrm{C}}-7\left(0-2000^{\circ} \mathrm{F}\right) \\
& \mathrm{T}_{\mathrm{C}}-6\left(0-2000^{\circ} \mathrm{F}\right) \\
& \mathrm{P}_{\mathrm{M}}-4(400-1500) \mathrm{gpm} \\
& \mathrm{P}-1 \text { (0-150 psig) }
\end{aligned}
$$

E. OBJECTIVES

(1) To determine the Mach-number profile at the exit of the diffuser.

(2) To document reference or baseline pressures and temperatures in the plenum. 
II. TEST 2

A. Duration = $10 \mathrm{sec}$.

B. $F / 0=1.9$.

C. Use NERVA water system (425 gpm).

D. Instrumentation (NERVA, see Figure 1) to be recorded as follows (ranges indicated in parentheses):

$$
\begin{aligned}
& \mathrm{P}_{\mathrm{S}^{-\mathrm{A}}} \quad\left(0-10 \text { psia) } \quad \mathrm{P}_{\mathrm{T}^{-1}}(0-10 \text { psia) }\right. \\
& \mathrm{P}_{\mathrm{T}}{ }^{-2} \text { (0-10 psia) Pressure channels: } 13 \\
& \mathrm{P}_{\mathrm{S}}{ }^{-\mathrm{B}} \quad(0-10 \mathrm{psia}) \quad \mathrm{P}_{\mathrm{T}}{ }^{-3}(0-10 \mathrm{psia}) \text { Temperature channels: } 6 \\
& \mathrm{P}_{\mathrm{T}^{-4}} \text { (0-10 psia) Water flow channels: } 1 \\
& \begin{array}{llll}
\mathrm{P}_{\mathrm{S}}{ }^{-2} & (0-10 \mathrm{psia}) & \mathrm{P}_{\mathrm{T}}{ }^{-5}(0-10 \mathrm{psia}) & \\
\mathrm{P}_{\mathrm{S}}{ }^{-5 \mathrm{D}}(0-10 \mathrm{psia}) & \mathrm{T}_{\mathrm{C}}-8\left(0-2000^{\circ} \mathrm{F}\right) & \text { Total NERVA channels: } \overline{20}
\end{array} \\
& \mathrm{P}_{\mathrm{S}}{ }^{-1 \mathrm{C}}\left(0-10 \text { psia) } \quad \mathrm{T}_{\mathrm{C}^{-7}}\left(0-2000^{\circ} \mathrm{F}\right)\right. \\
& \mathrm{T}_{\mathrm{C}}-6\left(0-2000^{\circ} \mathrm{F}\right) \\
& \mathrm{P}_{\mathrm{S}}-1 \mathrm{~B}\left(0-10 \text { psia) } \mathrm{P}_{1} \quad(0-150 \text { psig) }\right. \\
& \mathrm{P}_{\mathrm{S}}{ }^{-1 \mathrm{~A}}(0-10 \mathrm{psia}) \quad \mathrm{PM}-4(400-1500 \mathrm{gpm}) \\
& \text { XTC }\left(0-2000^{\circ} \mathrm{F}\right) \\
& \text { XMP } \quad\left(0-2000^{\circ} \mathrm{F}\right)
\end{aligned}
$$

E. OBJECTIVES

(1) To determine the Mach-number profile at the exit of the diffuser with the NERVA water-injection system flowing.

(2) To evaluate both the moisture probes and the stainless-stee1shrouded thermocouples in the corrosive environment. 
III. TEST 3

A. Duration $=60 \mathrm{sec}$.

B. $\quad F / 0-1.9$.

C. Use NERVA water system (425 gpm).

D. Instrumentation (NERVA, see Figure 1) to be recorded at rake location $\mathrm{A}$ as follows (ranges indicated in parentheses):

$$
\begin{aligned}
& \mathrm{T}_{\mathrm{C}}-6 \quad\left(0-2000^{\circ} \mathrm{F}\right) \quad \text { (2) } \mathrm{MP}-1 \mathrm{~A}\left(0-2000^{\circ} \mathrm{F}\right) \quad \mathrm{P}_{\mathrm{S}^{-1 B}}(0-5 \text { psia) } \\
& \mathrm{T}_{\mathrm{C}^{-7}}\left(0-2000^{\circ} \mathrm{F}\right) \quad \text { (2) } \mathrm{MP}-2 \mathrm{~A}\left(0-2000^{\circ} \mathrm{F}\right) \quad \mathrm{P}_{\mathrm{S}}{ }^{-1 \mathrm{C}}(0-5 \mathrm{psia}) \\
& \mathrm{T}_{\mathrm{C}}-8 \quad\left(0-2000^{\circ} \mathrm{F}\right) \quad \text { (2) } \mathrm{MP}-3 \mathrm{~A} \quad\left(0-2000^{\circ} \mathrm{F}\right) \quad \mathrm{P}_{\mathrm{S}^{-2}} \quad(0-5 \text { psia) }
\end{aligned}
$$

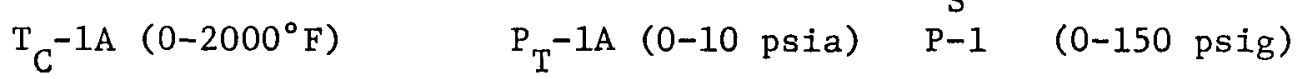

$$
\begin{aligned}
& \mathrm{T}_{\mathrm{C}}-2 \mathrm{~A}\left(0-2000^{\circ} \mathrm{F}\right) \quad \mathrm{P}_{\mathrm{T}}-2 \mathrm{~A}(0-10 \mathrm{psia}) \quad \mathrm{P}_{\mathrm{M}^{-4}}(400-1500 \mathrm{gpm}) \\
& \mathrm{T}_{\mathrm{C}}-3 \mathrm{~A}\left(0-2000^{\circ} \mathrm{F}\right) \quad \mathrm{P}_{\mathrm{T}}-3 \mathrm{~A}(0-10 \mathrm{psia}) \\
& \mathrm{T}_{\mathrm{C}}-4 \mathrm{~A}\left(0-2000^{\circ} \mathrm{F}\right) \quad \mathrm{P}_{\mathrm{S}}-1 \mathrm{~A}(0-5 \mathrm{psia}) \text { Pressure channels: } 9 \\
& \mathrm{~T}_{\mathrm{C}}-5 \mathrm{~A}\left(0-2000^{\circ} \mathrm{F}\right) \quad \text { Temperature channels: } 14 \\
& \text { Water flow channels: } 1 \\
& \text { Total NERVA channels: } \overline{24}
\end{aligned}
$$

\section{E. OBJECTIVE}

To verify existing mathematical models in regard to predicting penetration, mixing, evaporation, and heat-transfer phenomena occurring in large water-cooled rocket exhaust ducts. 


\section{Appendix A}

IV. TEST 4

A. Duration = $60 \mathrm{sec}$.

B. $F / 0=1.9$.

C. Use NERVA water system (425 gpm).

D. Instrumentation (NERVA, see Figure 1) to be recorded at rake location $B$ as follows (ranges indicated in parentheses):

$$
\begin{aligned}
& \mathrm{T}_{\mathrm{C}^{-6}} \quad\left(0-2000^{\circ} \mathrm{F}\right) \quad \text { (2) } \mathrm{MP}-1 \mathrm{~B} \quad\left(0-2000^{\circ} \mathrm{F}\right) \quad \mathrm{P}_{\mathrm{S}}-1 \mathrm{~B}(0-5 \mathrm{psia}) \\
& \mathrm{T}_{\mathrm{C}^{-7}}\left(0-2000^{\circ} \mathrm{F}\right) \quad \text { (2) } \mathrm{MP}-2 \mathrm{~B} \quad\left(0-2000^{\circ} \mathrm{F}\right) \quad \mathrm{P}_{\mathrm{S}}{ }^{-1 \mathrm{C}}(0-5 \mathrm{psia}) \\
& \mathrm{T}_{\mathrm{C}^{-8}} \quad\left(0-2000^{\circ} \mathrm{F}\right) \quad \text { (2) } \mathrm{MP}-3 \mathrm{~B} \quad\left(0-2000^{\circ} \mathrm{F}\right) \quad \mathrm{P}_{\mathrm{S}^{-2}} \quad(0-5 \text { psia) } \\
& \mathrm{P}_{\mathrm{S}}-5 \mathrm{D}(0-5 \text { psia) } \\
& \mathrm{T}_{\mathrm{C}^{-1 B}}\left(0-2000^{\circ} \mathrm{F}\right) \quad \mathrm{PT}-1 \mathrm{~B}(0-10 \mathrm{psia}) \text { P-1 (0-150 psig) } \\
& \mathrm{T}_{\mathrm{C}}-2 \mathrm{~B}\left(0-2000^{\circ} \mathrm{F}\right) \quad \mathrm{PT}-2 \mathrm{~B}(0-10 \mathrm{psia}) \mathrm{P}_{\mathrm{M}}{ }^{-4} \quad(400-1500 \mathrm{gpm}) \\
& \mathrm{T}_{\mathrm{C}}-3 \mathrm{~B}\left(0-2000^{\circ} \mathrm{F}\right) \quad \mathrm{PT}-3 \mathrm{~B}(0-10 \mathrm{psia}) \\
& \mathrm{T}_{\mathrm{C}}-4 \mathrm{~B}\left(0-2000^{\circ} \mathrm{F}\right) \quad \text { PS-1A (0-10 psia) Pressure channels: } 9
\end{aligned}
$$

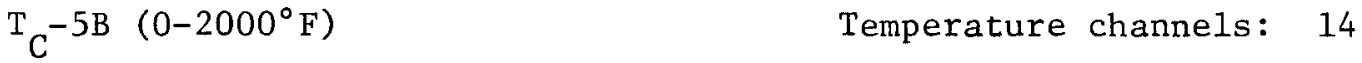

$$
\begin{aligned}
& \text { Water flow channels: } 1 \\
& \text { Total NERVA channels: } \overline{24}
\end{aligned}
$$

E. OBJECTIVE

To verify existing mathematical models in regard to predicting penetration, mixing, evaporation, and heat-transfer phenomena occurring in large water-cooled rocket exhaust ducts. 
V. TEST 5

A. Duration .. $60 \mathrm{sec}$.

B. $\mathrm{F} / \mathrm{O} \quad$ 1.9.

C. Use NERVA water system (1500 gpm) to simulate NERVA E-2 duct requirements.

D. Instrumentation (NERVA, see Figure 1) to be recorded at rake location $B$ as follows (ranges indicated in parentheses):

$$
\begin{aligned}
& \mathrm{T}_{\mathrm{C}^{-6}} \quad\left(0-2000^{\circ} \mathrm{F}\right) \quad \text { (2) } \mathrm{MP}-1 \mathrm{~B}\left(0-2000^{\circ} \mathrm{F}\right) \quad \mathrm{P}_{\mathrm{S}}{ }^{-1 \mathrm{~B}}(0-5 \text { psia) } \\
& \mathrm{T}_{\mathrm{C}^{-7}}\left(0-2000^{\circ} \mathrm{F}\right) \quad \text { (2) } \mathrm{MP}-2 \mathrm{~B}\left(0-2000^{\circ} \mathrm{F}\right) \quad \mathrm{P}_{\mathrm{S}}{ }^{-1 C}(0-5 \text { psia) } \\
& \mathrm{T}_{\mathrm{C}^{-8}} \quad\left(0-2000^{\circ} \mathrm{F}\right) \quad \text { (2) } \mathrm{MP}-3 \mathrm{~B} \quad\left(0-2000^{\circ} \mathrm{F}\right) \quad \mathrm{P}_{\mathrm{S}^{-2}} \quad(0-5 \text { psia) } \\
& \mathrm{T}_{\mathrm{C}}-1 \mathrm{~B}\left(0-2000^{\circ} \mathrm{F}\right) \quad \mathrm{PT}-1 \mathrm{~B}(0-10 \mathrm{psia}) \mathrm{P}^{-1} \quad(0-150 \mathrm{psig}) \\
& \mathrm{T}_{\mathrm{C}}-2 \mathrm{~B}\left(0-2000^{\circ} \mathrm{F}\right) \quad \mathrm{PT}-2 \mathrm{~B}(0-10 \mathrm{psia}) \quad \mathrm{P}_{\mathrm{M}}{ }^{-4} \quad(400-1500 \mathrm{gpm}) \\
& \mathrm{T}_{\mathrm{C}}-3 \mathrm{~B}\left(0-2000^{\circ} \mathrm{F}\right) \quad \mathrm{PT}-3 \mathrm{~B}(0-10 \mathrm{psia}) \text { Pressure channels: } 9 \\
& \mathrm{~T}_{\mathrm{C}}-4 \mathrm{~B}\left(0-2000^{\circ} \mathrm{F}\right) \quad \text { Temperature channels: } 14 \\
& \mathrm{~T}_{\mathrm{C}}-5 \mathrm{~B}\left(0-2000^{\circ} \mathrm{F}\right) \quad \text { PS }-1 \mathrm{~A}(0-10 \mathrm{psia}) \text { Water flow channels: } 1 \\
& \text { Total NERVA channels: } \overline{24}
\end{aligned}
$$

\section{E. OBJECTIVES}

(1) To determine the effect of water-droplet drag or momentum loss and pressure recovery.

(2) To verify present aerodynamic prediction calculations.

VI. $\quad$ TEST 6

Same as Test 4 with rake in location $A$. 


\section{Appendix A}

\section{RANGE CALCULATIONS FOR PRESSURE TRANSDUCERS}

Assume the following Mach No. profile*:

Mn Profile:

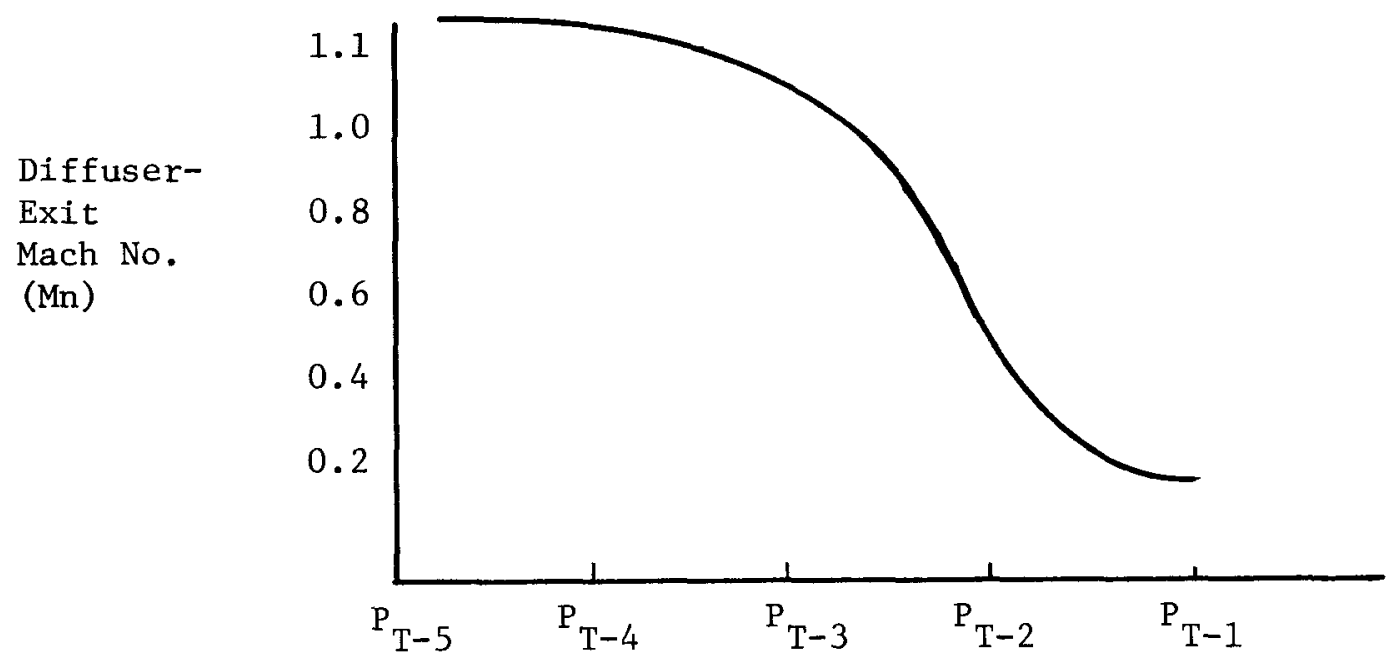

Assume $P_{S}$ at 2.5 psia.

Mn at $\mathrm{P}_{\mathrm{T}-5}=1.1$ at $\gamma=1.3 ; \mathrm{P}_{\mathrm{S}} / \mathrm{P}_{\mathrm{T}}=0.485$; therefore, $\mathrm{P}_{\mathrm{T}-5}=5.2$ psia.

$\mathrm{Mn}$ at $\mathrm{P}_{\mathrm{T}-4}=1.05$ at $\gamma=1.3 ; \mathrm{P}_{\mathrm{S}} / \mathrm{P}_{\mathrm{T}}=0.515$; therefore, $\mathrm{P}_{\mathrm{T}-4}=4.9$ psia.

Mn at $\mathrm{P}_{\mathrm{T}-3}=1.0$ at $Y=1.3 ; \mathrm{P}_{\mathrm{S}} / \mathrm{P}_{\mathrm{T}}=0.546$; therefore, $\mathrm{P}_{\mathrm{T}-3}=4.6$ psia.

$\mathrm{Mn}$ at $\mathrm{P}_{\mathrm{T}-2}=0.5$ at $\gamma=1.3 ; \mathrm{P}_{\mathrm{S}} / \mathrm{P}_{\mathrm{T}}=0.853$; therefore, $\mathrm{P}_{\mathrm{T}-2}=2.9$ psia.

Mn at $\mathrm{P}_{\mathrm{T}-1}=0.2$ at $\gamma=1.3 ; \mathrm{P}_{\mathrm{S}} / \mathrm{P}_{\mathrm{T}}=0.974$; therefore, $\mathrm{P}_{\mathrm{T}-1}=2.6$ psia.

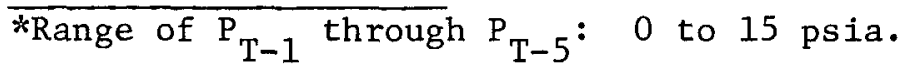




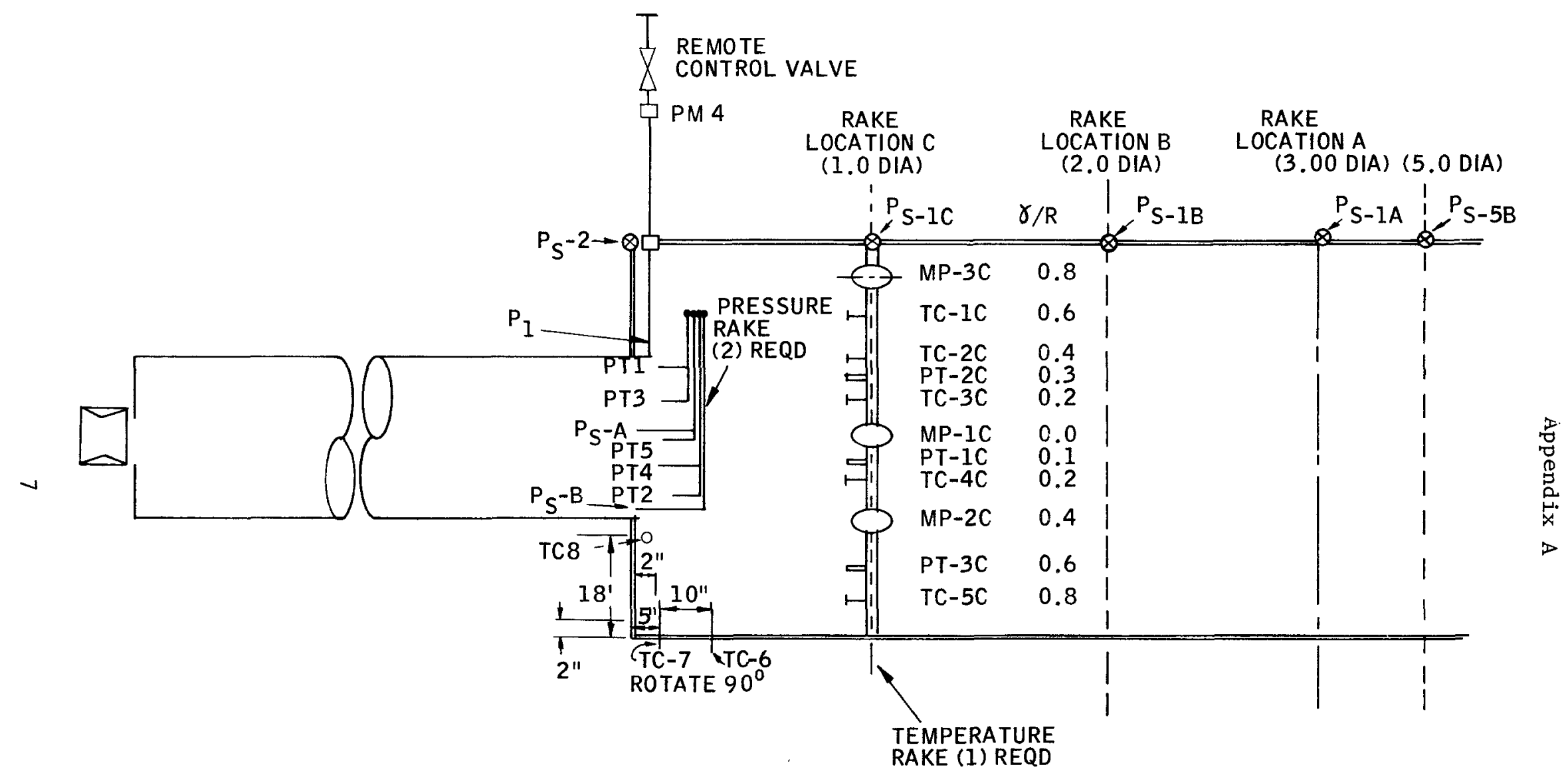

WALL STATIC $P_{S}$ IA THRU 5D

AXIAL LENGTH 15, 30,60, 90, AND 150 IN. FROM DIFFUSER EXIT 


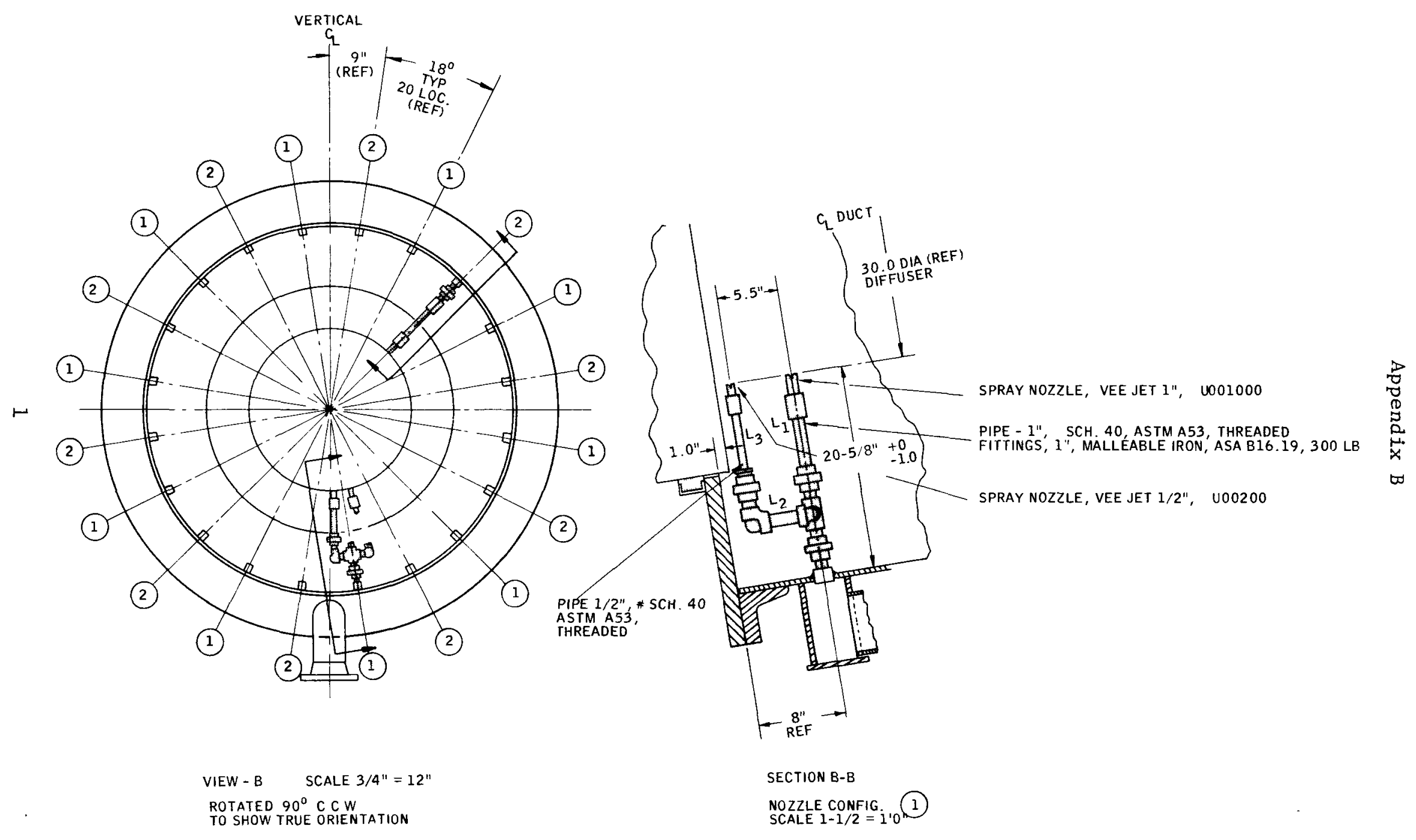




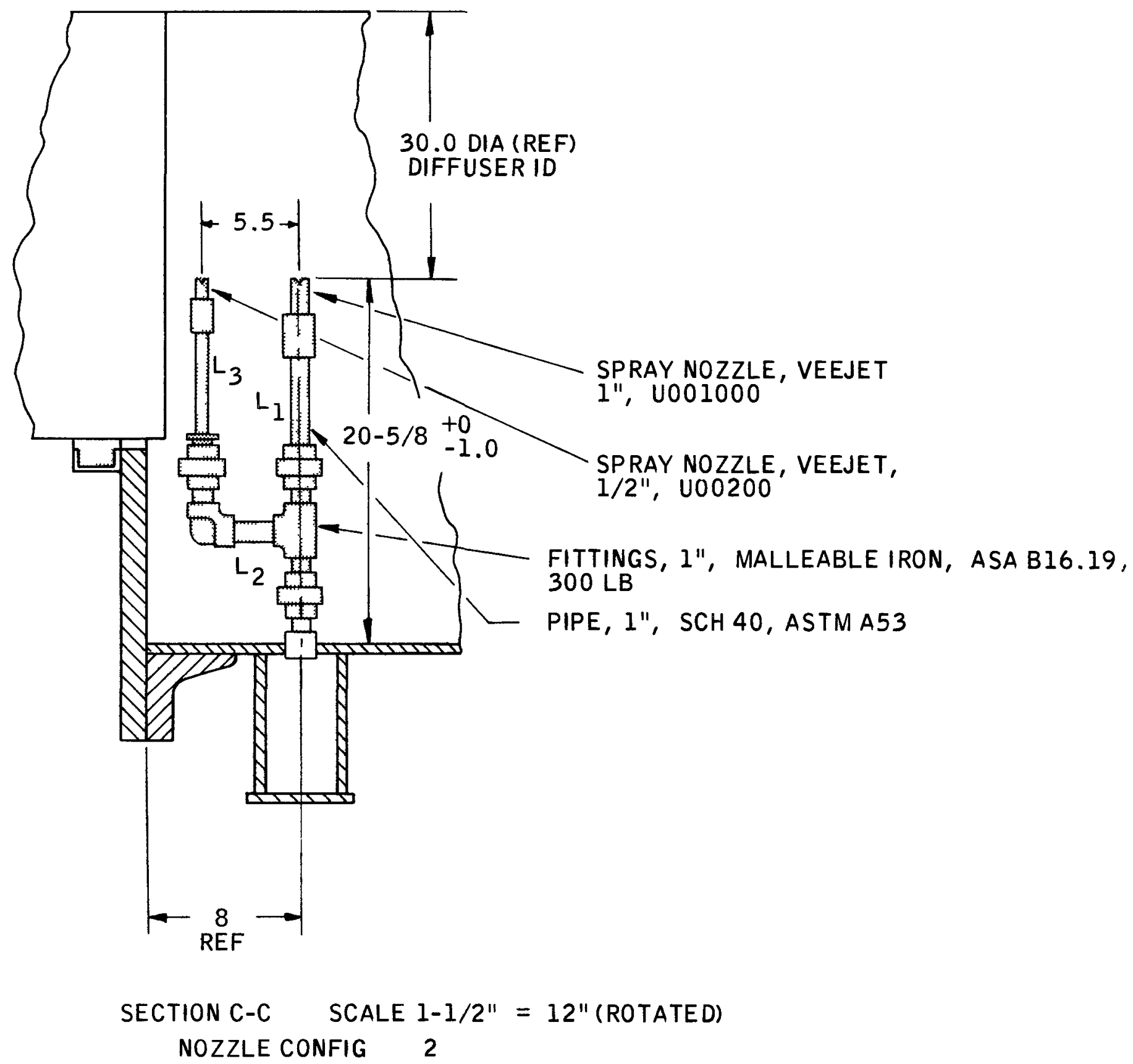

